Sergio DellaPergola*

\title{
Jewish Perceptions of Antisemitism in the European Union, 2018: A New Structural Look
}

https://doi.org/10.1515/actap-2020-2001

\begin{abstract}
This paper aims at providing a new systemic contribution to research about perceptions of antisemitism/Judeophobia by contemporary Jews in 12 European Union countries. The perspective - the viewpoint of the offended side - has been less prominent relatively in research literature on antisemitism. The data analysis demonstrates the potential power of Similarity Structure Analysis (SSA) as a better theoretical and empirical tool to describe and conceptualize the contents of chosen research issues. After a brief review of some methodological problems in the study of antisemitism, this paper will re-elaborate data first published in the report of the 2018 FRA study Experiences and Perceptions of Antisemitism - Second survey on Discrimination and Hate Crimes against Jews in the EU (FRA 2018a). Topics include the perceived importance of antisemitism as a societal issue, the contents of antiJewish prejudice and discrimination, channels of transmission, perpetrators of offenses, regional differences within Europe, and the role of antisemitism perceptions as a component of Jewish identification. Special attention is paid to the distinction between cognitive and experiential perceptions of antisemitism, and to the typology of practical, populist, political, and narrative antisemitism.
\end{abstract}

Keywords: affective, antisemitism, cognitive, contents, European Union, experiential, Judeophobia, perpetrators, SSA (Similarity Structure Analysis), transmission channels

\section{Introduction}

According to the second study of experiences and perceptions of antisemitism undertaken by the Fundamental Rights Agency of the European Union - FRA among Jews in 12 EU countries, in 2018, a large majority of respondents (85\%)

*Corresponding author: Sergio DellaPergola, The A. Harman Research Institute of Contemporary Jewry, The Hebrew University of Jerusalem, Mt. Scopus Campus, Jerusalem, Israel,

E-mail: sergio.dellapergola@mail.huji.ac.il 
considered antisemitism and racism to be the most pressing problem among a list of items submitted for evaluation across the EU member states surveyed (FRA 2018a). A large majority of respondents (89\%) believed that antisemitism had increased over the past five years in their country of residence. Most survey respondents said they were regularly exposed to negative statements about Jews. A large majority of respondents across all surveyed countries (80\%) identified the internet as the most common forum for negative statements about Jews. These findings, to say the least, are a matter of concern not only to Jews in Europe but also to the European Union itself, which initiated the investigation, hoping to derive useful information and feasible policy recommendations. Antisemitism, according to the 2018 survey findings, has become again a European problem, despite the Jews' infinitesimal proportion of the EU's total population, assessed at slightly above 2 per 1000 inhabitants in 2018 (DellaPergola 2019).

In global perspective - at least according to a world enquiry undertaken by the Anti-Defamation League (ADL 2014) - the frequency of contemporary antisemitic prejudice was on average lower in Western Europe than in Eastern Europe; a much lower incidence appeared in transoceanic English speaking countries; in Latin America, the incidence was intermediate between Western and Eastern Europe; and a much higher incidence prevailed in Islamic civilization areas. Countries in Southeast Asia usually displayed very low levels of antisemitic prejudice, especially where the impact of Christian and Islamic civilizations was marginal. Some of the antisemitic ideologies were originally developed in a mostly Christian Europe, some in the older civilization areas of the Middle East, and some elsewhere. Particularly noteworthy was the growing speed and intensity of import, export, and circulation of antisemitic ideas, and the translation of prejudice into organized social and political movements in an increasingly globalized world.

Although the world has witnessed the wide geographical spread of antisemitism, unlike in the past, most contemporary Jews currently live in cultural areas characterized by relatively low intensities of antisemitism. These also are the more highly developed and democratic areas of the world (DellaPergola 2018). The more relevant basis for observing antisemitism and its perceptions has tended, therefore, to become less the local episode of discrimination or aggression and more the broader perception and diffusion of the fundamental themes at stake. Today, beyond local salience, perceptions of antisemitism simultaneously reach and affect all or the vast majority of those who perceive themselves as Jews and in one way or another feel part of a symbolic, cultural, or otherwise global Jewish collective. Antisemitism has increasingly come to be perceived as an insidious transnational phenomenon, not necessarily related to direct contact with Jews as real-life individuals but largely touching upon collective and geographically 
diffused sensitivities. The resonance and impact of antisemitic discourse and its perceptions by Jews have been enormously magnified by the communication networks inherent in globalization and transnational processes.

Beyond these descriptive observations about the contemporary scene, the nature of antisemitism and its perception in society and of its perceptions by Jews remains somewhat elusive. What is the ultimate trope of antisemitism? Does it feature a recognizable conceptual articulation and structure? Does a particular statement, episode, or sequence of actions constitute antisemitism? Is antisemitism universal or local, timeless or conjunctural, fixed or mutant? What are its main channels of transmission? Who are the perpetrators, and why and how do they operate? Is there a measurable relationship between the amount of antisemitism in society and its perception among Jewish communities? What is its perceived subjective meaning among those exposed to it? What is the effect of antisemitism on its targets? And why do two contemporaneous sources provide such disparate accounts: one contends that antisemitism is increasing, whereas the other says it is not (Staetsky 2019b).

A large library of diversely oriented analyses is devoted to documenting antisemitism and trying to provide answers to some of these questions (e. g., Adorno et al. 1950; Almog 1988; Bauer 1988; Brown 1994; Cotler 2009; Ettinger 1978; Gerstenfeld 2005; Glock and Stark 1966; Lewis 1999; Lipstadt 2019; Marcus 2015; Michman 2014; Nirenberg 2013; Paxton 2004, Poliakov 2003; Rosenfeld 2019; Wistrich 2010). Numerous works have undertaken an analysis of antisemitism in a given national context (e. g., Baum et al. 2016; Ben Rafael 2014; Bokser Liwerant and Siman 2016; DellaPergola 2015; Gudkov and Levinson 1992, Kovács 2014; Küntzel 2013; Rudling 2006; Wieviorka 2005). At a broader level of conceptualization, syntheses of the literature and typologies of the antisemitic syndrome are available (e. g., Bauer 2002; Michman 2003; Jikeli 2015). There also are polemic and militant advocacy pamphlets (e. g., Jewish Voice for Peace 2017, UN Watch 2018), along with systematic classifications of the types of data extant or needed to measure antisemitism (e. g., ISGAP 2018; Popper 2018). The majority of this literature has addressed the phenomenon from the viewpoint of the hegemonic society and of its consequences for the Jewish minorities living there.

Despite this impressive body of knowledge and analysis, and as surprising as it may seem, the state of the art in the study of antisemitism and of its perceptions is still unsatisfactory - especially with regard to its theoretical conceptualization (Judaken 2018). Significantly, the perceptions of antisemitism by Jews - the target - have been relatively less investigated. This study deals with Jewish perceptions of antisemitism in Europe from an empirical social scientific perspective. Some initial effort is thus needed to define and assess the complex of ideas, behaviors, and institutions external to the Jews - labeled in first approximation as 
antisemitism. Moreover, it is important to operationalize and measure the perceptions of antisemitism from the interior of the target population.

Beginning with a rough generalization, antisemitism may be perceived as an outlook aimed at achieving one or more of three main goals:

- Physical violence and annihilation of the Jew;

- Marginalization and exclusion of the Jew from civil, social, economic, and cultural life;

- Worsening of the Jew's private quality of life by arousing fear, frustration, and anxiety.

Whereas in long-term historical experience, the first two goals were achieved with some degree of success, in contemporary practice, the third goal probably seems more relevant. In such an elementary characterization, the boundary between the Jew as an individual and the Jews as a collective is often not easy to detect. This may importantly affect Jewish perceptions of antisemitism that simultaneously pertain to self and to others related to the self by some religious, ethnic, symbolic, cultural, or other types of bonds.

A more comprehensive working definition of antisemitism was elaborated and made available by the European Monitoring Centre on Racism and Xenophobia (EUMC 2004; see also Porat 2018). Building on those premises, the International Holocaust Remembrance Alliance (IHRA 2016) subsequently issued the following, in its own terms, non-legally binding and actually rather bland working definition: "Antisemitism is a certain perception of Jews that may be expressed as hatred toward Jews. Rhetorical and physical manifestations of antisemitism are directed toward Jewish or non-Jewish individuals and/or their property, toward Jewish community institutions, and religious facilities".

The explanatory text that followed this definition was much more incisive and explicit and specified 11 modalities of behaviors and attitudes embodying antisemitism. Two of these referred to attributing excessive power to Jews; two referred to denial or minimization of the Holocaust; six referred to delegitimization of the State of Israel, and one directly addressed the desire to annihilate the Jews. This simple typology did not emerge from a vacuum but rather represented the product of an effort to synthetize the major features of antisemitism as they developed over time and can be detected today.

The many relevant research efforts deployed in this respect analyzed the issues mainly from the historical and literary angles. Less evident or, at least, less central, an empirical social scientific perspective largely drew on the other disciplinary perspectives to create its own conceptualization of antisemitism. Empirical social research can claim to have one modest advantage over other disciplinary approaches: it must abide by transparent and pre-established criteria of plausibility 
and repeatability, also known as significance tests. If these criteria are not met, the results lack validity, which should disqualify their circulation. Self-imposed rigor may limit the scope and imagination of investigation, but these constraints are compensated for by a supposed premium on reliability and objectivity.

From an empirical social scientific perspective, fundamental axes of research on antisemitism should always - but often do not - include a minimum core of essential elements:

- The nature and frequency of antisemitic events;

- The conceptual contents of offenses;

- The place of antisemitism as a component of Jewish identity;

- The ideological background of perpetrators;

- The geographical, demographic, and socioeconomic correlates of the offenders and of the offended;

- The depth of damage caused by an offense;

- The emotional reaction by the offended;

- The transmission channels of offense;

- $\quad$ The cumulated influence (total number of persons exposed to) offense;

- The Jewish response to offense;

- The general response and efficiency of sanctions applied against offenses and offenders.

Research undertaken in recent years actually provided some valuable notions about the specific contents, channels of dissemination, and perpetrators of antisemitic ideas and actions, and of their perceptions among the Jewish public. I would argue, however, that over time, the more theoretical approaches to antisemitism have become part of a broader kulturkampf in which personal, ideological, and political narratives often played a prominent role in research agendas, methodologies, and interpretative strategies.

A foundational turning point in Jewish history occurred after the establishment of the State of Israel and the transition of Jews from minority status among other nations to political sovereignty. Israel's independence created a novel opportunity for the expression of anti-Jewish attitudes and actions by those who opposed such a development on grounds related both to the international political context and to the very fact that the operating actors were Jews. It also created the need to reflect on the State of Israel's presence on the regional and global scene as an autonomous factor and on the nature of its actions. Israel's existence significantly affected Jewish identities, behaviors, and experiences. For a variety of demographic, social, and cultural reasons, it became increasingly difficult to disentangle practically and analytically the development and fate of the Jewish Diaspora from that of the State of Israel. Concern for Israel became a new facet in 
the clustered paradigm of perceived Jewish identification, but Israel also became a new target of anti-Jewish hostility, in part interrelated with other pre-existing forms of prejudice. The issue of the relationship between anti-Zionism and antisemitism became one of the dominant aspects of the current debate about antisemitism and its perceptions, sometimes obscuring other no less important aspects.

The present study deals with how perceptions of antisemitism are articulated among Jews in the European Union. As part of the effort to improve research on Jewish perceptions of antisemitism, this paper tries to bridge between the predominant historiographic approach and a quantitative methodology. Ideally, a multidisciplinary approach should be adopted in the study of antisemitism. One needs to integrate new and different state-of-the-art analytic perspectives through the use of sophisticated tools now available for archive scanning, retrieving, and storing documentation, data processing, textual analysis, evaluation of artistic performances, and multi-cultural contextualization (e. g., Jickeli and AlloucheBenayoun 2013; Shainkman 2018; Lindert and Marsoobian 2018; Weisz 2018). To describe and unveil both the immediately evident and the latent conceptual dimensions of contemporary antisemitism and its perceptions requires in-depth analysis of evidence and of its implications, comparisons across different geocultural contexts, original utilization and improvement of available analytic tools.

Diachronically and spatially, several measurable aspects of antisemitism displayed contrasting levels and trends, ranging between higher and lower frequencies, and between stable or mutable patterns, thus evoking contradictory interpretations and conclusions. Resolving these contradictions requires careful reflection and the application of deep theoretical and methodological elaboration to clarify the immediately perceptible descriptive elements. This hopefully will be demonstrated in the following pages.

\section{Documenting and Conceptualizing Contemporary Antisemitism}

\subsection{Historiographic Debates and Social Scientific Theory}

Antisemitism in the most simplified caption is a negative perception of Jews. Perceptions of antisemitism imply that some kind of phenomenology exists exterior to those who report about it. Clearly, any person or group of persons tend to report their perceptions of that phenomenology through the lens of their own characteristics, experiences, and - admittedly - biases. 
Before I turn to the analysis of contemporary Jewish perceptions of antisemitism in the EU, three cardinal questions deserve mention. The first concerns the paradox of definitions. The term antisemitism constitutes an oblique euphemism, rendered even more anachronistic in the form of the hyphenated antiSemitism. Wilhelm Marr's (1879) new lemma was directed with explicitly negative intentions against the target group. Paradoxically, a term that should have been disqualified because of its actively "against-them" meaning and purpose came to be used as a legitimate neutral term - no matter how worrying - in Jewish discourse. Regardless of the semantic, religious, or historical intentions of proposers and users, the actual concern was about an intentionally negative attitude against Jews. Especially in long-term perspective, Judeophobia would be more appropriate as the overarching term of reference (Judaken 2018). Keeping in mind that intention - and despite my own reservations about the word - in the present paper for simplicity, I shall regularly use the conventional unhyphenated form of antisemitism.

A second issue concerns whether or not Jewish historical and sociological experience possesses a fundamental coherence. The central analytic question here is whether or not Jewish history or Jewish sociology can be traced back to a set of shared principles and experiences. There admittedly existed significant cultural and structural variability across Jewish populations in various historical epochs, on different continents, and in varied regions. The Jews' prevalent status as a minority in society as a whole typically generated parallel positions of Jews versus the hegemonic others in different places. The theory that Jewish history and society were essentially explained by different local circumstances and did not share some fundamental commonality could lead to the conclusion there was not and there could not be one antisemitic syndrome. According to this point of view, each local antisemitic manifestation should be judged separately on the merits of the particular civilization within which it occurred. Taking this argument to the extreme logically leads to the conclusion that there could not be one Jewish Shoah; there had to be several according to places, each with different premises and outcomes. A better assessment should consider how interaction between certain historically transmitted and broadly shared Jewish norms, behaviors, and socialstructural features, and the variable and non-shared patterns of societal environment could determine the final Jewish historical outcomes in each particular situation. This applies to the level of antisemitism and its perceptions.

A third question concerns the uniqueness or broader generalizability of antisemitism and its perceptions. Such debate in part reflects the different implications of a fundamentally deductive versus inductive approach chosen by an investigator to implement a research plan. The deductive, epistemological stance posits the existence of a general concept of evil, or of hate, which can then be articulated into 
several threads, one of them being hostility against Jews and its ultimate outcome - the Shoah. In this context, quite obviously, the Jewish case is no more than a particular manifestation of a much wider phenomenology relating racism, xenophobia, and all other possible forms of anti-group prejudice to the ultimate outcome of genocide. The explanatory onus is then transferred to the broader issue of the nature of evil or hatred. The attempt to explain world and human society in universalistic terms quite unavoidably leads toward normative theological exegesis or other immanent and apodictic types of explanation about the nature of humankind. The broader the explanatory approach, the more comprehensive but also the more unachievable the explanation without recurring to theological categories.

The symmetric stance - moving the analysis from below to above, from the particular to the general, from hypothesis formulation to its validation - is the one adopted in this paper, as usually practiced in the empirical social sciences. It involves accumulating knowledge from partial and imperfect pieces of evidence, whose summation may eventually lead to a clearer and more general picture. Hence, dealing with the particularistic aspects of a given topic not only does not represent a limit but actually constitutes a crucial component in the process of gaining a more comprehensive perception of that topic and assessing its extensive implications.

Facing the endeavor to improve the conceptualization of perceptions of antisemitism, several serious methodological problems emerge from the existing literature. I shortly review here four aspects of the broader connection between antisemitism and its perceptions among Jews.

Universalism versus Jewish particularism. Numerous thinkers - some of them Jewish - emphasized the universalistic character of the antisemitic phenomenology rather than its particularistic anti-Jewish orientation. Critical statements pertaining to historiographic discourse or social scientific theory maintained that antisemitism is not an analytical category (Engel 2009); understanding antisemitism is not specifically about the Jews (Finkelstein 2005); assessing genocide is not primarily about the Shoah (Meierhenrich 2014). These views advocated that detecting universal human behavior patterns and formulating ulterior research agendas was preferable over the assumedly parochial research horizons and policy-oriented goals of a more specific Jewish focus.

Intentionalism versus alternative explanations. A second issue was whether vilifying, damaging, or destroying the Jewish people, namely, during the years of World War II, required an intentional ideological design or rather was a manifestation of a more general causal thread. Influential contributions to the broader theoretical perspective were Hannah Arendt's attention to the banality of people and circumstances that could epitomize the historical event (Arendt 1963); 
Zygmunt Bauman's emphasis on modernity and the role of societal modernization (Bauman 1989); Christopher Browning's attention to bureaucracy and the role of an efficient body of civil servants (Browning 2004); and Timothy Snyder's bloodlands, stressing the inherently violence-prone nature of certain geocultural areas (Snyder 2010). Negative attitudes toward Jews were also explained as related to the broader need to define one's own collective identity in relation to denying some other's identity. Negative otherness attributed to the Jew might then be understood as a dialectic tool within broader national or meta-national discourse (Pinto 1996; Rein and Weisz 2011).

Jews as proxy. Another research thread (noted by Bokser Liwerant 2017) addressed Jews as the archetypal paradigm for developing general social or historiographic theories. In such cases, the Jewish collective was considered as a proxy for broader generalizations rather than as a real social phenomenon. Examples refer to the conceptualization of diasporas (Brubaker 2005; Cohen 1997), international migration, and transnationalism (Feldt 2016; Levitt and Waters 2002; Schiller Glick, Basch, and Blanc-Szanton 1992), human capital creation (Coleman 1988), or the origins of totalitarianism (Arendt 1951). In this endeavor, little or no weight was given to whether the perceptions of Jews - the studied group - confirm and conform to the theoretical paradigm and why.

Jews as co-responsible. Some scholars stressed negative or problematic collective Jewish mental and behavioral patterns, thus partially blaming the Jews themselves for the incidence of antisemitism. Examples are Arnold Toynbee's characterization of the Jews as a fossil remnant of the Syriac society (Toynbee 1947); Benedetto Croce's critique of the Jewish pretension of chosenness and his blaming their refusal to assimilate into the Greco-Roman Christian mainstream as a cause for new potential persecutions (Finzi 2006, quoted in DellaPergola and Staetsky 2015); Sergio Romano's unfading memory, charging the Jews' refusal to forget the Shoah for slowing down Europe's progress and integration (Romano 1997); Enzo Traverso's end of modernity, lamenting the Jews' nationalist twist and the loss of their alleged leading role in modern Western intellectual progress (Traverso 2016); Ian Lustick's holocaustia, complaining that a narrow and obsessive focus on Shoah in Israel's Jewish society was the cause for the failure of peace negotiations with the Palestinians (Lustick 2017); or Shlomo Sand's invention of the Jewish people, arguing that the Jews' construction of a non-existent corporate past canceled the claim for Jewish national sovereignty (Sand 2009).

Attempts to interpret the problematic relationship between society and the Jews, and often also to interpret society at large through the Jewish collective, alluded to perceived contradictions such as Karl Marx's assertion about the Jews' cultural existence: "the emancipation of the Jews is the emancipation of mankind from Judaism“ (Marx 1844), as against Jean-Paul Sartre’s opposite contention: "the 
Jew is a man regarded as Jewish by non-Jews: it is the gaze of others that makes the Jew, a Jew“ (Sartre 1946). Many Jews perceived historiographic and sociological interpretations such as those just reviewed, if not as justifications, at least as rationales for understanding (if not minimizing) antisemitism. Primo Levi once wrote: "understanding [explaining Shoah] is nearly like justifying“ (Levi 1976, p. 347). Jewish perceptions (as outlined later in this paper) may significantly contribute to elucidating theory and to generating a better assessment of the antisemitic phenomenology.

\subsection{A Summary of Antisemitic Outlooks: Locked Modernizations}

As noted, this study of Jewish perceptions of antisemitism in Europe relied on the socio-scientific paradigm of inductive analysis and probation and was based on information collected at the grass level from people representative of the broader Jewish population of the European Union. The methodology chosen was data collection from a large number of informants, selected as randomly as possible and queried about a fixed number of pre-coded questions of interest. Evidently, a survey based on mostly pre-established questions and answer options required a preliminary reflection about the nature of antisemitism and its perceptions by Jews, namely, what type of discursive or behavioral contents could be pertinent for inclusion in the survey instrument. The identification and selection of antisemitic terms of reference was not always self-evident, and one of the objectives of the research was to make it explicit and recognizable. Toward the 2012 FRA study, a preliminary review, classification, and selection of items was undertaken by a team of experts, and the same operation was repeated in advance of the 2018 FRA study, upon which the present paper is based (FRA 2013 and 2018a; Staetsky 2019a; Staetsky et al. 2013).

What, then, should be included in an enquiry about perceptions of antisemitism? There is no agreement about what the different possible conceptual facets of antisemitic offense are and whether they constitute one integrated complex or cluster - as maintained by some authors (e. g., Feldman 2018; Wistrich 2010) - or constitute separate topics each with its own logics and implications - as maintained by others (e. g. Engel 2009). As a preliminary answer, I would note that one nearly invariable perception of the antisemitic syndrome is the attribution of certain characteristics to the Jew as a collective ideotype and the incorporation of all the Jews within that ideotype. I would argue that a perception of antisemitism immediately arises once the words you or they/them are uttered in relation to a Jewish individual, population or community. Such uncritical attribution of collective 
characteristics prominently appears also among writers whose original intention was to advocate the case of greater justice for and incorporation of Jews into modern society (Cattaneo 1837; Grégoire 1788). More recent and systematic sociological investigation clearly shows how Jewish communities - though under a panoply of civilizational commonalities (Eisenstadt 1992) - feature intense individual variation nationally and locally. On the other hand, along with widespread double standards applied to Jews and others, the bank of anti-Jewish concepts and symmetrically their perception as antisemitic by the Jews themselves ceaselessly grew throughout historical, religious, political, and cultural change.

In historical perspective, the situation of the Jews was not comparable when they operated as minorities within an ancient, absolutist empire or theocracy, within a proto-national society, within an institutionalized national context, or as the majority of the population within a modern state - Israel - which also comprises non-Jewish minorities. Anti-Jewish attitudes often developed from characterizing specific Jewish individuals, then extending the characterization to an entire Jewish community, then (if applicable) toward broader national or transnational frameworks expressed by Jews. The emerging of ever new antisemitic conceptual foci and the existence of supporters of each of these foci across multiple and diverse Jewish existential contexts elicit a short review of societal transformations and their relationship to antisemitism. It is imperative, in this context, to distinguish between Jewish and non-Jewish perceptions.

Chronologically, the earliest reported notions of negative attitudes toward Jews came from ancient Jewish scriptures and therefore constituted Jewish perceptions of non-Jewish perceptions of Jews. Admittedly, anti-Jewish notions reported as coming from outside the group could be real or construed through the filter of Jewish imagination. Jewish sources did not provide the evidence whether or not the negative concepts and facts really existed. It is also immaterial whether or not the situation portrayed and its timing or societal context corresponded to historical reality. The notions reported in the Jewish narrative about negative nonJewish perceptions of Jews are relevant because they single out those hostile judgments or sanctions that affected Jewish sensitivity in the past.

Whereas antisemitism may be considered a factor exogenous to the Jewish collective, its precondition and raison d'être from the beginning was the existence of some kind of corporate Jewish entity. This required consciousness of the existence of such an entity on both sides - the perpetrators and those who were the target of hostility. For the antisemitic act or expression to cause offense, damage, or uneasiness to Jews, the Jews themselves had to be aware of that offensive intention. This implied the existence of a corporate identification among the individuals targeted by the offense. Jewish perceptions of negative attitudes by others were therefore integrally intertwined with collective Jewish identity formation and awareness. 
The first reference in ancient Jewish sources to a concept of people specifically addressing the sons of Israel - who much later would be known as the Hebrews and/or the Jews - was attributed to an external observer, Pharaoh (Exodus, 1: 9 [Hertz 1956]): a large number of individuals holding some shared property were said to constitute an entity defined as a people. The large size and quick pace of growth of such people aroused strategic concern. No particular values or behavioral characteristics were mentioned for the sons of Israel to constitute a people. Their common properties, therefore, amounted to shared ancestral origin, in addition, probably, to shared language and population size. Thus, the Jewish perception of a non-Jewish perception of too many Jews was synchronic and inherent in the onset of awareness of a Jewish peoplehood - as reported by Jewish sources.

Another relevant Jewish source is the Book of Esther, which portrayed the Jews in the Kingdom of Persia in the fifth century BCE. Here again, a Jewish narrator reported the already familiar syndrome of a political ruler who wanted to destroy the Jewish population (Esther 3:2-8). This followed a perceived intolerance of the Jews' alleged pride and contempt of the established order. Two additional significant elements for conceptualizing antisemitism included a perception of the Jewish people as a dispersed transnational entity - hence a foreign element within the constituted body of the dominant population and culture - and the purported Jewish refusal to reject their (religious) customs and adjust (assimilate) to the locally prevailing norms. Moreover, there was an explicit allusion to the Jews' unlimited intelligence and power (Esther 6:13).

More direct information about negative perceptions of Jews by non-Jews came from non-Jewish sources not mediated by the target group's own perceptions. New anti-Jewish motifs emerged throughout history in correlation with crucial breaking points in the endless flow of development and modernization. In Greco-Roman antiquity, one enlightening text was Cicero’s "Pro Flacco," delivered in Rome in the year 59 BCE (Stern 1976), which included comments about Jews such as: what a big crowd, how they stick together, how influential they are, they adhere to barbaric superstition but also send gold to Jerusalem, which was stopped for the welfare of the state. More than a century later, a text by the Roman historian Tacitus (Stern 1980) addressed the Jews' different customs, at once perverse and disgusting, the augmented wealth of the Jews, their internal honesty and compassion, as against hatred toward the rest of mankind, and their dwelling apart. I do not contend that Cicero or Tacitus, both leading members of the pagan pre-Christian intellectual elites, were antisemites in the modern sense. I would stress, however, the long-term historical resilience of certain leitmotifs of antiJewish polemics. Jewish monotheism and its elaborated legal code, but also the Jews' immigrant status had attracted Roman pagan attention and hostility, with 
particular emphasis on the Jews' separateness and cohesiveness, primitive customs, unreliability, and allegiance to Jerusalem.

A crucial factor in determining non-Jewish perceptions of Jews was the subsequent evolution of world religions. Christianity, especially after the fourth century, became the hegemonic faith of the Roman Empire and introduced the new and vitally important deicide paradigm - Jewish responsibility for the killing of Jesus - along with the blood libel and accusations of ritual murder and the myth of the wandering Jew (Yuval 2006). These premises, and their later elaborations in the different Catholic, Lutheran, other Protestant, and Russian and Greek Orthodox matrices, served as justifications for harsh anti-Jewish canonic doctrines and societal marginalization. Islam further simplified and diffused monotheism and introduced a dual anti-Jewish paradigm: on the one hand, respect for the Jews but condemnation for their non-compliance with their duties as the chosen people (The Qur'an, 2:62-64, 5:68-69); on the other hand, stigma for their intrinsic unfaithfulness and bestiality (The Qur'an, 8:55-60).

The modern rise of the paradigm of the Nation resulted in the formation of nation-states - either as the manifestation of God's will or as secular and antithetic to God. The bestowing of citizenship on the people brought about a quest for national homogeneity and allegiance. Most revealing in this transition was the attitude of the Catholic Church toward Jewish Conversos. The quest for blood purity implied the Jews' non-eligibility as members of the nation on grounds of foreignness and physical and intellectual pollution (Poliakov 2003, vol. 3). Acceptance of the converted could not be adjudicated only on theological, intellectual, or spiritual grounds but also involved a patently unattainable anthropological transformation (Poliakov 2003, vol. 2).

Cutting across national identities, the fight against national hegemonies dominated by powerful and exploitative economic elites brought about the new notion of social class homogeneity and solidarity. A new brand of anti-Jewish accusations focused on the Jews' alleged responsibility for economic exploitation and disruption and their selfishness (Poliakov 2003, vol. 3). The Protocols of the Elders of Zion brought about a new synthesis of theories of Jewish conspiracy and world dominance (Ben-Itto 2005; De Michelis 2004; Segel and Levy 1995).

More recent variations of the anti-Jewish syndrome included post-colonial and third-world anti-global hostility on grounds of whiteness (Mignolo 2009), and a neo-pagan mode of piety for the human body, related to opposition to male circumcision and advocacy of animal integrity in opposition to ritual animal slaughtering, which ultimately focused on Jews but not on other groups as deviant from enlightened social norms (Dencik and Marosi 2018).

Israel's independence in 1948 as a declaredly Jewish state - conceptually a filiation of nineteenth-century idealist nationalism but also an expression of long- 
held sentiments and dreams by diaspora Jews- engendered a new, hostile argumentative layer. Even more significantly than the independence of Israel, the June 1967 war with the occupation of Palestinian territories commenced a new antiIsraeli outlook, which also abundantly drew on several pre-existing anti-Jewish concepts. Two different camps advocated anti-Israeli discourse centered on contentions of illegitimacy as well as demonization on political grounds: anarchists and post-colonials rose against Jewish national sovereignty as a matter of principle theoretically applicable to other nationalisms as well, while Arab nationalists supported an alternative sovereignty instead of Israel's over the same territory. On the Jewish side, a new dilemma emerged facing the growingly visible discursive combination of philo-semitism with anti-Zionism, and of pro-Zionism with antisemitism (Consonni 2015).

In the historical sequence of anti-Jewish outlooks, the Shoah was paradoxically not innovative. The Shoah was not the fruit of a new anti-Jewish paradigm; it rather represented the attempt to bring pre-existing paradigms to final fruition. In contemporary antisemitic phenomenology, praising the genocidal fact as such and lamenting that not enough Jews had been killed, merely reproduced already mentioned themes. Shoah denial is not innovative either and echoes several of the previously mentioned antisemitic slogans, such as Jewish myth creation and economic exploitation.

Summing up, the multiple ideological foundations of antisemitism did and do include numerous potential strands but also contradictions. These, in turn, profoundly shaped Jewish perceptions of antisemitism. Capital elements of the perceived antisemitic repertoire included ancient Middle-Eastern views of Jews as too numerous, not subservient, dispersed, separate, keeping to their customs, intelligent, and strategically powerful; the pagans' outlook - a large crowd, barbarian customs, sticking together, foreignness, and allegiance to Jerusalem; the Christian deicide and ritual murder; the Islamic infidelity and bestiality; the originally Catholic and later nationalist and fascist Right's view of the nation's contamination; the Marxist and anarchist Left's social-class exploitation; the Protocols' conspiracy; the physical and cultural Nazi anthropologists and philosophers' racial inferiority, stressing the Jew as a physical and moral degenerate, entailing a component of non-whiteness; and the Liberals' - their unwillingness to assimilate basically come back full circle to the early pagan contention. Christians and Muslims viewed the Jew as the enemy, but also as possible neophyte, hence a subjugated subject. Political antisemitisms from the Right and from the Left stigmatized the Jew for opposed, singularly specular reasons. For ancient pagans and modern Liberals, the main concern was and remains assimilation of the Jews. Opposition - primarily Islamic but not only - to the modern State of Israel brought about a synthesis of two different paradigms: against the Jews, and against a Jewish state. 
Why is this repetition of essentially known concepts and circumstances relevant here? First, it is important to realize the continuous and cumulative build-up and growing complexity of the antisemitic syndrome. Secondly, one may posit that each turning point and steep change on the uninterrupted historical-societal itinerary generated a new perspective on Jews, hence a new format of antisemitism, in addition to the existing ones. Turning to the contemporary scene, different groups of people - in our optics here, different types of perpetrators seemingly stopped and fixed their negative perceptions of Jews at one or another junction of the long-term historical continuum. In a singular division of labor, each type of perpetrator picked up and adopted one or another of the once innovative, later societally embedded concepts as their own chosen term of reference. As history proceeded, new strata of antisemitic prejudice continuously built upon the pre-existing ones (Bokser Liwerant 2019). The contemporary antisemitism typology thus comprises a coalescence of several modes of locked modernizations. Each brand of antisemitic outlook is anchored in history and - alone or in combination with others - represents the elective, self-sufficient, and self-perpetuating source of inspiration for different contemporary perpetrators.

Ultimately, relatively few resilient, aggressive, and self-perpetuating concepts populated the antisemitic repertoire, each element being self-sufficient, but also recombining with others to create a lethal blend. The hostile Jewish stereotypes just listed offered a solid blueprint for formulating a contemporary survey questionnaire about perceptions of antisemitism. Such a complex repository of antisemitic slogans and of their perceptions by Jews calls for cogent classification, data collection, processing, and analysis of empirical data. Some of the results will be reviewed below.

\subsection{European Jewish Perceptions of Antisemitism in Perspective}

Today, Europe comprises an estimated core Jewish population above 1.3 million larger than four EU member countries: Malta, Luxembourg, Cyprus, and Estonia. European Jews are part of a large, transnational network, much of which is located on other continents such as North America and Israel. Jews born in Europe or the descendants of Jews born in Europe are aware and even proud of their cultural origins, but only a minority of all contemporary Jews of European origin actually live on the European continent (DellaPergola 2019). In the modern era, the pendulum of demographic growth or decline repeatedly oscillated. After the Shoah and World War II, one important factor was the liquidation of European colonialism and the ensuing "repatriation" of Jews to the European homelands of 
former colonies - primarily to France but also to several other countries. Large numbers of Jewish immigrants came from North Africa and the Middle East, areas that previously had functioned as protected or self-sufficient niches although relatively less socioeconomically developed. Many more arrived from Eastern Europe before, during, and after the Soviet era. Europe was perceived among the world's more developed areas. But Europe also was the source of significant Jewish emigration, prompted among other determinants by perceptions of growing antisemitism and fears of terrorism.

Contemporary perceptions of antisemitism in the European Union, in fact, reflected the European way to antisemitism and could not be assessed without recalling earlier stages and experiences related to the longue dureé of antisemitism on the European continent. Jews have been present in Europe since antiquity, but the ineludible fact is that from the beginning, they had arrived from some extraEuropean location. Jews were immediately perceived as strangers when they entered societies that pre-existed and functioned based on already established systems of mores and institutions. The foundational ideotypes and beliefs and the essential components of Jewish corporate life were imported from the Middle East, with Jerusalem at its ideal center. Large sectors of the ancestors of contemporary European populations, indeed, came from other continents, and such inflow, intermingling, conflict, and assimilation of populations and cultures was a constant feature in European social and intellectual history.

Jews' extended exposure to European civilizations enabled long periods of pacific and successful integration. Absorption by Jews of European mores and ideas generated deeply embedded national and transnational modes of Jewish ritual, thought, and institutional formation. Such forms of adaptation, change, and growth crucially influenced other branches of world Jewry, primarily through circulation of greatly diverse Jewish cultural patterns, political ideas, and personal skills within the European continent, then in the Americas, and in other countries overseas, and also - through the boomerang of European colonization - rejoining the older Jewish presence in the Middle East.

Judeophobia and antisemitism were not a European invention but thrived and diversified in Europe. In Europe, a long tradition of ethnic cleansing was applied to Jews on many occasions in the form of massive expulsions, ghettoization, attempted mass conversion, and mass murder. The European colonization of extra-European continents often brought about the ethnic cleansing of civilizations that pre-existed there. The sequence of expulsions of Jews from the Iberian Peninsula was intended to be the final act of the Jewish presence in Spain and Portugal and occurred simultaneously with the initial stages of Europe's expansion and subsequent colonization of the geocultural and geopolitical space that was to become the Caribbean and Latin America. An all-encompassing concept of 
hegemonic purity and homogeneity rooted in Europe was exported overseas and coherently applied to local civilizations, after it had been abundantly tested on the skin of European Jews. Europe was the source and prime exporter of many leading ingredients of hatred and discrimination - as well as of the tools needed for their implementation. These ranged from the wooden and rusty metal torture devices now hosted in Cordoba's Museum of the Inquisition - to more sophisticated, symbolic, subliminal, and subversive mechanisms of social inclusion and exclusion.

Each of the component nations of the European palimpsest contributed certain original turning points in the course of the history of antisemitism. Some of the most valued tenets of the alleged superiority of the European over other civilizations included the quality of its (Roman inspired) juridical system, time punctuality, efficient allocation of power to achieve targets, postponed gratification, and putative rationality (Szakolczai 2016; Weber 1904-5). The Shoah provided a glaring demonstration of how the implementation of those supposedly positive traits, when put in the service of unrestrained ideology could generate a civilizational regression of planetary significance.

For sure, in the assessment of antisemitic perceptions, the question of European continental and national particularism should be given adequate attention. Jewish perceptional differences that still cut across European societies are worth of consideration and study. The ensuing analysis will elucidate unique national patterns of Jewish perceptions of antisemitism in the framework of broader transnational patterns. The particular, however, should eventually be placed within a holistic approach to antisemitism and its meanings.

\section{Sources and Methods}

\subsection{Recent Approaches to the Study of Antisemitism}

The study of contemporary antisemitism utilizing the social sciences approach should first of all specify the main investigative strategies pursued, the sources of available data, the respective limitations, and the principal interpretative implications.

The first stage has entailed assembling and collating inventories of events rated as antisemitic. Such events may include violence or harassment against a specific person as a Jew, against other Jewish persons, Jewish properties, or Jewish institutions. Such events may be reported or denounced by Jews and/or by others. Such databases were developed by community and academic-oriented Jewish organizations, as well as by general public organizations (FRA 2018b; Kantor 2018; 
Knobel 2013; OSCE-ODIHR 2016). The advantage of these types of documentation is that they represent factual events that really happened. Examining the variation of their frequency diachronically and spatially enables the creation of a historical series of data, which, in turn, may constitute the background for local and international comparisons between simultaneous fluctuations in antisemitism and in other social aspects. The limit of this method is primarily its dependency on people's willingness and ability to report such events. Research evidence (including FRA 2013 and FRA 2018a) indicates that reporting is extremely reticent and imperfect, leading to gross underreporting of such events. In addition, clearly, only a small minority of individuals within a given population are involved in explicit acts of harassment, profanation, and violence. Antisemitism comprises a much wider range of actions and written or verbal expressions apt to touch upon Jewish sensitivities. The possible ratio stands at several thousand documented acts of antisemitic acts worldwide per year, versus tens or hundreds of millions of people holding and/or expressing antisemitic views during the same year.

A second approach explored the frequency and nature of anti-Jewish attitudes among the total population (ADL 2014; ADL 2015). In the largest such study on record, in 2013, the Anti-Defamation League approached 500 individuals in each of 102 countries, for a total of over 50,000 respondents (ADL 2014). Respondents were asked to express agreement or disagreement with a list of anti-Jewish prejudices. Those who agreed with six or more statements were included in an index of antisemitism. The study did not investigate actual discrimination enacted against Jews. This, incidentally, might have been difficult or even impossible, considering that in many countries the Jewish population is very small and many or most people do not know personally any Jew. There may be doubts about the meaning of such a definition and measuring procedure of antisemitism, exclusively circumscribed to the cognitive dimension, but one cannot minimize the usefulness of the ADL study, which for the first time provided some comparable measure of the extent of antisemitism in 102 countries. Another serious caveat concerns the description of society as a rigid dichotomy of antisemites and not-antisemites. It is actually clearly demonstrable that antisemitic prejudices and attitudes are diffused gradually and flexibly across populations (DellaPergola 2015; Staetsky 2017), and this should be reflected in data analysis.

An American organization, the Pew Research Center, repeatedly investigated the attitudes toward Jews of representative samples of the total population in several countries, including Europe (Pew Research Center 2016/16 and 2017), as did, among others, the American Jewish Committee (e. g., Jodice 1991; Karmasin 1992) and the CNN broadcasting network (Greene 2018). A recent and quantitatively more impressive research framework is represented by the several Eurobarometer surveys of perceptions of the existence of antisemitism among general 
population samples in each of the 28 member countries of the European Union (e. g., European Commission 2019). These surveys also explored the extent of knowledge about Jews and Judaism in the respective countries.

A third type of approach has focused on perceptions of antisemitism by the Jews themselves. Major examples were the two large surveys of Jewish populations undertaken by the FRA in 2012 among Jews in nine EU countries (FRA 2013) and in 2018 among Jews in 13 countries (FRA 2018a). Results of the 2018 study (see more detailed discussion below) constitute the principal basis of the present paper. The basic demographic profiles of those included in the surveys were shown broadly to correspond to data on Jews known from other independent sources, which confirmed the reliability of the samples. The two studies, in addition to providing detailed evidence about Jewish perceptions and experiences with antisemitism, collected data on the sociodemographic and Jewish identification profiles of respondents.

All the different cross-sectional public opinion studies mentioned so far whether aimed at the total population or at Jews only - attempted to cover a wide range of perceptions and experiences related to antisemitism. In addition to general issues of sampling quality and errors, their validity is limited to the specific points in time when they were carried out. Repeated observations - as in the case of the 2012 and 2018 FRA surveys - allowed the construction of rough time-series and the assessment of ongoing trends. Longitudinal surveys, involving compilation of repeated observations of the same individuals over different points in time, would produce a better sense of changing perceptions among the same individuals hence a more accurate picture of the evolution of perceptions over time. To the best of my knowledge, however, such a survey design has not yet been tested in the field of antisemitism studies.

A fourth method of investigation has focused on the contents of discourse, mostly about Jews and/or about Israel. This important field, which so far has been explored insufficiently, consists of the analysis of openly or latently antisemitic verbal and textual contents expressed in the conventional printed (e. g., Partington 2012) and electronic media, in the web and in the fast-developing social media. In exploratory work undertaken so far, selected key words related to Jews, Judaism, and other general topics were suggested to samples of respondents and the associations emerging in relation to those words were verified (Guetta 2013; Petrenko and Mitina 1997; Russian Jewish Congress - Levada Center 2018b). More systematically, it is possible to examine various potential channels of diffusion of anti-Jewish prejudices, such as in large bulks of electronic mails, the display of internet sites, exchanges on Facebook networks, and the like (Schwarz-Friesel and Reinharz 2017). Carefully selected semantic associations among words can result in more powerful and lasting effects on larger audiences than mere acts of violence accomplished in 
specific locations. Whereas the latter are easy to detect and report, the former may be more elusive, as they require devoting substantial time to reading and listening, careful coding of contents, as well as a wide command of historical, philosophical, and literary sources, and meticulous attention to nuances.

Studies incorporating broad sets of external indicators distributed along a defined time span have been infrequent although they could provide the explanatory context to specifically antisemitic attitudes and behaviors that are observed over the same time span - for example, we may note the attempt to find a correlation between antisemitic manifestations and the fluctuations of the economic conjuncture (Epstein 1993); the military situation in the Middle East (Eddy 2014); or Muslim immigration to Europe (Feldman and Gidley 2018). For sure, further research needs to be undertaken in order to ascertain whether observed and perceived expressions of antisemitism reflect contingent situations related to occurrences in specific times and places or rather reflect a manifest or latent feature inherent in society and scarcely sensitive to changing circumstances.

\subsection{The FRA 2018 Study}

This paper develops a new analysis of the data collected in the second survey on Jewish people's experiences and perceptions of hate crime, discrimination, and antisemitism, undertaken in 2018 at the initiative of the European Union's Agency for Fundamental Rights, FRA. The main results were published in FRA (2018a). I reelaborated the original data taking advantage of Similarity Structure Analysis (SSA), a technique of data processing based on Facet Theory (see below).

The FRA 2018 survey built strongly on the experience and methodology developed for the 2012 FRA survey on discrimination and hate crime against Jews, which covered nine EU Member States (France, the UK, Germany, Hungary, Belgium, Italy, Sweden, Latvia, and Romania. Data for the latter country were omitted in the final analysis because they were of poor quality). The conceptual infrastructure was provided for the most part by an academic advisory committee that included several leading specialists on issues of contemporary European Jewry convened in 2012 by the Jewish Policy Research (JPR) Institute, JPR, in London. FRA was mainly interested in assessing the practical instances of physical aggression and harassment and the extent of Jewish responses to them, as well as the awareness of existing laws aimed at protecting the Jewish community. These aspects are not dealt with in detail in the present study, which mainly focuses on perceptions and experiences of antisemitism contents, transmission channels, and perpetrators. Such topics were discussed and defined by the advisory committee reflecting the themes covered in the previous section of this paper. 
The 2012 FRA survey generated a crop of research papers, which examined the issues both in the integrated perspective of the eight countries covered, and in the local framework of specific country reports. The latter related to the United Kingdom (Staetsky and Boyd 2014), Italy (DellaPergola and Staetsky 2015), Belgium (Ben-Rafael 2014), France (Cohen 2012 and 2013), Sweden (Dencik and Marosi 2017), Germany (Glöckner 2013), Hungary (Kovács 2013a), and Latvia (Kovács 2013b).

In 2017, a stakeholders' consultation was carried out in Vienna at the initiative of the FRA to elaborate the feasibility plan of a new study to be conducted in 2018 in 13 countries - Austria, Belgium, Denmark, France, Germany, Hungary, Italy, Latvia, the Netherlands, Poland, Spain, Sweden, and the United Kingdom. An expanded academic committee reflecting the larger number of participating countries advised on the design and implementation of this survey. The FRA's 2018 survey collected data from 16,395 self-identified Jewish respondents (age 16 or over) in 12 EU Member States (the data for Latvia were omitted from the final analysis because of poor quality). Countries were selected for the study primarily because of their relatively larger Jewish population size but also in view of their locations in the different regions of the continent: north, south, east, and west. The 12 EU countries covered correspond to 97\% of the EU core Jewish population, estimated at above one million in 2018 (DellaPergola 2019).

In preparation for the 2018 survey, the 2012 survey questionnaire was subjected to a review that resulted in changes in some of the questions. Efforts to reduce the survey length were taken, with a view to minimizing the respondent burden. This included reviewing possible questions for deletion and reducing the number of items and answer categories in individual questions. Some questions were deleted; others were streamlined, rephrased or repositioned in the questionnaire to improve the flow when answering the questions. The questionnaire was also revised to establish a design compatible across most common, latest operating systems (such as Microsoft Windows, Apple's iOS, Linux) and that also could work on different types of devices, including desktop and laptop computers, tablets, and smartphones that could be used for completing the survey. Questionnaire revisions aimed at retaining comparability with the 2012 survey to the extent possible. The 2018 survey questionnaire is available in a separate report (FRA 2018c).

The survey collected data through an open online survey, which was open for respondents to complete during seven weeks in May-June 2018. Eligible participants were all those self-defining as Jews, aged 16 or over, and resident in one of the survey countries. The questionnaire was administered online and could be accessed via an open web link that was publicized on the FRA website, through extensive advertisement in Jewish organizations, Jewish media outlets, and social 
networks. People who had connected with the survey were asked to snowball to acquaintances who might not have been aware of it. Some doubts remain whether the most marginal and unconnected layers of the Jewish public actually had or wanted to have access to the survey instrument. Information collected about the patterns of affiliation of respondents provided a reasonable sense of confidence that the survey did reach the peripheral fringes of the community (Staetsky 2019a). In some cases, participation of Jews belonging to the Haredi sectors of the Jewish community may have been lower than average.

A consortium of Ipsos MORI and the Institute for JPR, both based in the United Kingdom, managed the survey data collection under the administrative supervision of FRA staff. National research teams of academic experts and local researcher and community liaison points in each survey country supported the survey implementation.

JPR collected information on the size and composition of the Jewish population in each country and on Jewish community structures in the European countries involved, identified ways to raise awareness about the survey among Jews in the selected countries, and implemented a capillary communication strategy. Ipsos MORI ensured the technical set-up of the survey, including the translation of all survey materials, development of the survey website, and compliance with the standards of data security, privacy, and confidentiality.

Throughout data collection, responses were monitored using the online monitoring tool provided by Ipsos. This enabled monitoring of response levels on a daily basis and enabled observing the impact of particular communications campaigns by different organizations across the survey countries and checking the distributions of responses by age, sex, geography, and Jewish affiliation to assess how the communications campaigns were reaching difference segments of the target population. Because of the voluntary and self-selected nature of respondents, the sample cannot be considered strictly representative as would be a random probabilistic sample of the target population. Comparisons between the survey results and Jewish population distributions by age, sex, and major geographical region available from other national and Jewish community sources showed relatively modest amounts of bias. For the purpose of population characteristics description, the sample can be weighted according to the distributions in those other sources. As the present paper is concerned with relationships between variables rather than with population profiles, unweighted data were used here.

The data collection outcomes confirmed the experience of similar online surveys that the launching day is critical. In this case, over 4,000 responses were obtained on the first day alone, constituting nearly a quarter of the total sample. Following the processes undertaken to assess the quality of the data and cleaning 
of the dataset, the final dataset included 16,395 completed questionnaires across the 12 valid survey countries, excluding Latvia. The average time for survey completion was $33 \mathrm{~min}$, and the median duration was $27 \mathrm{~min}$.

The response rate in 2018 was significantly higher than in 2012 (see Appendix Table). In the seven countries where data can be compared for both dates, the number of valid respondents increased from 5,663 in 2012 to 13,083 in 2018, an increase of $131 \%$ or more than double. The number of respondents increased especially in France (+233\%), the UK (+222\%), Germany (+103\%), Belgium (+79\%), and Sweden $(+47 \%)$. This improved coverage of the Jewish population testifies to considerably more efficient advertising of the survey, enhanced access to the web, and also probably greater awareness of and interest in the topic investigated.

\subsection{Perceptions of Antisemitism Inside and Outside the Jewish Community}

One important research question emerging from the various sources of data reviewed so far is whether the existence of antisemitism is perceived to an equal extent by those who are its target and by the many more around them who constitute the majority of population. The correlation that may exist between internal and external perceptions of antisemitism at the country level can be judged by comparing different studies that have addressed, respectively, Jewish or general population samples in the same places and at more or less the same time. Several such studies undertaken in recent years allow for such comparisons.

In Figure 1, I compared the ADL data for 2013 and the FRA data for 2018 for the 12 countries included in the latter study. It is important to note that the ADL study of total populations concerned primarily the cognitive perceptions of antisemitism, whereas the FRA study of Jewish populations also covered its experiential aspects. The FRA data reported in Figure 1, however, relate to a cognitive question about the concern with antisemitism as a societal issue in the country of residence; thus making it comparable with the ADL data. In the figure, the horizontal axis measures the diffusion of antisemitic prejudice in society at large assumed here as the explanatory variable - and the vertical axis measures the Jewish perception of the phenomenon - assumed here as the dependent variable.

In the ADL study, the proportion of the total population rated as antisemitic ranged between a low of $4 \%$ in Sweden and a high of $45 \%$ in Poland, while among Jews in the FRA study, perceptions of antisemitism as an important issue in society ranged between a low of 56\% in Denmark and a high of 95\% in France. It thus clearly demonstrates how much more sensitive Jews are than others when assessing antisemitism and the environment within which it develops. The general 


\section{FRA 2018}

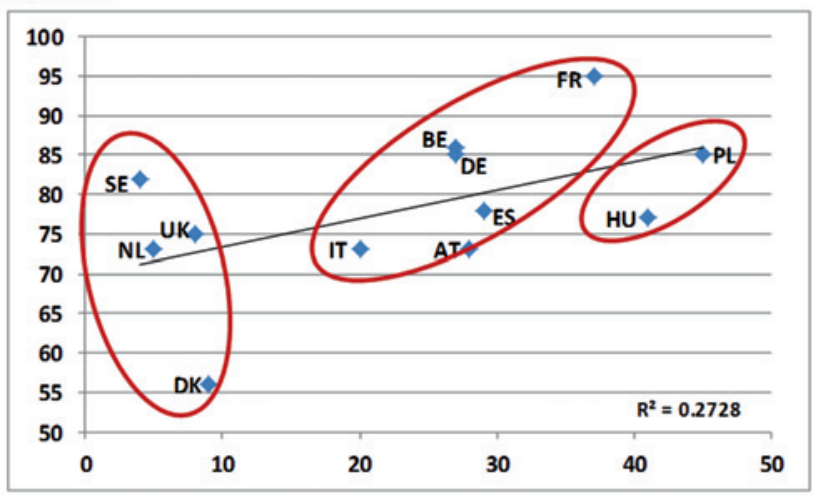

ADL 2013

Figure 1: Comparing Measures of Antisemitism in 12 EU Countries - FRA 2018 Percentage Assessing Antisemitism as a Very Serious or fairly Serious Issue in Society vs. ADL 2013 Percentage of Antisemitic Respondents.

Key to Countries: AT: Austria; BE: Belgium; DE: Germany; DK: Denmark; ES: Spain; FR: France; HU: Hungary; IT: Italy; NE: The Netherlands; PL: Poland; SE: Sweden; UK: United Kingdom.

ranking of countries along the two measures, however, was overall very consistent, showing a $52 \%$ positive correlation. The determination quotient $\left(\mathrm{R}^{2}=0.2728\right.$, or $\left.27 \%\right)$ indicates how much of the variance in perceptions by Jews (the variable on the vertical axis) is statistically explained by attitudes among the general public (the variable on the horizontal axis). If the apparent outlier case of Denmark is omitted, the variance explained is somewhat reduced to $20 \%$. The result is statistically significant although not very powerful. The data in Figure 1 suggest quite clear regional differences between northern, western, and eastern European countries. Regional differences within the EU were clearer from the ADL than from the FRA survey data.

A similar comparison between the same ADL data and the 2012 FRA data (based on eight countries) resulted in a much higher correlation and explained variance: 54\%. The 6-year gap between the two FRA surveys may account for part of the inconsistency. Clearly, the sensitivity of Jews to perceived antisemitism is higher than on average among the surrounding population. In a reported context where perceptions of antisemitism were increasing rapidly, however, patterns of change in each country seem to have gone in somewhat different directions, thus reducing the strength of the immediate relationship between perceptions among the general population and within the Jewish community.

The 2018 FRA study of Jewish perceptions of antisemitism and the European Council's 2018 Eurobarometer study of antisemitism perceptions among society at large provide similar comparisons. The Eurobarometer survey was undertaken in 
all 28 member countries of the European Union in 2018. Interestingly, the 12 countries investigated in the nearly simultaneous FRA survey happened to be those that registered the highest perceptions of antisemitism among the Barometer 28 , with the sole exception of Spain. In this case, the comparison can be improved by distinguishing in both surveys those who perceive antisemitism as a very important or very serious problem and those who view it only as a fairly important or fairly serious problem. Looking first at those viewing antisemitism as a very serious issue (Figure 2), their incidence according to the Eurobarometer ranged between a low of less than 10\% in Poland, Spain, Hungary, and Denmark, and a high of over 35\% in Sweden. According to the FRA survey, the range was between 15\% in Denmark and 65\% in France. Jewish perceptions again appeared significantly higher than total perceptions. Statistically, country variance across the Eurobarometer respondents explained $17.5 \%$ of the country variance among FRA respondents. This coefficient of determination is considerably lower than that observed on the basis of the ADL study.

The relationship between general and Jewish perceptions was even weaker with reference to the perception of antisemitism as the aggregate of a very serious or fairly serious issue (Figure 3). The respective percent frequencies increased from a low of $20 \%$ in Spain and a high of $80 \%$ in Sweden according to the Eurobarometer, and from a low of 55\% in Denmark to a high of 95\% in France according to the FRA. With the possible exceptions of Denmark and Spain, the range of

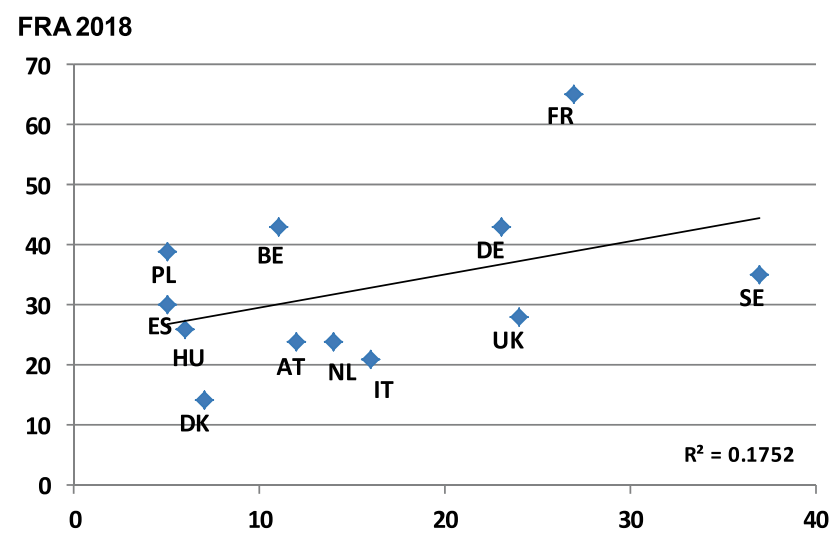

Eurobarometer 2018

Figure 2: Comparing Measures of Antisemitism in 12 EU Countries: “Antisemitism is a Very Serious Problem in Your Country.” Percentages - FRA 2018 vs. Eurobarometer 2018.

Key to Countries: AT: Austria; BE: Belgium; DE: Germany; DK: Denmark; ES: Spain; FR: France; HU: Hungary; IT: Italy; NE: The Netherlands; PL: Poland; SE: Sweden; UK: United Kingdom. 
FRA 2018

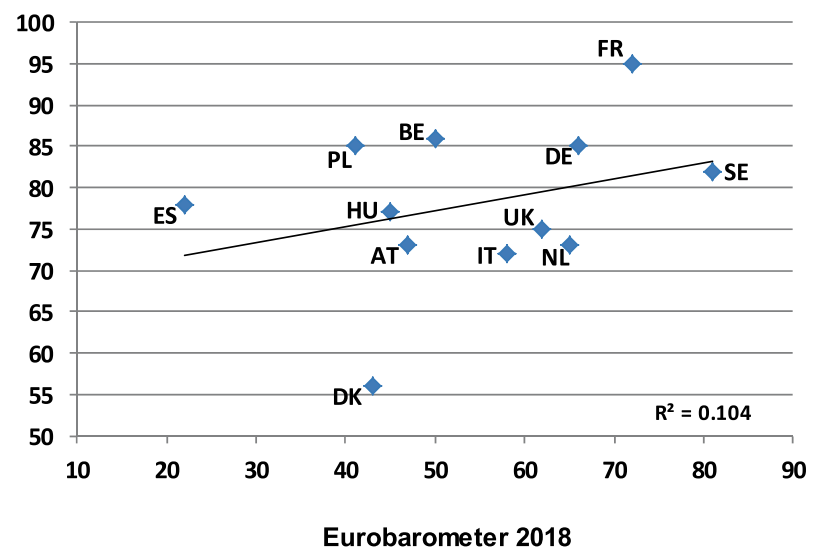

Figure 3: Comparing Measures of Antisemitism in 12 EU Countries: "Antisemitism is Very Serious or Fairly Serious Problem in Your Country." Percentages - FRA 2018 vs. Eurobarometer 2018.

Key to Countries: AT: Austria; BE: Belgium; DE: Germany; DK: Denmark; ES: Spain; FR: France; HU: Hungary; IT: Italy; NE: The Netherlands; PL: Poland; SE: Sweden; UK: United Kingdom.

intercountry variation in acknowledging the seriousness of the antisemitism threat in society was somewhat reduced. Consequently, the amount of country variance in Jewish perceptions explained by country variance in general perceptions was a modest $10.4 \%$.

Looking at these correlations, it is remarkable how Poland and Sweden occupied diametrically opposed positions in the ADL study seen above, versus the Eurobarometer study. The frequencies for Spain and Hungary were among the higher among the countries examined according to the ADL criteria and among the lower according to the Eurobarometer, although the percentages themselves were not that different. Possibly, the disparity partially is a reflection of the five-year lag between these two surveys of general public opinion, and their different methodologies. Part probably depended on the different respondents' evaluation of antisemitism as a phenomenon permeating the society of the respective countries (Eurobarometer), as against the personal attitudes by respondents with regard to Jews (ADL).

This observation prompted me to compare the findings of the ADL and Eurobarometer studies, both aimed at the total population, but with significantly different formulations of the dependent variable being investigated. As already noted, in the case of Eurobarometer, it was the assessed significance of antisemitism in society; in the case of the ADL, it was the assessed percentage of people with antisemitic views. The results are presented in Figure 4. 
ADL 2013

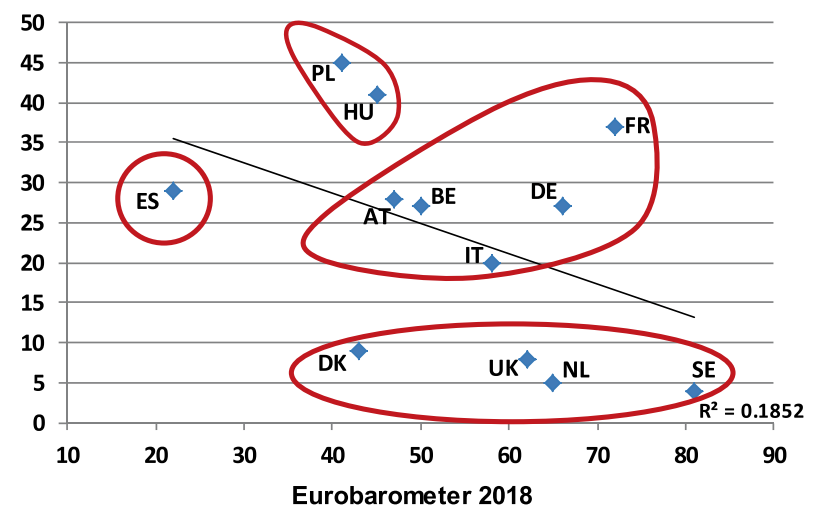

Figure 4: Comparing Measures of Antisemitism in 12 EU Countries - Eurobarometer 2018 Percentage Assessing Antisemitism as a Very Serious or Fairly Serious Issue in Society vs. ADL 2013 Percentage of Antisemitic Respondents.

Key to Countries: AT: Austria; BE: Belgium; DE: Germany; DK: Denmark; ES: Spain; FR: France; HU: Hungary; IT: Italy; NE: The Netherlands; PL: Poland; SE: Sweden; UK: United Kingdom.

An extraordinary inverse relationship emerged between the findings of the two surveys, with an amount of explained variance of $18.5 \%$, which if not exceptionally high, was nevertheless significant. These data are enlightening because they reveal the possible contraposition between personally harboring antisemitic prejudices, and perceiving antisemitism as a problem in society. Moreover, once again a definite clustering of European countries into regional areas with distinct perceptional patterns emerges: the low range of the ADL measure, tending to be higher on the Eurobarometer measure, included northern countries such as Sweden, Denmark, the Netherlands and the United Kingdom; the higher of the ADL range combined with the lower on the Eurobarometer range included countries of the former Soviet bloc area such as Poland and Hungary; the intermediate range included western countries such as France, Belgium, Germany, Austria, and Italy; Spain was in an outlier position, the lowest by Eurobarometer and among the higher by the ADL.

In any case, the amount of coherence that appeared to exist between the two general studies (ADL and Eurobarometer) and the FRA specifically Jewish study, while not absolute, consistently showed more acute and sensitive perceptions of antisemitism among Jews than among the general public. This may reflect a situation in which the perception of antisemitism has become over time an integral part of the patterns of Jewish identification - as will be argued later in this paper. 


\subsection{Cognitive, Experiential and Affective Domains}

Another important question concerns the definition of the relevant boundaries of interest when researching perceptions of antisemitism. As is well known from general research in the field of social psychology, the whole gamut of human attitudes and perceptions can be classified into three main domains: cognitive/ intellectual, behavioral/experiential/ instrumental, and affective/emotional (Tooby and Cosmides 1992). Likewise, in the study of antisemitism, we may imagine the total attitudinal and perceptional space of an individual or of a collective of individuals as a bi-dimensional shape. Figure 5 schematically exemplifies the expected partition of that space among those three main perceptional domains. In a multiple variable analysis aimed at better understanding perceptions and experiences of antisemitism, each of the variables included should ideally fall within any of the three delineated domains. This expectation would be true if we assume that the questions or indicators actually included in a given study succeeded in covering the entire human perceptional space and its domains.

Most historical and social scientific studies about antisemitism have stressed either a cognitive or a behavioral dimension. Considerable existing information inappropriately confounds these two aspects, whose empirical incidence is

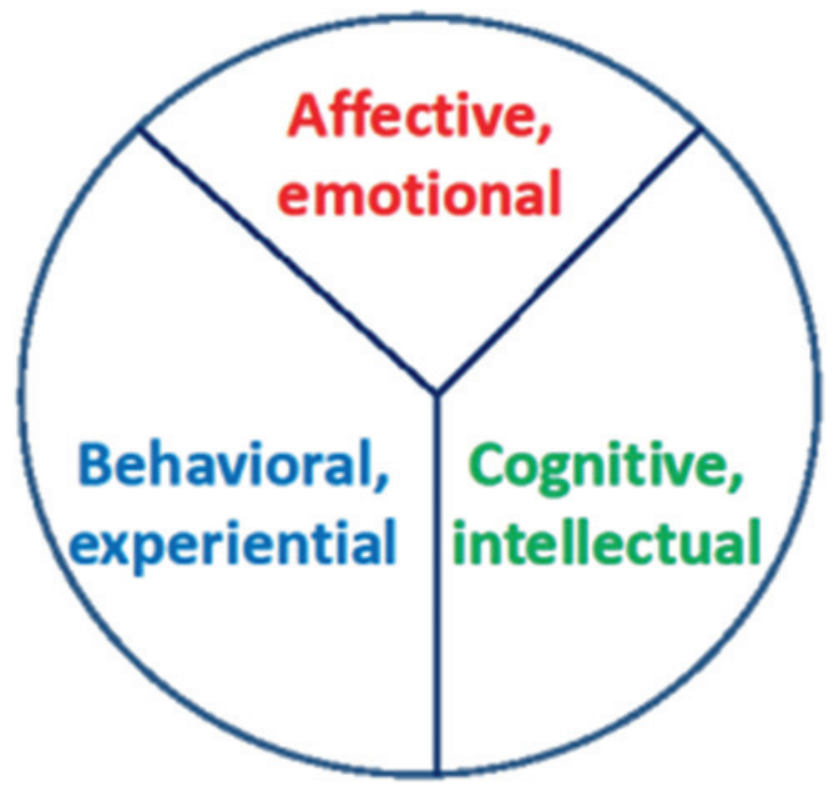

Figure 5: Illustrative Distribution of Perceptions of Antisemitism by Main Domains. 
actually widely different: for the most part, cognition of antisemitism is more diffused than actual experience of it. Surprisingly, the third domain, the affectiveemotional, has often been neglected in serious social scientific discourse. The affective/emotional aspect has been kept at the margins or basically ignored in studies of antisemitism, with the exception of specialized clinical-psychological studies directly focused on those aspects (e. g., Helmreich 1996; Weinfeld, Sigal, and Eaton 1981). And yet, I argue, it is crucially important to answer the question: How does antisemitism affect a person's emotional and affective perceptions? For example, does antisemitism generate among Jews anxiety, anger, fear, aggressiveness, passivity, activism, loneliness, solidarity, creativity, or other feelings? Does it strengthen or weaken previously held Jewish religious or ethnic identities? Does it strengthen or weaken Jewish community relations and networks? Does it strengthen or weaken empathy, solidarity, and national identification with the country of residence of affected Jews? This still appears to be an uncharted research area.

Each of the above-mentioned contexts requires different analytic tools and probably also different explanatory frameworks. To exemplify some of the emerging differences, I show in Table 1 a short synthesis and comparison between variables related to antisemitism as investigated at the cognitive and at the experiential level in the 2018 FRA survey of Jews in 12 EU countries. The data compare the highest frequencies reported among the different perceptional options that were offered to respondents within each selected area of interest.

In each instance chosen, the reported frequencies were higher at the cognitive level than at the experiential level. This accents the difference between awareness or belief that a given expression or behavior is antisemitic and actually hearing that expression or experiencing that behavior. Table 1 in particular synthetizes selected contents that Jews may perceive as offensive concerning alleged characteristics of the Jews themselves, the Holocaust, or the State of Israel. The

Table 1: Highest Frequencies Reported Regarding Selected Antisemitism Perceptions and Experiences in 12 EU Countries, 2018.

\begin{tabular}{lrr}
\hline Area of concern & Cognitive & Experiential \\
\hline Contents of antisemitism & $95 \%$ & $51 \%$ \\
Negative on Holocaust & $95 \%$ & $35 \%$ \\
Negative on Jewish characteristics & $94 \%$ & $43 \%$ \\
Negative on Israel & $85 \%$ & $51 \%$ \\
Channels of transmission & $89 \%$ & $80 \%$ \\
Anti-Jewish discrimination & $49 \%$ & $21 \%$ \\
\hline
\end{tabular}

Source: FRA 2018a, Figures 5, 6, and 7, Tables 5, 7, 8. 
frequency ranking of three major areas of contents appears to be reversed in the experiential data versus the cognitive data. The table also compares cognitive and experiential frequencies regarding the most used channels of transmission of such negative contents and frequencies of discrimination possibly (cognitive) versus actually (experiential) suffered.

These examples indicate that it is imperative carefully to specify the meaning of the data presented in any given analysis of the empirical evidence; unfortunately, this has not been a firm rule in past and ongoing research about antisemitism. In the present study, reflecting the database available and its limits, attention was devoted to the profile of and differences between cognitive and experiential domains. Unfortunately, relevant aspects in the affective domain were not investigated in the FRA study, and therefore their incidence cannot be compared with that of the other domains. The emerging evidence strongly suggests that future research on antisemitism should take into consideration all possible domains of the human perceptional sphere.

\subsection{Similarity Structure Analysis - SSA}

In the case of data analysis that focuses on quantitative analysis, the dominant mode in the literature has been the presentation of simple tabulations of data frequencies. Plain description or simple juxtaposition of results, beyond a first impression, does not usually generate more complex insights about theories or processes that would require the simultaneous processing of vastly larger quantities of information. A great improvement has been the use of causal inference, where a given variable is posited as the one to be explained (the dependent variable) and one or more other variables are posited to be the explanatory factors. This enables verifying the overall validity of a given hypothesized model and the respective explanatory suitability of each variable included in the model (e. g., Rebhun 2014; Cohen 2018; Zick, Küpper, and Hövermann 2011).

The present paper demonstrates the use of SSA (Guttman 1968; Amar and Levy 2014) in developing an original and thus far little exploited approach to the study of Jewish perceptions of antisemitism. SSA is part of the broader concept of Facet Theory, which is an approach to theory construction integrating research planning with data analysis. SSA aims at exploring the interrelationships that exist among large numbers of variables rather than focusing on explaining only one at a time. SSA computes the correlations between each of the different answers, in this case based on the original FRA survey response distributions within each of the $12 \mathrm{EU}$ countries. In SSA, correlations are based on rank orders of variables' values and not on the actual metrics of their quantitative differences. To make the concept of 
correlation absolutely clear to the general reader, if two or several respondents gave identical answers to two different questions, this means that the inherent contents of those two questions were very similar, and the two questions were strongly correlated. If the answers provided by different respondents were different, the correlation between those questions was weaker or even negative. The SSA software transforms these correlation coefficients - stronger or weaker into appropriate distances - respectively, shorter or larger - between points on a bi-dimensional map, each point representing one variable. The emerging visual configurations are helpful in assessing the overall contents of subject matter and its logical partitions. Different spatial domains detected on a map - each with its own shared homogeneous contents visually similar to the example shown in Figure 5 above - represent a higher order of generalization concerning the one or more variables included in each domain. Such conceptual domains can be hypothesized a priori or left to be determined by the software. Each domain thus detected may contain one or more variables according to the number of pertinent questions that were asked in the survey instrument.

SSA maps shown later in this paper represent the entire configuration of all possible distances between each variable and each of the others - as resulting from the different response options provided by over 16,000 respondents in the 12 countries investigated. This is the largest number of Jewish respondents ever obtained in a research project undertaken in Europe. The total response obtained and the inter-country differences in consensual versus polarized perceptions of antisemitism provide the empirical evidence needed to evaluate the internal articulation and plausible structure of the topic observed.

SSA has the advantage of not being very sensitive to imperfect representation of the target population because of biased sampling. The method focuses on associations between variables rather than on their frequencies. It has no explicit pretension of searching for causal-directional relationships between variables, although it may help to establish causality hypotheses. It rather attempts to present a picture of logical interrelationships and affinities between different concepts and variables, thus refining the understanding of connections or incompatibilities between relevant domains of contents. Causal directionality of those associations will sometimes be self-evident although under other circumstances, it may remain not adjudicated. SSA's main goal is to stimulate theory and hypothesis formulation toward a better holistic understanding of the topic studied. It may be useful to develop new typologies or to demonstrate the inconsistency of existing ones.

Each of the SSA maps that will be presented below is the equivalent of a bivariate or multi-variate statistical table in which one dimension is the 12 countries observed, and the other dimension is the category distribution of the antisemitismrelated variable (or variables) in question. Moderate rotations in the different map 
displays do not have analytic meaning. Some rotations were introduced in the graphics that follow to make the results more easily readable and immediately comparable. All the original tables were published in the original FRA report (FRA 2018a).

To exemplify the approach adopted in this paper, I reproduce in Table 2 one of the tables from the FRA 2018 survey report. These data constitute the basis for the elaboration of Figure 6 presented in the next section of this paper. In the figure, as will be seen, the HUDAP software (Amar and Toledano 2001) transforms the original table into a matrix where the differences between the values reported in each row - representing the different response options - are modulated according to the differences across the different columns - representing the different countries included in this study.

Modulating the categories in each variable by the 12 countries covered in the 2018 survey amounts to attributing the same weight to each country. This is obviously incorrect in terms of the size of the respective Jewish populations: the core Jewish population in the 12 counties ranged in 2018 between 450,000 in France and 4,500 in Poland (DellaPergola 2019). On the other hand, the actual final target and recipient of the antisemitic message - if any - is the individual Jew. Had we modulated the tables by the over 16,000 respondents, and not by the 12 countries, the large numerical impact of the major Jewish populations would have minimized the impact of the smaller ones, thus biasing the total picture in the direction of France, the UK and, to some extent, Germany. By choosing to present the following data unweighted by the size of a country's Jewish population, the underlying hypothesis is that there exists a strong dependency of Jewish life on the unfolding of cognition and experiences at the national level of each country. I thus make this hypothesis explicit, while acknowledging that alternative analyses conducted at the individual respondent level might produce somewhat different results. Experience from previous research suggests that those differences would not affect the main thrust of the analysis, as in most cases inter-country perceptional differences would tend to prevail over intra-country differences.

By the same token, each of the subsequent SSA maps in this paper was derived from one or more tables in the original FRA report (FRA 2018a). The present study indeed largely complements the original 2018 FRA report by using the same database, although differently. Rather than describing facts and frequencies, as prevalent in most research including the original report, I aim at uncovering the deeper layers of explicit and latent meaning of the antisemitic phenomenology in the European Jewish context. One original contribution of this paper is the combination of various tables into one conglomerate map, thus transforming the original bi-variate analysis into a multiple-variable analysis. After computing the correlations emerging from intercountry variation not on one but simultaneously 
on several variables, the product is as if the pertinent maps of the respective variables had been superimposed one over the other. This helps to detect and integrate relationships between categories and concepts originally presented as separate items. I trust the reader will find the following analysis intuitively accessible and innovative, no less enlightening than the original materials, and a useful complement to the initial publication of the FRA 2018 survey results.

\section{The Ingredients of Antisemitism}

In this section I shall introduce, one by one, the main variables or ingredients that form a large share of the whole perception of the contemporary antisemitic phenomenology at least as observed in 2018 in 12 countries of the European Union. In the first place, I shall aim at revealing the internal structure and meaning of each aspect separately. In a later section, I shall analyze the interactions that exist between different variables in order to obtain a better, multiple variable picture of how Jews in Europe perceive the explicit and latent logic and mode of operating of contemporary antisemitism. The technique followed here is SSA, as illustrated in the methodology section above.

\subsection{Social and Political Issues}

Initially, in order to demonstrate the method of analysis followed, I shall address the perception of antisemitism in the broader context of problematic societal issues in the 12 EU countries included in the 2018 FRA survey. Respondents were asked to assess their concern about a selection of social and political issues in the respective countries. The question [B02] was: To what extent do you think the following items are a problem in your country? The issues listed included unemployment, crime levels, immigration, antisemitism, racism, intolerance towards Muslims, and government corruption. This exploration of cognitive perceptions aimed at placing antisemitism in a broader context, namely, to what extent Jews perceive antisemitism as a predominant and central concern or rather than one among many other social issues in their country today.

Figure 6 reports the emerging SSA configuration based on seven categories. As already noted, this is the graphic equivalent of Table 2 above. Figure 6 graphically demonstrates the internal configuration of the main variable (main societal issues), reflecting the underlying statistical correlations between its various categories. The display provides a basis for a more complex understanding of the inherent meaning of that variable, which, in turn, may produce useful insights for more complex theoretical elaboration. The several categories listed in the original table are 


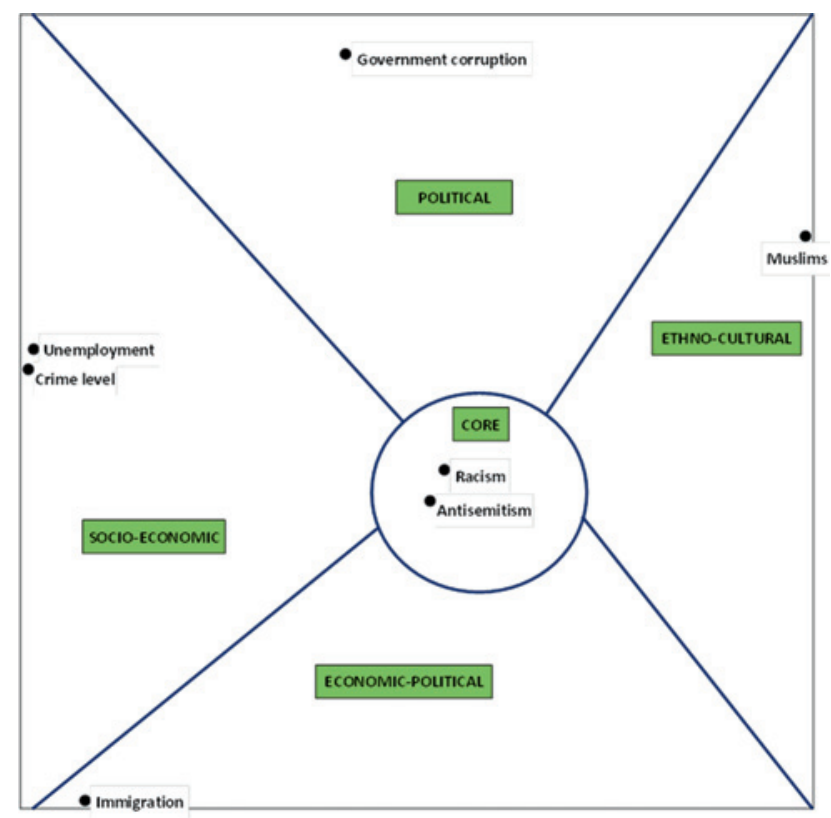

Figure 6: SSA of Perceptions of Selected Social and Political Issues, Modulated by Countries.

scattered on the map in a way that suggests the existence of broad er underlying conceptual domains. Had more items been included in the original questionnaire, they either might have filled some of the empty spaces that appear within each of the main domains detected or might have generated additional principal domains.

Of the various items selected for evaluation, concern about antisemitism was the issue evoking the highest response ( $85 \%$ of respondents) followed by racism (84\%). The issue drawing the lowest response was government corruption (38\%). Quite significant variation emerged across countries regarding the different issue frequencies. In the SSA map, social and political issues judged as nationally significant display a circular-radial pattern with a clear central focus. Antisemitism and racism clearly figure at the core of Jewish public concerns. The analytic meaning of the display is that - not unexpectedly - perceptions of antisemitism and of racism are highly and mutually correlated and evidently constitute the societal issues of paramount Jewish concern. Fears of antisemitism and racism are correlated with other issues more strongly than each of the other issues is with all of the others on the list. Such worry is widely shared across the whole Jewish population spectrum. Jewish respondents perceive other concerns in more selective modes also reflecting their exposure to different national contexts, as well as different personal characteristics and sensitivities. 
The other societal concerns are displayed as wedges around the central core and reveal interesting interrelationship patterns. Unemployment (67\% of respondents) and crime level (70\%) appear strongly clustered in a socioeconomic domain. European Jews do not perceive these issues as belonging to the same domain as immigration (65\%), which in recent years constituted a high-profile theme in public political and socioeconomic discourse in many European countries. Intolerance toward Muslims (57\%) following the recent arrival or generational coming of age of large minorities from North Africa and other Middle East and African countries is not perceived by Jews as part of the same immigration domain either. Finally, government corruption appears as a further separate concern domain.

On the face of these data, perceptions of European Jews appear to be remarkably at odds with the main thread of political debates in most contemporary European societies. This may, perhaps, be interpreted as a symptom of many Jews' persisting ability to preserve sober and independent judgment vis-à-vis the main social and political issues that animate national political discourses and decisions. It is also possible, however, that these data are a symptom of Jews' estrangement and disenchantment from mainstream European politics. The strongly perceived centrality of concerns related mainly to the Jewish community itself and an evaluation of other main issues that differs from the majority of society may carry momentous consequences for continuing a relationship of mutual understanding between Jews and the majority of the population.

\subsection{Contents of Antisemitism}

Following the discussion sketched earlier in this paper, antisemitism can be conceptualized in many different ways. Several of the main possible contents were suggested to the respondents through questions that addressed both cognitive and experiential levels. One of the aims of the FRA survey was better to document the differing incidence of the phenomenon as something that cognitively "is in the air" versus its actual manifestation in the experience of real people. A substantial gap of tens of percentage points separates opinions about the phenomenon from actual experiences of its occurrence. Here the aim is to ascertain whether the structure of Jewish perceptions is similar or different at the cognitive and experiential levels.

\subsubsection{Cognitive Level}

Reflecting accumulated knowledge from previous scientific research and general wisdom as discussed above in this paper, a broad catalogue of statements 
offensive to Jews was compiled. A selection of these statements was included in the 2018 FRA survey. One initial analysis here is devoted to where, when, and to what extent Jews in Europe perceive such statements as antisemitic. The question [B17] was: Would you consider a non-Jewish person to be antisemitic if he or she believes (items as listed)? Figure 7 reports the relevant SSA map based on six categories.

It is immediately apparent that the configuration in Figure 7 is different from the one displayed in Figure 6. Instead of a circular-radial shape (with or without a central focus), we have an axial-parallel shape. The analytic difference is that a circular shape has no beginning and no end, hence no hierarchy, whereas - if existing - a central spot may indicate the dominant or at least the main connective element among all others. An axial shape, on the other hand, displays an ordinal (if not hierarchic) progression of some underlying element or component, from one extreme end to an opposite end. In other words, the various elements under examination appear to be ordered according to an underlying logic.

Reading Figure 7 from the upper right corner to the bottom left corner, we find in succession a perception that it is antisemitic: to believe that Jews are not nationals in a given country's context - 94\% of respondents; that one would not marry a Jew - 59\%; that one always notes who is Jewish among personal

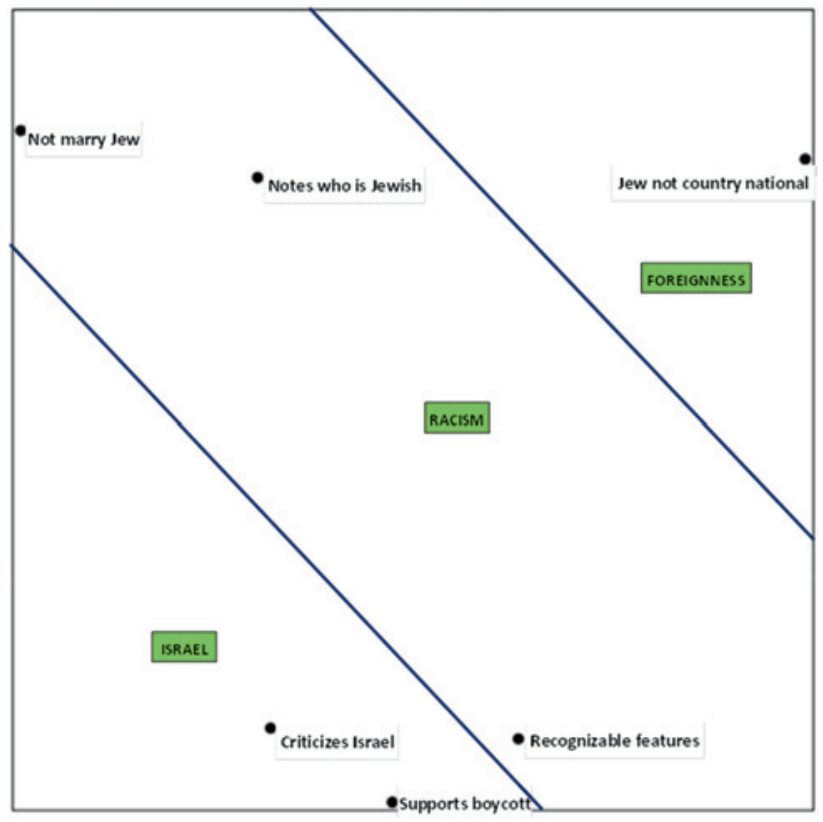

Figure 7: SSA of Perceptions as Antisemitic of Certain Opinions or Actions by Non-Jews, Modulated by Countries. 
acquaintances - 55\%. These perception categories can be collapsed into one comprehensive domain grounded in the Protocols of the Elders of Zion, i. e., classic nineteenth and twentieth-century antisemitism. The opposite bottomleft corner hosts perceptions of antisemitism in the case when the State of Israel and its citizens are depicted as entities to be criticized and boycotted. If an explicit question about BDS (Boycott, Disinvest, Sanction) had been asked, that is where in all likelihood it would have been placed. The rationale behind the figure's display seems to be historical chronology. Jewish foreignness is certainly the most ancient element, followed by a more modern elaboration about racist discrimination, while Israel, evidently, is the more recent development in global and Jewish history. As time goes by, Israel tends to become integrally incorporated within the Jewish perceptions of antisemitic notions and behaviors.

It is noteworthy in this respect that only 38\% of European Jews believe that criticizing Israel is antisemitic, whereas $82 \%$ believe that boycotting Israel and Israelis is. The categories of opposition to Israel and of Jews possessing recognizable features (75\% of respondents) are conceptually separated. It is, nevertheless, interesting to note the closeness of the respective categories. This demonstrates a Jewish perception of the existence of a diffused opinion that not only Jews but also Israelis possess distinctive and negative physical or character features. If this reading is accurate, it means that anti-Israel hostility pertains to a domain not necessarily or not exclusively related to contemporary political contingencies - normally the object of much debate and critique, including considerable disagreement within the Jewish camp. Emerging illegitimacy rather tends increasingly to reflect an alleged intrinsic property, hence becoming cognate to classic antisemitism.

\subsubsection{Experiential Level}

I turn now to a similar analysis of the perceptions of antisemitic contents as actually experienced by respondents. The question [B15a] was: In the last 12 months, have you ever personally heard or seen non-Jewish people in our country suggest that (Items as listed)? Multiple answers allowed. Figure 8, based on eight categories, presents the pertinent SSA map.

Not unlike the previous map based on cognitive perceptions, experiential perceptions in the current map result in an axial display whose components can be synthetized in four or five domains. In the upper-right corner, we find judgments of Jews responding to attributes that conform to the tenets of the Protocols of the Elders of Zion, such as dominance, foreignness and selfishness (Jews hold too much power $-43 \%$ of respondents; interests of Jews are different from the rest of population - 22\%; Jews are not capable of integrating into the given country's 


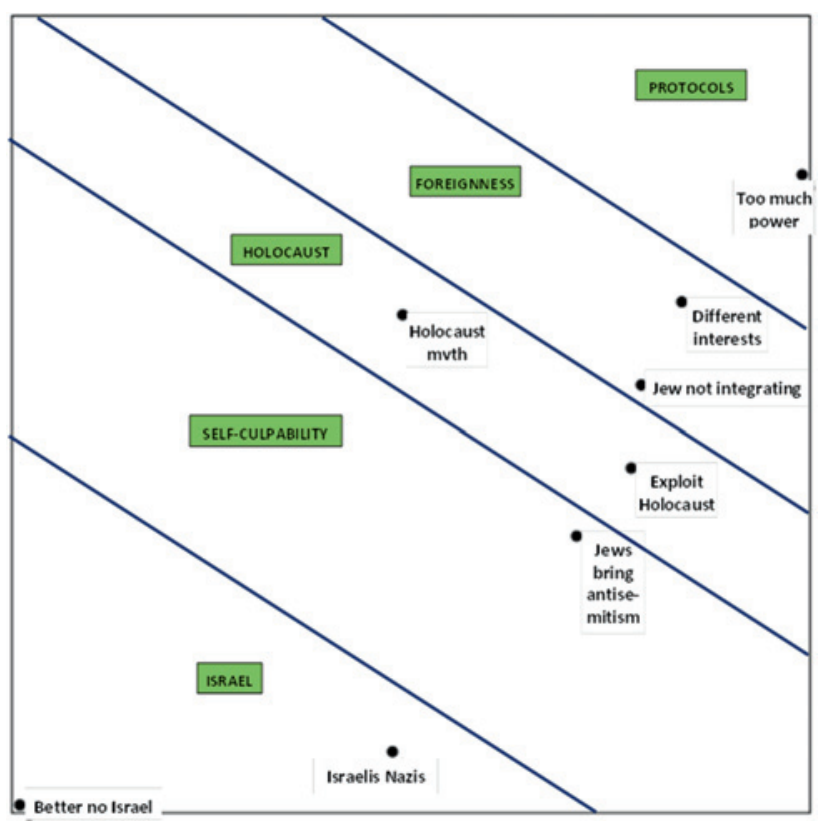

Figure 8: SSA of Selected Antisemitic Statements Heard or Seen by Non-Jewish People, Modulated by Countries.

society - 11\%). Another domain concerns judgment about the Shoah (The Holocaust is a myth or has been exaggerated $-24 \%$; Jews exploit Holocaust victimhood for their own purposes - 35\%). Next is a domain about self-culpability (Jews bring antisemitism on themselves - 32\%). The final domain in the bottom-left corner concerns Israel (Israelis behave as Nazis toward the Palestinians - 51\%; The world would be a better place without Israel - 33\%).

As in the previous display, the ordering of the different parallel bands seems to reflect some historical chronology: from the older patterns of classic anti-Jewish prejudice, through the denial and minimization of Shoah, to the more recent delegitimization of the State of Israel. The formats of Figure 7, reflecting the cognitive perceptions, and Figure 8, reflecting the experiential perceptions, respond to the same underlying ordinal-hierarchical logic. Proximity of Jewish perceptions concerning the Holocaust and Israel is a significant finding to be kept in mind for further consideration.

\subsubsection{Combined Levels}

A joint display of the perceived contents of antisemitism (Figure 9) is significant in conjunction with the separate cognitive and experiential displays. Figure 9 


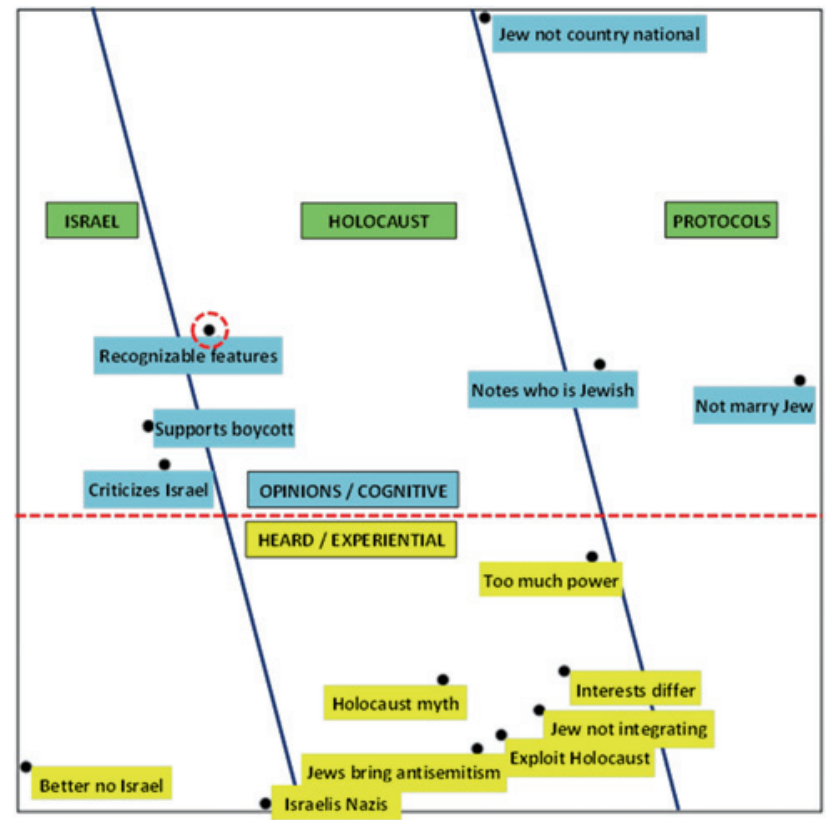

Figure 9: SSA of Combined Cognitive and Experiential Perceptions of Antisemitic Expressions, Modulated by Countries.

presents the combined processing of the 14 categories displayed in Figure 7 and Figure 8 . When mapping together data from two different variables, it may be expected that the domains subdivide and regroup either according to the perceptional mode (cognitive vs. experiential) or according to the inherent substantive contents of the questions involved.

On the one hand, it is notable how neatly distinct the cognitive and experiential perceptions appear horizontally divided on this map. The two perceptional domains tend to form separate "banks" of questions and issues. On the other hand, the substantive contents are clearly organized into three main domains: from right to left, Protocols-type, Holocaust, and Israel oriented - regardless of the cognitive or experiential nature of the category. It is remarkable how close Holocaust-related categories are perceived to be to the classic antisemitic concepts. Apparently, in the course of time and since the previous 2012 FRA survey, a certain evolution in the Jewish perceptions of hostile concepts and behaviors occurred. This entails a coalescence of Holocaust-related categories with old, classic antisemitism and of Israel-related categories within the overall antisemitism pattern. Indeed, we find one cognitive category apparently out of context: the one saying that Jews have 
recognizable features appears in the Holocaust domain. This seems to be another proof of the gradual coalescence of the various contents components of the overall antisemitic paradigm. Such perceptional changes may or may not have reflected actual changes within the general societies of European countries, but they are, nonetheless, real within the contemporary Jewish community perception.

I shall note, in conclusion, that because of a lamentable oversight by the principal investigators, the Christian theme of deicide was not included in the survey questionnaire and therefore it cannot be assessed empirically in this analysis. It can be hypothesized that it would occupy a spot close to the classic prejudice markers as displayed here.

\subsection{Channels of Transmission}

Antisemitism, in addition to involving a complex array of ideas, attitudes and behaviors, requires certain mechanisms of diffusion in order effectively to attain its goals. In the course of history such channels of transmission radically transformed under the impact of modernization and technological change.

\subsubsection{Cognitive Level}

I first examine respondents' assessment at the cognitive level of how selected channels of antisemitism transmission, operating in the different countries, are perceived as problematic. The question [B04a] was: To what extent do you think the following are a problem in your country (items as listed)? The results appear in Figure 10, based on seven categories.

In the circular-radial display of the selected channels of transmission, we note four main domains. The first domain concerns those modes involving physical action and aggression. Items covered in the 2018 study included: in the street or other public places (mentioned by $73 \%$ of respondents); vandalism of Jewish buildings or institutions (66\%); and desecration of Jewish cemeteries $(63 \%)$. The central position of the cemeteries desecration item in the map is notable and testifies to the high sensitivity attributed to this particular mode of action by the Jewish public at large. Considering the physical and immediately documentable nature of this type of offense, it will be here defined as Practical antisemitism. A second domain includes expressions on the internet, including social media (89\%, the most reported of all transmission channels), and mural graffiti (64\%). Because of its immediate, spontaneous and defamatory character it will be here defined as Populist antisemitism. A third domain involves the Media other than the Internet, namely, the printed and electronic press (71\%). Because of its thoughtful and 


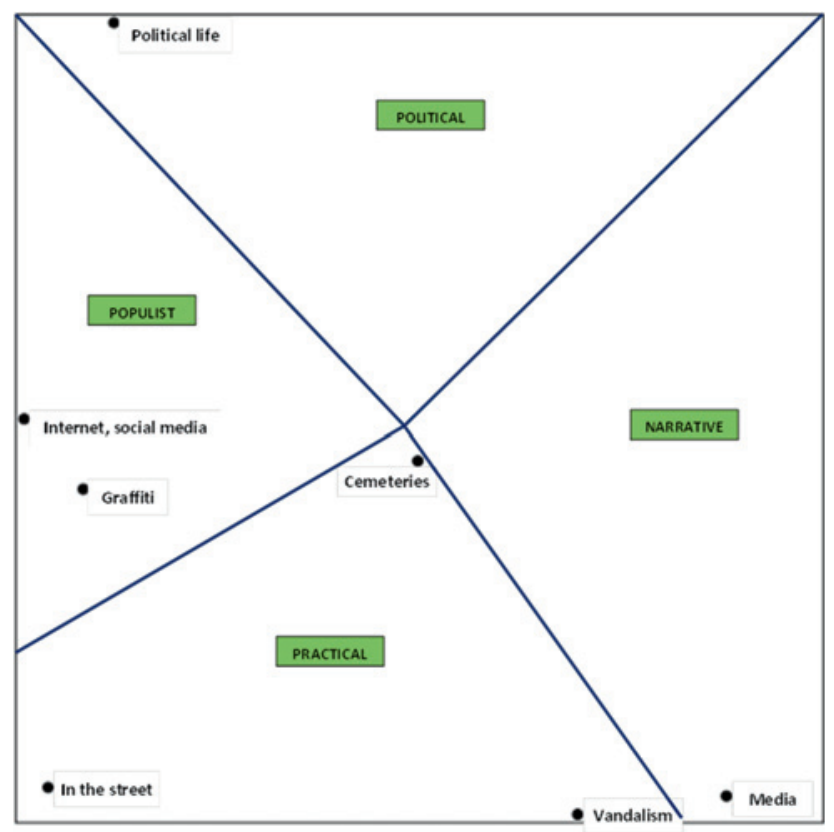

Figure 10: SSA of Assessment of Manifestations of Antisemitism against Jewish Community as a Problem, Modulated by Countries.

researched character, it will be here defined as Narrative antisemitism. A fourth domain involves Political life (70\%), where the contents are conveyed by a Political antisemitism mode of thought and action, also influenced by other public concerns and interests and conducted by actors involved in leadership struggles and currying favorable public opinion.

\subsubsection{Experiential Level}

At the experiential level, we are interested in assessing where and through which transmission channels Jews actually encountered antisemitic expressions, behaviors, or personal harassment. The question [B16a] was: In the last 12 months, where did you personally hear or see these comments (items as listed)? Multiple responses possible. The pertinent map, based on 11 categories, appears in Figure 11.

The patterns reported in Figure 11 reflect the specific tools and channels included in the survey questionnaire. At first sight, the map features many similarities with the previous one, with the exception of the Practical mode of antisemitism which was not included in the question asked here. As with the cognitive question reported above, the most frequent transmission channel of antisemitic 


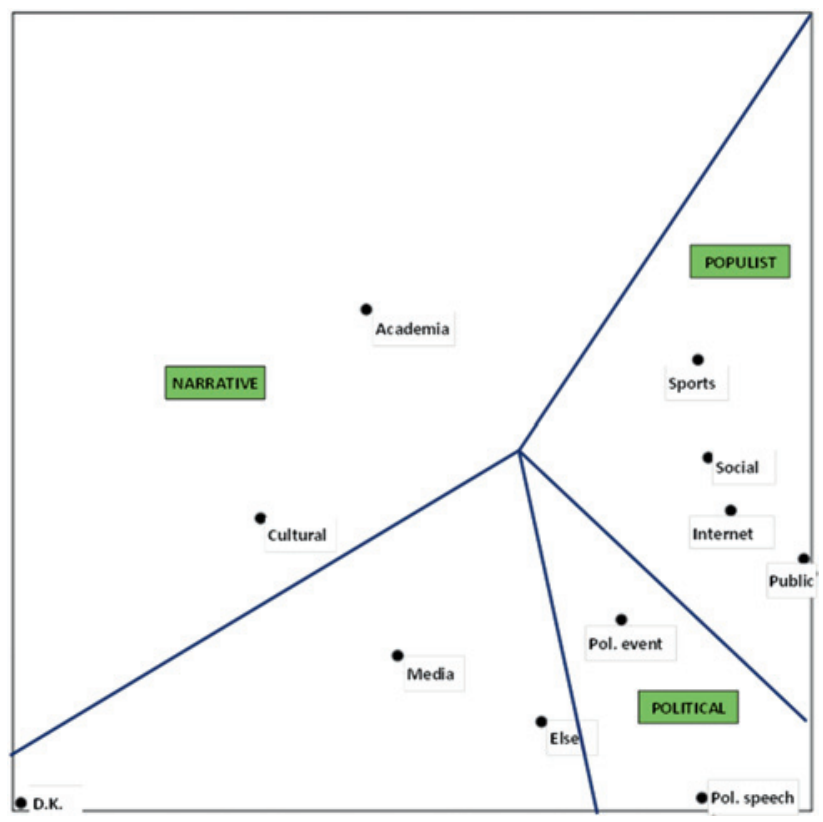

Figure 11: SSA of Context of Negative Statements about Jews made by Non-Jewish People, Modulated by Countries.

messages was: on the internet, including social media ( $80 \%$ of respondents). This pertains to the Populist antisemitism domain along with: in a social situation (47\%); in a public space (44\%); and at sports events (11\%) - stressing again the spontaneous and undisciplined character of such contexts. The more thoughtful, elaborated Narrative antisemitism domain primarily included: In academia (19\%) and At cultural events (18\%). The Political antisemitism domain included: at political events (48\%) and in political speeches or discussions (40\%). The category in the Media other than internet and social media (56\%) appears at the center of what might be a domain of its own along with a minor amount of response referring to undetermined channels (Somewhere else - 13\%; Don't know - 4\%). On further consideration, the edited and censored character of the mainstream printed and electronic media suggests considering it as a cognate to the Narrative mode. Reading the map differently, however, one notes that the position of the Media category appears to be intermediate between the Narrative and Political domains, occupying exactly the same space that in the previous figure was defined Practical antisemitism. It is as if in the experiential perceptions of European Jews, the media played the same immediate and brutal role of cemetery profanation or other forms of vandalism. 


\subsubsection{Combined Levels}

The results of a combined processing of the 17 categories on transmission channels of antisemitism already seen in Figure 10 (cognitive) and Figure 11 (experiential) are displayed in Figure 12. The question here might be again whether the predominant organizing principle of the pertinent categories is the mode of perception (cognitive vs experiential), or the substantive meaning of the category. The actual data in Figure 12 provide a revealing blend of the two modes.

The separation between cognitive and experiential domains is very clearly distinguishable, with only one exception not included within a coherent contiguous space: the experiential notion of Political event, which is included in the cognitive area of the map. This category, however, appropriately pertains to a Political antisemitism domain together with a cognitive category, political life, and another experiential category, political speech. In general, cognitive categories are spatially more compact and concentrated than experiential categories, meaning that Jewish perceptions are more coherent and shared regarding cognition than regarding experience.

The main partitions of channels of transmission, however - Practical, Populist, Narrative, and Political - appear clearly, and each of them includes categories

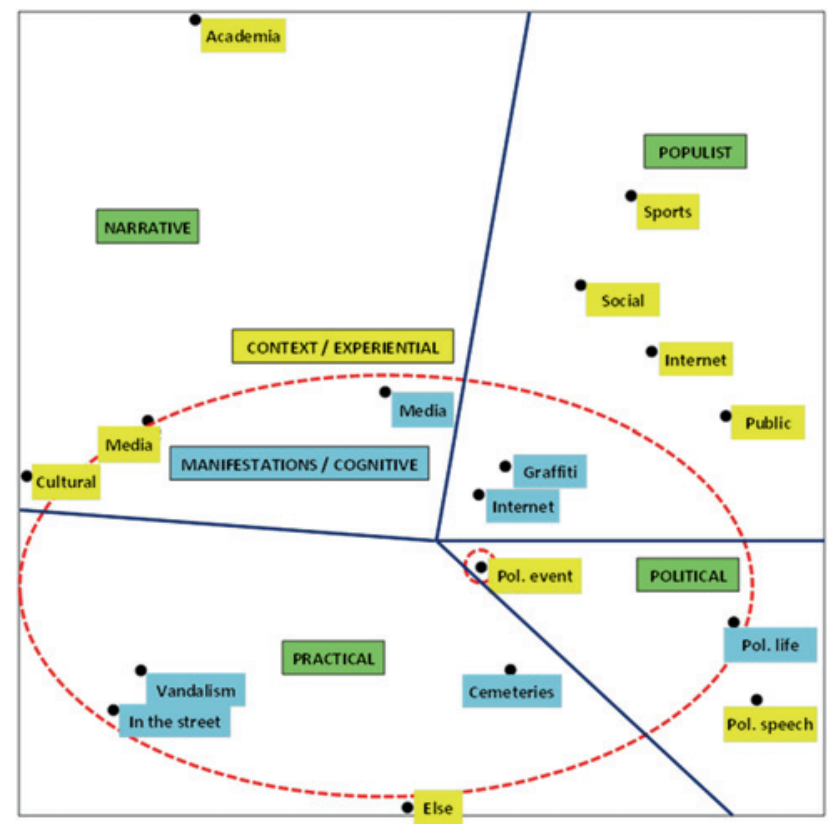

Figure 12: SSA of Combined Cognitive and Experiential Perceptions of Channels of Transmission of Antisemitism, Modulated by Countries. 
pertaining to both cognitive and experiential modes. What appears here is a robust new typology of perceptions of antisemitism to be followed in the subsequent analysis. Remarkably, the two transmission channels that were investigated in both modes - the Internet including social media and the Media other than internet - appear coherently within the respective domains (Populist and Narrative antisemitism, respectively). The currently leading channel of transmission - the Internet - is perceived at the cognitive level as intriguingly proximate to the veteran and sometimes celebrated category of Graffiti. It may be inspiring, indeed, to perceive the little screen universally available nowadays as cognate to the old wall where one could freely trace expressive drawings and mottos. Finally, one notes that the transmission category Else falls within the domain of Practical antisemitism, thus confirming what had been hypothesized for the map of experiential categories.

\subsection{Sanction against Jewish Rituals and Discrimination against Jews}

One further dimension of antisemitism perceptions relates to the concerns expressed by Jews in Europe regarding instances of possible (cognitive) and actual (experiential) discrimination suffered.

\subsubsection{Cognitive Level}

The cognitive aspect was explored through a question about attitudes to possible government sanction against two significant Jewish rituals: circumcision of Jewish male infants (brit milah) and ritual slaughter of animals (shechitah). The original survey question [F10] was formulated as follows: In the last 12 months, have you personally heard or seen non-Jewish people suggest that circumcision and traditional slaughter (shechitah) should NOT be allowed to take place in your country? The possible answers were: yes to both, yes to one only, or no. Reference is to a cognitive perception that such issues were raised in public debate rather than to an experiential exposure of respondents to the issue. With regard to the countries included in the 2018 FRA study, however, such sanctions against the ritual slaughtering of animals have already been implemented in Sweden, Denmark, and Belgium, with severe regulation in several other countries (Feder 2019). Legislation to ban circumcision was suggested in different countries but was not implemented anywhere in the countries surveyed here (Triadafilopoulos 2019). In general, government or other public opposition to protection of two significant Jewish rituals can be interpreted as a potential sanction against widely held Jewish tenets, and by extension, against Jews as such. 
With varying intensity across countries, the topic of European legislation possibly curtailing free access to traditional options among Jewish communities was at the center of much attention and public debate in recent years. The percentage of total respondents for whom the prohibition of circumcision would be a problem was $82 \%$, versus $69 \%$ for traditional slaughter. It should be acknowledged that the frequencies of actual practice of any of the mentioned Jewish rituals - i. e. circumcising one's own sons and consuming kosher meat - can be very different among any given Jewish population, and actual observance frequencies can be very different across the $12 \mathrm{EU}$ countries investigated here. The relevance of the Jewish rituals mentioned here apparently involves the cognitive and emotional perceptions of Jewish individuals more than their behavioral sphere.

Overall, 9\% of Jews in the 12 EU countries heard about the prohibition of circumcision, $11 \%$ about prohibition of ritual slaughtering, and 38\% about both, for a total of $58 \%$. Hence $42 \%$ had not heard about either. The pertinent SSA is reported in Figure 13. In the emerging map based on two categories (articulated in three partly overlapping options), the answers appear to be plotted in a circularradial pattern. The total space is divided primarily between a domain of negative and a domain of positive answers. The positive answers domain is further partitioned between having heard about both issues, or about one issue only. Logically,

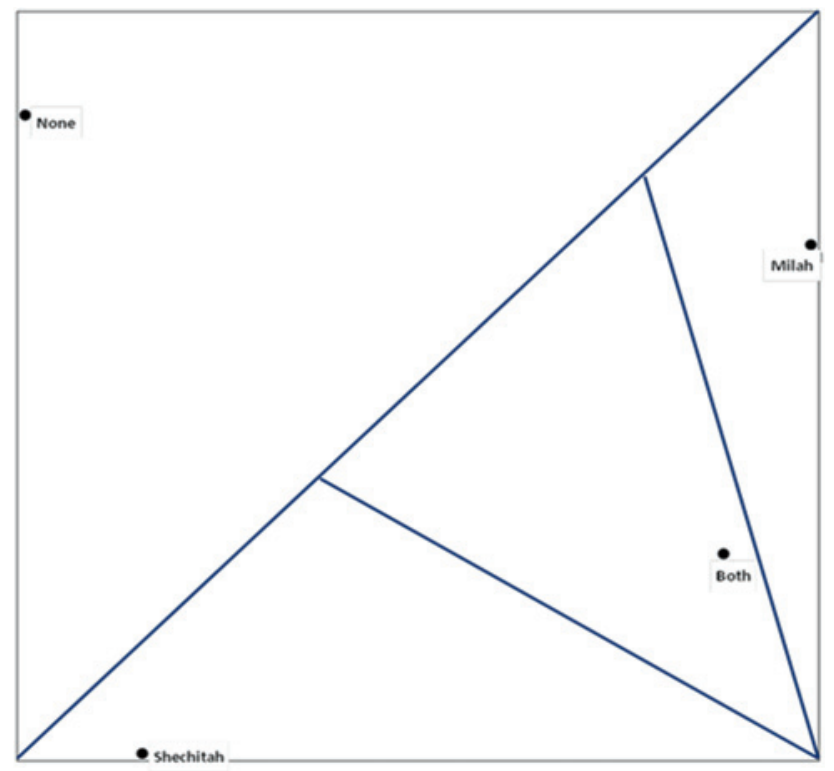

Figure 13: SSA of Perceptions of Public Sanction against Brit Milah and Shechitah, Modulated by Countries. 
the domain pertaining to the answer both represents the overlap of the two domains pertaining to either circumcision or ritual slaughter, and it therefore occupies an intermediate position between the two.

\subsubsection{Experiential level}

The experiential level of actual discrimination suffered by Jewish respondents is explored through perceptions regarding four different possible manifestations related to their personal characteristics. The original survey question [F01] was: In the PAST 12 MONTHS have you personally felt discriminated against in your country for any of the following reasons: Skin color; Ethnic origin or immigrant background; Religion or belief; Age; Sex/Gender; Disability; Sexual orientation; Gender identity; For another reason. Multiple responses possible. Here we focus on four aspects: gender, age, religion, and ethnicity. The percentage of respondents indicating one of the other grounds for discrimination was relatively low $5 \%$ or less in the $12 \mathrm{EU}$ Member States), and the number of respondents with relevant experiences was too small for country level analysis. Therefore, they were omitted from the present analysis (Figure 14, based on four categories).

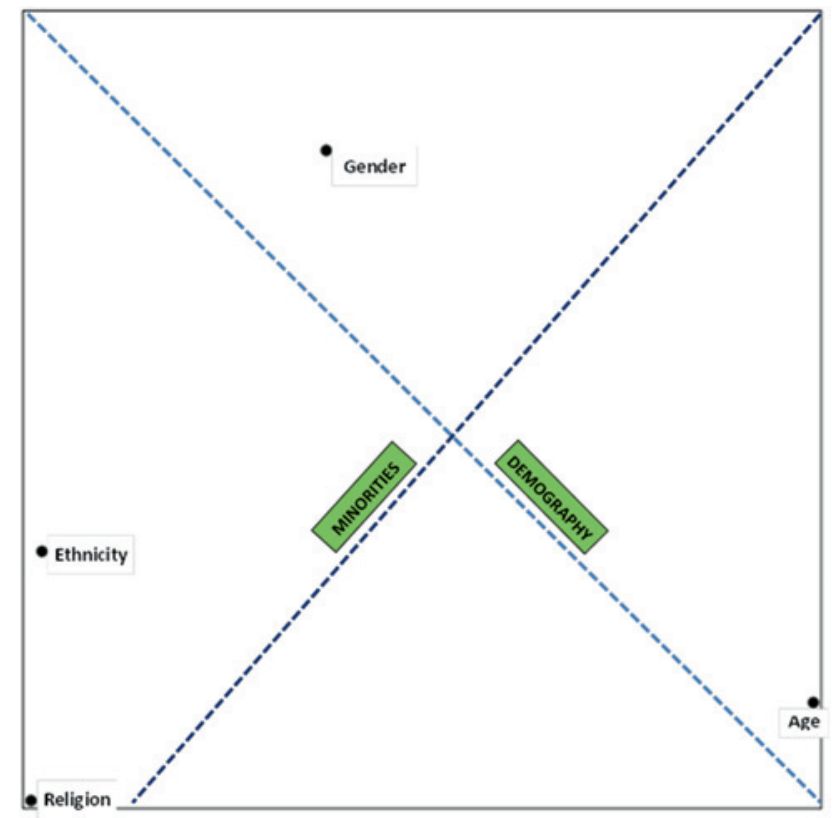

Figure 14: SSA of Perceptions of Discrimination Suffered by Jews on Selected Grounds, Modulated by Countries. 
Among Jewish respondents in 2018, 21\% reported having felt personally discriminated on grounds of religion or belief, $13 \%$ because of age, $12 \%$ because of gender, and $11 \%$ because of ethnic origin or immigrant background. The selected options appear once again in a circular-radial pattern. Religion and ethnicity occupy relatively close positions, testifying to a closer connection between the two. Gender and age occupy more distant and apparently unrelated positions.

The partitions outlined in Figure 14 suggest two possible interpretations of the data. Perhaps the more obvious is that age and gender represent demographic categories, thus forming one domain, whereas religion and ethnicity both constitute socio-cultural categories directly related to the Jewish identity of respondents, and thus regroup in another domain. An alternative construct might be that gender, in this case women, as the two socio-cultural categories, pertains to a shared domain of (normative) minorities that in most contemporary societies still struggle to achieve full equality of rights and equity of treatment. Women actually constitute the majority of population in most developed countries, but in many respects their status is similar to that of a minority that still must go a long way before it will have achieved full parity with the societally hegemonic group - in this case, males. Both possible interpretations are outlined in Figure 14.

\subsubsection{Combined Levels}

The combined configuration of feared sanction (cognitive) and suffered discrimination (experiential) appears in Figure 15, which results from the joint processing of the six categories displayed in Figure 13 and Figure 14.

The two original variables - the cognitive and the experiential - can be distinguished as separate domains divided by the dotted line in the map. More significantly, however, the combined categories form two recognizable domains, one pertaining to the life cycle (age and gender) and one to ethno-religious identities. Among the latter, two relate to actual discrimination on religious and ethnic grounds and two to feared sanction against circumcision and animal slaughtering. In particular, the categories of circumcision and religion appear in the same domain although they pertain to two different survey questions. The main finding here is the clear substantive connection between perceptions of antisemitism, despite their different cognitive or experiential nature.

\subsection{Perpetrators}

Perceptions of antisemitic offenses go together with perceptions of who are the perpetrators of anti-Jewish harassment or violence. The 2018 FRA survey carried 


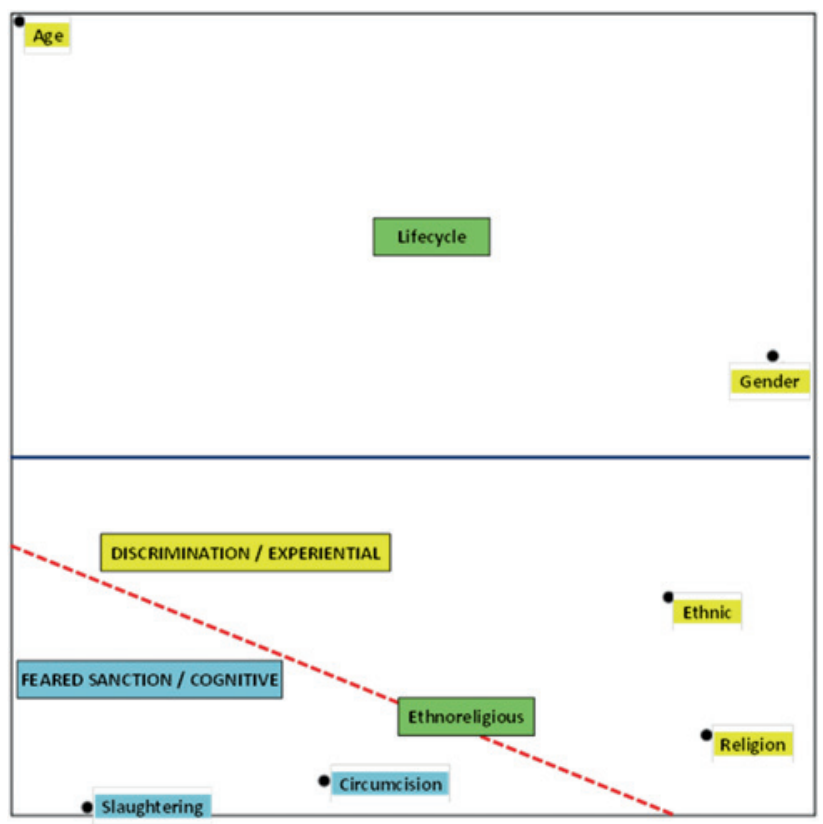

Figure 15: SSA of Combined Perceptions of Sanction Against Jewish Rituals and Discrimination Suffered, Modulated by Countries.

the following question [C06]: Who did this to you (items as listed)? Multiple responses possible. The categories of possible offenders were predetermined and included a variety of options ranging from ideological - political or religious actors, to persons known through various kinds of social networks, to undetermined perpetrators. The findings, based on 10 categories, appear in Figure 16.

The display on Figure 16 is axial, i. e., it reflects a categorical ordering of the variables involved. In the upper-right corner a strong perceptional proximity appears between Right-wing perpetrators (13\% of respondents) and holders of Christian extremist views (5\%). In the bottom-left corner there emerges some proximity between Left-wing (21\%) and Muslim extremist perpetrators (30\%). Quite logically, then, we find that the Right-wing/Christian domain stands at the opposite end of the map to the Left-wing/Islamic domain. It should be noted that following a specific FRA request, the categories mentioning the two religious backgrounds were confined to holders of extremist views, which may have significantly limited the reported frequency of these types of perpetrators.

In between, there appears a domain of perpetrators identified by various types of personal relationships or other personal characteristics (work or school/college colleague $-16 \%$; a teenager or group of teenagers $-15 \%$; an acquaintance or friend 


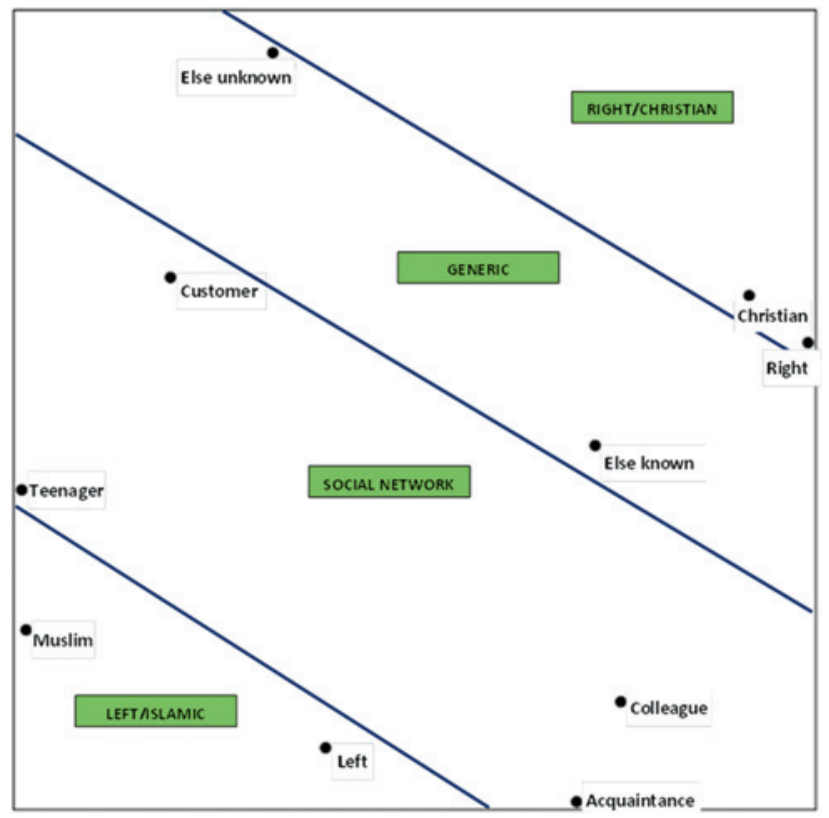

Figure 16: SSA of Perceptions of the Perpetrator(S) in the Most Serious Antisemitic Incident of Harassment in the 5 Years before the Survey, Modulated by Countries.

$-15 \%$; a customer or client from work - 5\%). Finally, a generic domain appears for others (someone else I cannot describe - 31\%; someone else I can describe - 13\%). Interestingly, the generic type domain is closer to the right-wing/Christian domain, while the identified type domain, namely, colleagues and acquaintances, is closer to the left-wing/Islamic domain. Whether this hints at the personal political opinions of respondents - closer to the Left than to the Right - cannot be determined here. The proximity between teenager and Muslim perpetrator also deserves attention.

It is worth recalling that the SSA spatial displays do not reflect the frequencies reported but rather the correlations between the various categories. It is noteworthy, however, that the cumulated percentages of perceived perpetrators (including multiple reporting) are as follows: Right/Christian - 18\%; Left/Islamic $51 \%$; other specified - 51\%; other unspecified - 48\%). Wide variation characterizes the individual country distributions. I shall mention here merely that perpetrators with a Muslim extremist view were relatively the more numerous ones reported in Austria, Belgium, Germany, Denmark, France, the Netherlands, and Sweden. Perpetrators with a left-wing political view were the more frequent in Spain, Italy, and the UK. Perpetrators with a right-wing political view were the more frequent in Hungary and Poland. 


\subsection{Multiple Reporting}

One final synthetic look at the different variables reviewed so far is obtained by comparing the propensity to report multiple options to a single question - for those variables where multiple options were allowed. In such cases, the total frequency of reported categories was considerably above $100 \%$. Multiple reporting can be interpreted as an indication of a perception of greater diffusion of antisemitism across the spectrum of options pertinent to each specific question. It can also be interpreted as an indication of greater sensitivity to antisemitism by respondents, some of whom would report each minimal sign of the phenomenon, while others would focus only on the more powerful and worrying perceptions. Figure $17 \mathrm{de}-$ scribes the variation across countries of the tendency to report multiple options for each of the seven variables examined (sanction of Jewish rituals is not included because options were mutually exclusive with no multiple reporting).

What again immediately appears in this circular display is the perceptional difference between cognitive and experiential variables. Cognitive variables are characterized by a much greater tendency to multiple reporting than experiential variables. Within this main distinction, on the cognitive side, we note a strong

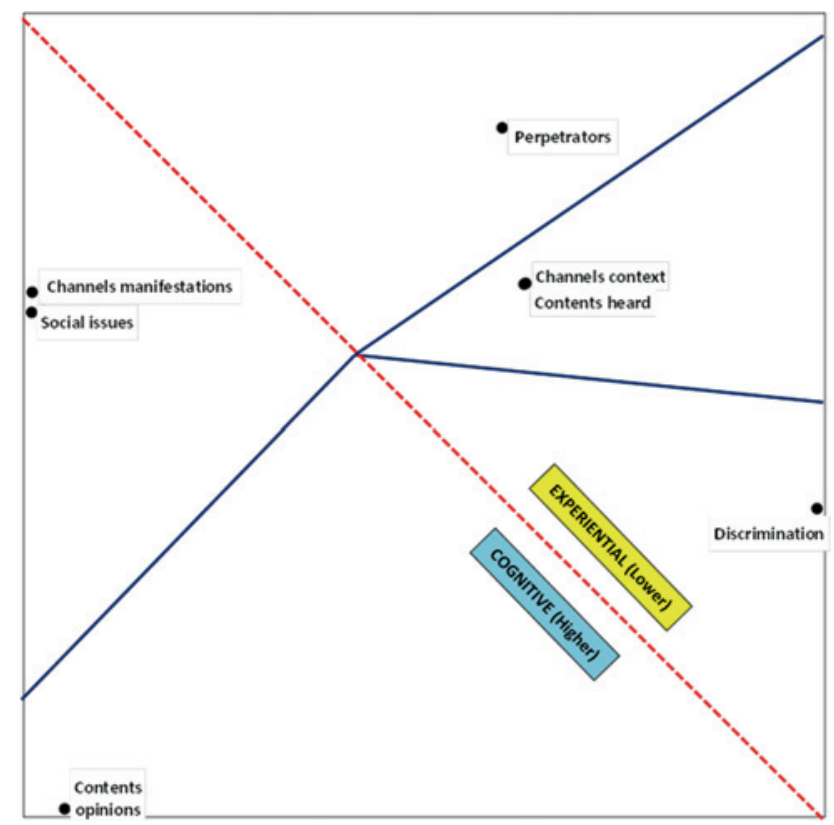

Figure 17: SSA of Patterns of Multiple Reporting Concerning Perceptions of Antisemitism, Modulated by Countries. 
correlation between multiple reporting of social issues of national concern and of transmission channels of antisemitism. Antisemitism perceptions, as expressed through selected predetermined opinions, appear in a different domain. On the experiential side, the dots indicating the two variables - antisemitic contents actually heard and their transmission channels - perfectly overlap so that only one dot appears on the map. Such nearly total correlation between patterns of multiple reporting concerning the contents and the transmission channels of antisemitic experiences provides a first indication of a singularly important finding: the tool becomes a proxy for the contents. I shall further elaborate on this finding later in this report. In the experiential part of the map, multiple reporting about perpetrators occupies a domain not too distant from antisemitic contents and its transmission channels, with a further domain for multiple reporting about discrimination suffered.

\section{The Multiple Layers of Antisemitism}

After reviewing individually each of the single ingredients of Jewish perceptions of antisemitism, in this section, I examine how the multiple layers of the phenomenology combine in determining a more complex picture.

\subsection{Contents of Antisemitism and Transmission Channels}

I look first at the combined perceptional patterns of contents of antisemitism and their transmission channels, including both cognitive and experiential aspects (Figure 18, based on 31 categories). The first observation is that the perceptional separation between cognitive and experiential aspects, as already noted above, prevails upon the substantive distinction between antisemitism contents and transmission channels. The two perceptional spaces can be clearly separated (see dotted line) with one exception only: the experiential category of political speech is included within the area of cognitive categories. It appears coherently included in the political antisemitism domain together with other categories, all of them cognitive. The whole perceptional space is also clearly divided into four main domains, Populist, Political, Practical, and Narrative - which already emerged in the preceding analysis of individual antisemitism ingredients.

Each of the four antisemitism domains includes both cognitive and experiential variables. Remarkably, the cognitive category Internet (including other social media) occupies the center of the whole configuration. Evidently, this recently emerged and now dominant transmission channel has become totally identified with the subject matter it transmits. Proceeding through the different domains in clockwise direction from the upper right corner (Populist antisemitism), most of 


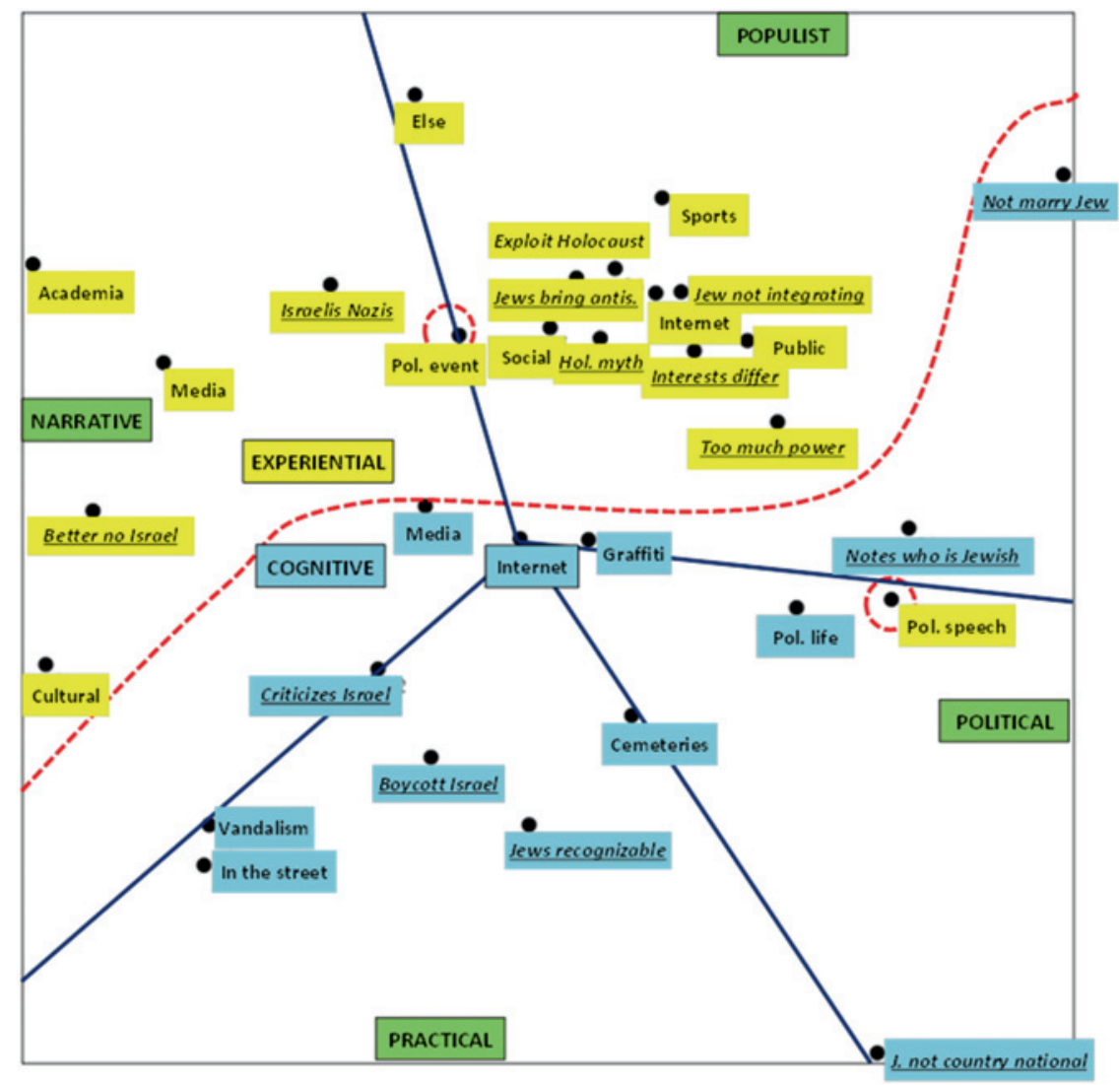

Figure 18: SSA of Combined Cognitive and Experiential Perceptions of Contents of Antisemitism and Transmission Channels, Modulated by Countries.

a. Variable in Underlined Italics Address Contents; Variables in Regular Fonts Address Transmission Channels.

the concepts classified under the conventional Protocols-style antisemitism show up in this domain: alleged characteristics of the Jews as a foreign, selfish, predatory, and polluting element of society, to be avoided, marginalized, and, if possible, destroyed. Remarkably, Holocaust denial and minimization has become fully incorporated within these older negative stereotypes. Perceptions of Populist antisemitism contents are fully integrated within and not distinguishable from the perceptions of transmission channels. The latter involve in spontaneous ways the social and public space and sports events. As noted, prominently represented here are personal expressions of hatred and hostility through the internet, the social media, and their straightforward ancestor - the mural graffiti. 
The Political antisemitism domain, too, draws from both cognitive and experiential variables. One such variable, experiential political events, actually appears out of range, marked by a circle midway between Populist and Narrative domains. On the other hand, the Political domain also hosts the caption: Jews are not country nationals - on the political side of classic antisemitism.

The Practical antisemitism domain, along with the already noted cognitive perceptions of vandalism against Jewish cemeteries and institutions and other street manifestations, includes the classic antisemitic notion of Jews as physically recognizable. It also includes the more recently emerging phenomenon of an Israel boycott. Because of their physical practical connotations, both categories remarkably fit the respective domain. The Boycott Israel's position is particularly interesting: the map shows its unequivocal perception by European Jews as a mode of practical antisemitism.

Finally, the Narrative antisemitism domain, along with the more sophisticated transmission channels of the Media other than internet, Cultural events, and Academia, clearly focuses on anti-Israeli contents: at the cognitive level it is Criticize Israel; at the experiential level - Israelis [are] Nazis, and The world would be better without Israel. The Media variable is represented here in both versions, cognitive and experiential, pointing again to the perceptional coherence between the two. The perceptional proximity of Academia with anti-Israel attitudes is a finding that cannot be ignored and requires further elaboration. The right to criticize Israel without being accused of antisemitism has been indeed a dominant leitmotif over recent decades, especially among the more educated sectors of society. The turning point obviously was the 1967 June war. Short of further interpretations, it is important to take notice that this is what European Jews feel and communicate through the web of category correlations unveiled by the SSA analysis.

\subsection{Social Issues, Sanction, and Discrimination}

I look next at the combined patterns of perceptions of national Social issues, Feared sanction (circumcision and slaughtering of animals), and Discrimination suffered, all inclusive of cognitive and experiential aspects (Figure 19, based on 13 categories). The map emerging here seems more complex and less straightforward than the previous one, but it provides several useful and also unexpected insights. Keep in mind that both Social issues and Feared sanctions are cognitive variables, whereas Discrimination suffered is experiential. In Figure 19, the domains pertaining to each survey question are separated by dotted lines, whereas the emerging contents domains are separated by the continuous lines. In the cognitive sphere, Social issue categories are indicated by triangle markers, and Feared sanction categories are marked by black dots. 


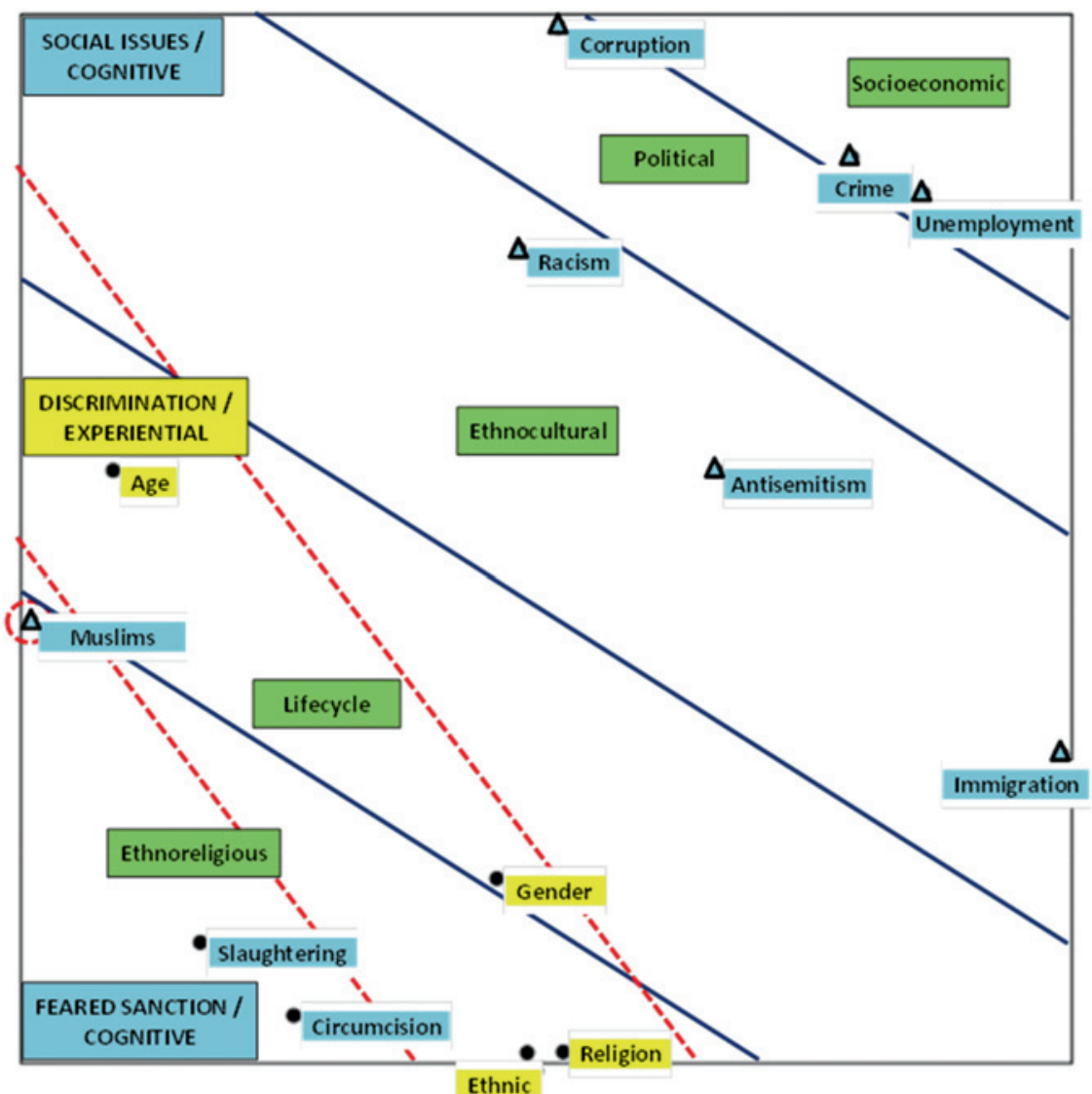

Figure 19: SSA of Combined Cognitive and Experiential Perceptions of Social Issues, Feared Sanction and Discrimination Suffered, Modulated by Countries.

In the bottom left corner of the map, the Ethnoreligious categories coalesce into one coherent domain, regardless of the different perceptional modes: Fear of sanction against circumcision and animal slaughtering, along with Discrimination suffered on grounds of Religion or Ethnic origin. The other categories of experienced discrimination - Age and Gender - both show up in a diagonal band forming a distinct Lifecycle domain. In turn, national social issues are spread across several domains, as already noted above in Figure 6. In the upper right corner, Crime and Unemployment form a Socio-economic domain, followed in axial sequence by a Political domain (Government corruption). Antisemitism stands at the center of an Ethno-cultural domain also inclusive of Racism and, in this case, of Immigration. 
One intriguing aspect concerns the position on the map of Intolerance toward Muslims (marked by a dotted circle), a social issue that stands quite remote from Immigration and all other social issues and very close to the Feared sanction/ cognitive/Ethnoreligious domain. One possible interpretation is that European Jews do perceive the problematic position of Muslims as a possibly sanctioned and discriminated minority. Jews may thus feel some possibly latent sense of affinity between their own position and that of Muslims in Europe. On the other hand, the interpretation might be oriented in a totally different direction: the proximity of Muslims with Jewish feared sanction and suffered discrimination might be a sign of a latent perception of Muslims constituting a menace to the position of Jews in society as people enjoying full equality and civil rights. If true, this would attribute to Muslims a dual role - among those who suffer intolerance by the majority of society but also among those who constitute a menacing source of intolerance against Jews. To appreciate which version may be closer to reality, we need to turn our attention to the nature of perpetrators of antisemitic acts.

One final thought again relates to the position on the map of the Feared discrimination domain. In the preceding description of variables, this one was attributed to the cognitive sphere. It may well be, however, that the highly emotional nature of the debate about the issue of circumcision implies that this domain pertains more to affective than to cognitive perceptions. This may indicate that if enough questions about the affective/emotional realm had been asked, the relevant categories would have found an independent place in the overall antisemitism perceptional space.

\subsection{The Perceived Position of Perpetrators}

I shall now examine how the perception of perpetrators integrates with the various perceptions of antisemitism examined so far. This is obtained by processing perpetrators perception data simultaneously with other relevant variables and condensing the findings in appropriate SSA maps.

\subsubsection{Contents of Antisemitism and Transmission Channels}

I look first at the combined cognitive and experiential perceptions of contents of antisemitism and transmission channels, jointly with perpetrators (Figure 20). With the additional input of perpetrators' categories, Figure 20, based on 38 categories, reproduces very faithfully Figure 18, with the exception of [2] Media, which appears now to be transferred from the Narrative antisemitism to the Practical antisemitism domain. 


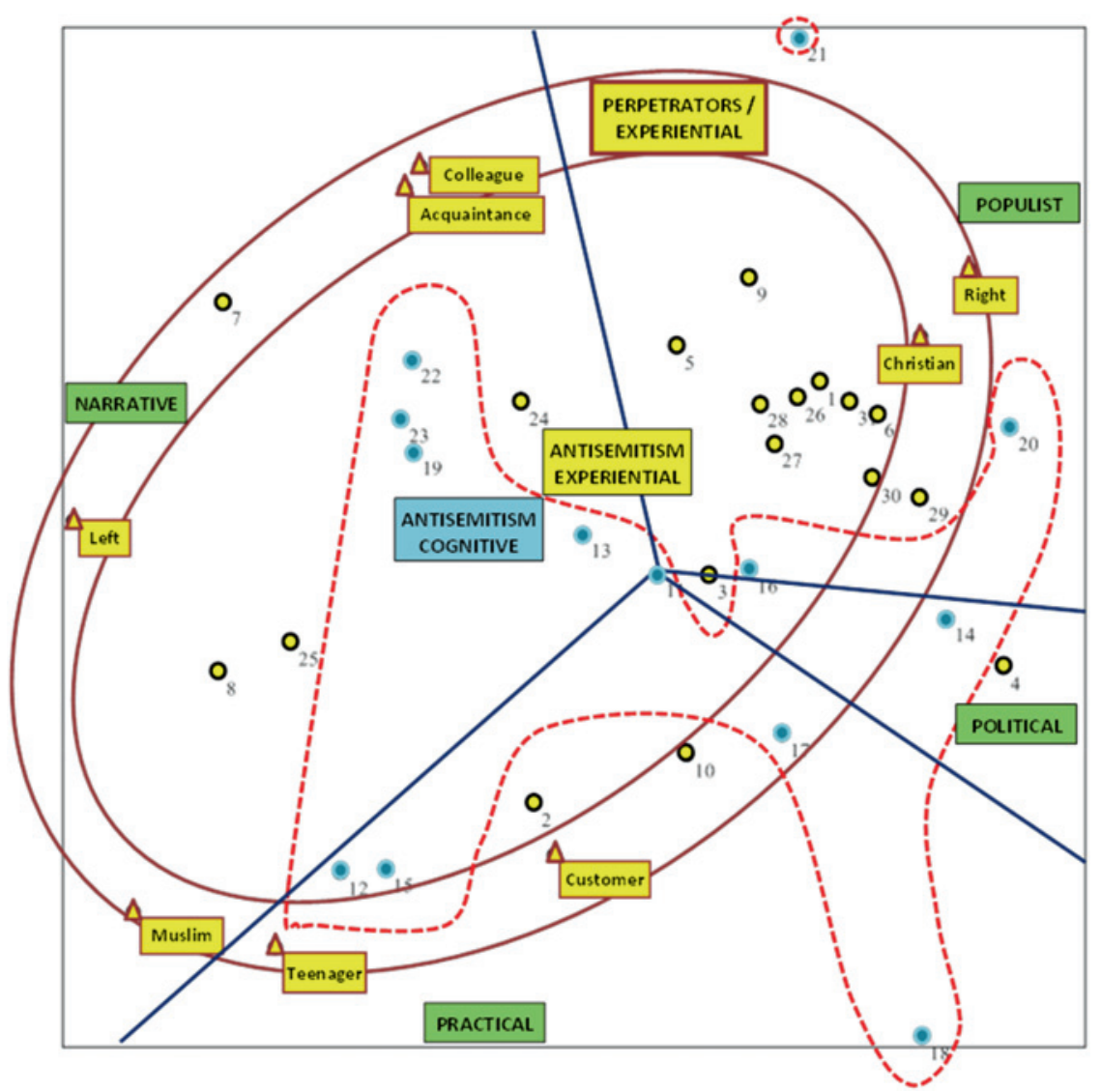

Figure 20: SSA of Combined Cognitive and Experiential Perceptions of Contents of Antisemitism and Transmission Channels, with Perpetrators, Modulated by Countries.

In the map, Perpetrator categories - classified as experiential perceptions appear as yellow triangle markers, cognitive antisemitism (contents and transmission channels together) as blue dots, and experiential antisemitism (contents and transmission together) as yellow dots. With only very modest positional changes, the main partition between cognitive and experiential variables confirms my previous observations. The cognitive variables are regrouped mainly in the central parts of the configuration, with only a few outliers, namely: [21] Would not marry a Jew and [18] Jews not country nationals. Again, the cognitive perception of Internet including other social media, as the consensually agreed leading conveyor of antisemitism, occupies the center of the entire configuration. 
Perpetrator categories appear on the map as an elliptic, external pattern running all around the other variables, and intersecting through the four main classification domains of Jewish antisemitism perceptions: the Populist, the Political, the Practical, and the Narrative. A clear division of labor appears in the first place between the Right-and-Christian and the Left-and-Islamic types. The former are strongly associated with the Populist antisemitism domain, characterized by instinctive, improvised, conventional anti-Jewish prejudice. The latter are strongly associated with the Narrative antisemitism domain, characterized by cultivated, thoughtful, anti-Israel prejudice. Other types of perpetrators stand in between. The colleague and acquaintance perpetrator types appear in between Populist and Narrative antisemitism domains; the teenager but also the customer perpetrator types appear in the Practical antisemitism domain. Here it becomes more apparent how the Political antisemitism domain is much closer to the Right/Christian than to the Left/Islamic perpetrator types.

\subsubsection{Social Issues, Sanction, and Discrimination}

I turn now to the combined cognitive and experiential perceptions of national social issues, feared sanction, and discrimination suffered, jointly with perpetrators (Figure 21). Figure 21, based on 21 categories, reproduces with some adaptations the contents of Figure 19, with the additional input of perpetrators' categories. As in the previous Figure 20, perpetrator categories appear on the map as an elliptic, external pattern running all around the other variables.

The different topics outlined in Figure 21 - see the diagonal dotted lines appear again as distinct domains, once again outlining the separation between cognitive and experiential variables. Several substantive domains comprise the different categories: Socioeconomic, including Crime and Unemployment; Political, including Government corruption; Ethno-cultural, including Antisemitism, Racism and Immigration; Lifecycle, including Age and Gender; and Ethno-religious, including a combination of feared sanction against Jewish rituals (circumcision and slaughtering), Discrimination suffered (on religious and ethnic background), and concern for intolerance against Muslims. The latter again appears significantly out of its natural context among other national social issues covered in the FRA study. At the center of the whole configuration stands Antisemitism as a cognitive social issue of concern.

The findings emerging here are of capital importance: among a large representative sample of European Jews, the cognitive aspects of antisemitism - more than anything else - constitute an organizing origin and central principle of all other perceptional aspects. 


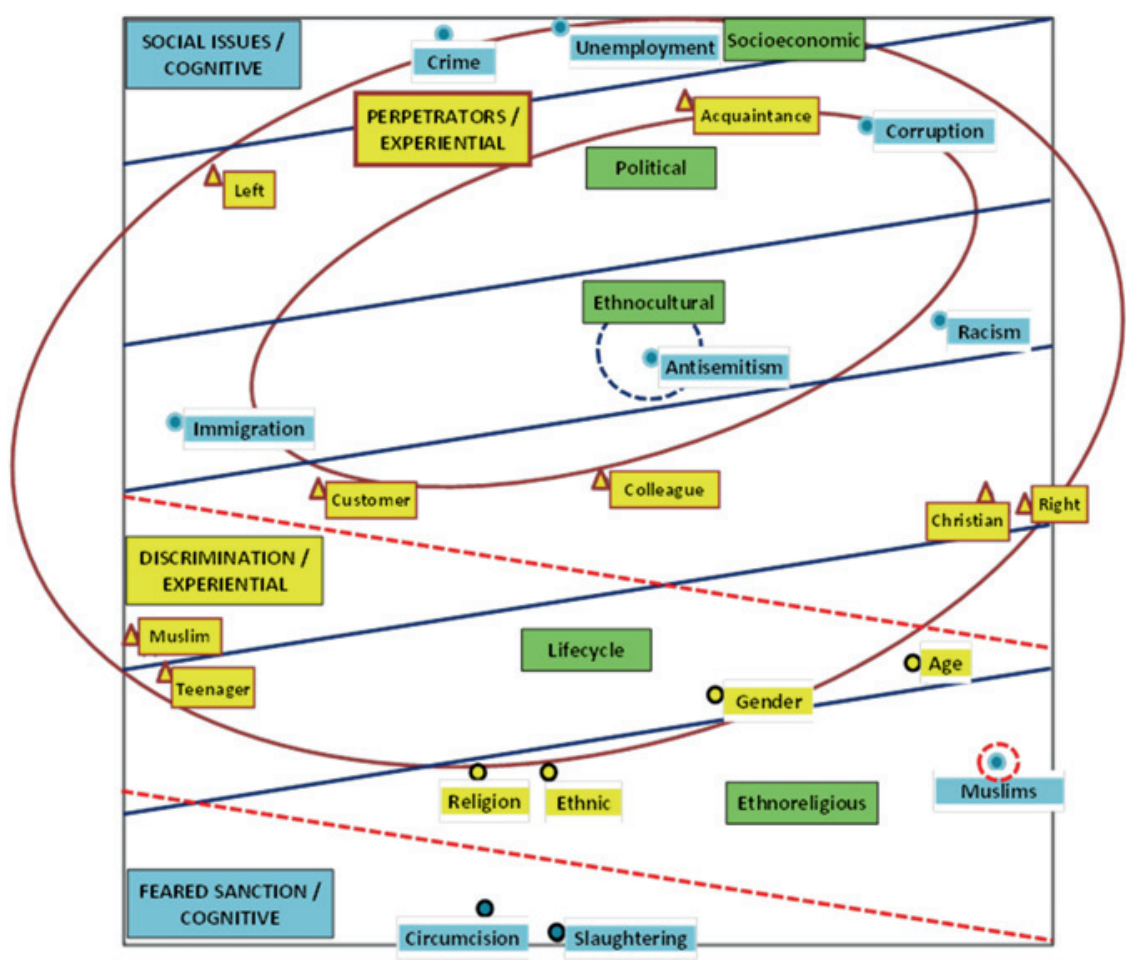

Figure 21: SSA of Combined Cognitive and Experiential Perceptions of Social Issues, Feared Sanction and Discrimination Suffered, with Perpetrators, Modulated by Countries.

The position of perpetrators on this map reveals other important underlying principles of antisemitism perceptions. In Jewish perceptions, Right-wing and Christian perpetrators strongly correlate with racism and intolerance versus Muslims. Left-wing and Islamic perpetrators tend to be perceived more in the association with general social issues, such as crime, unemployment, and immigration. Concern with immigration, in turn, is associated with Muslims as antisemitism perpetrators. The complex dual role of Muslims in Jewish perceptions reemerges here patently: Muslims are seen simultaneously as victims of societal discrimination and as perpetrators of anti-Jewish offenses. The correspondence between Teenager and Muslim perpetrators now becomes clearer. It also points to an affinity with the already described composite domain of feared sanction against Jewish rituals (cognitive) and discrimination of Jews on religio-ethnic grounds (experiential). The possibility that Feared sanction about circumcision and ritual slaughtering actually pertains to an affective/emotional rather than cognitive realm is confirmed here. 


\subsection{The Whole Picture}

The final more complex and multiple-variable picture in the present analysis is obtained by superimposing all the perceptional layers examined so far: contents of antisemitism, transmission channels, societal issues, feared sanction, discrimination suffered, and perpetrators (Figure 22, based on 52 categories). Reading of the map is not the easiest because of the many and diverse variables included. The need to accommodate so many factors within one synthetic map may cause the shifting of some variables from the position already noted in previous maps to different positions, reflecting the more numerous and complex interrelations with all other variables examined. To render the reading easier, a legend reports the full list of variables, their detailed respective categories, their numbering on the map, and the respective different recognizable markers.

\begin{tabular}{|c|c|}
\hline \multicolumn{2}{|c|}{ Legend: } \\
\hline Transmission channels, experiential & 27 Holocaust myth \\
\hline 1 Internet, social media & 28 Jews bring antisemitism \\
\hline 2 Media, not internet & 29 Too much power \\
\hline 3 Political event & 30 Jewish interests differ \\
\hline 4 Political speech & 31 Not integrate in country \\
\hline 5 Social event & $\Delta$ Perpetrators, experiential \\
\hline 6 Public space & 32 Muslim extremist \\
\hline 7 Academia & 33 Christian extremist \\
\hline 8 Cultural event & 34 Left wing \\
\hline 9 Sports event & 35 Right wing \\
\hline 10 Else & 36 Acquaintance \\
\hline Transmission channels, cognitive & 37 Colleague \\
\hline 11 Internet, social media & 38 Customer \\
\hline 12 In the street & 39 Teenager \\
\hline 13 Media, not internet & $\Delta$ Social issues, cognitive \\
\hline 14 Political life & 40 Antisemitism \\
\hline 15 Vandalism & 41 Racism \\
\hline 16 Graffiti & 42 Crime level \\
\hline 17 Cemeteries desecration & 43 Unemployment \\
\hline O Antisemitism contents, cognitive & 44 Immigration \\
\hline 18 Jews not country nationals & 45 Muslims \\
\hline 19 Physically recognizable & 46 Government corruption \\
\hline 20 Notes who is Jewish & Sanction feared, cognitive \\
\hline 21 No marry with Jew & 47 Circumcision \\
\hline 22 Criticizes Israel & 48 Ritual slaughter \\
\hline 23 Supports Israel boycott & Discrimination suffered, experiential \\
\hline O Antisemitism contents, experiential & 49 Religion \\
\hline 24 Israelis "Nazis" & 50 Age \\
\hline 25 World better without Israel & 51Gender \\
\hline 26 Jews exploit Holocaust & 52 Ethnic origin \\
\hline
\end{tabular}




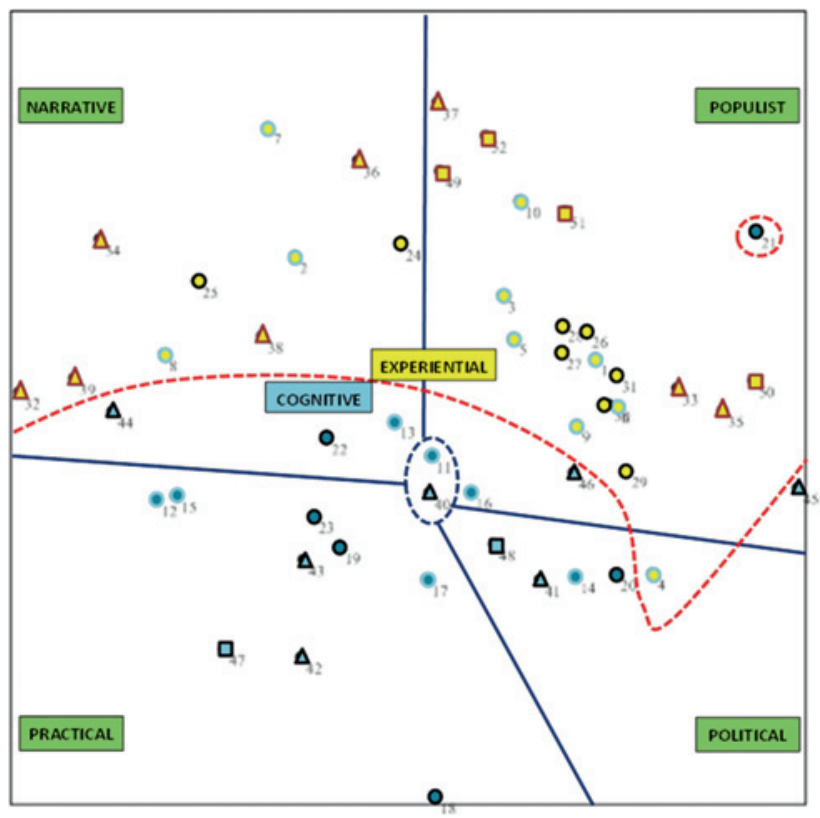

Figure 22: SSA of Combined Cognitive and Experiential Perceptions of Contents of Antisemitism, Transmission Channels, Social Issues, Feared Sanction and Discrimination Suffered, with Perpetrators, Modulated by Countries.

The fundamental findings have already been established from the previous analysis. In the first place the distinction between cognitive and experiential variables determines a clear-cut division with only one evident outlier: [21] Would not marry a Jew - a cognitive-attitudinal questions positioned within the experiential-behavioral main domain.

Within this basic distinction, the four-fold main antisemitism typology hypothesized and largely confirmed by the foregoing analysis appears as an important organizing principle within the gamut of antisemitism perceptions. At the center of the whole configuration, two categories constitute the origin, synthesis, and main focal point actually shared by all four antisemitism domains. This dual central point includes: [40] Antisemitism - a cognitive variable - entering this map as the prime national social issue of concern; and [11] Internet including social media - also a cognitive variable - entering as the prime transmission channel. The focus of antisemitism perceptions on the cognitive more than on the experiential sphere is the crucial qualifier of the whole syndrome investigated here. The two variables of contents and transmission produce a powerful synergy through 
the two categories Antisemitism as the prime perceived national issue and the Internet as its prime perceived diffusor.

The combination of so many aspects of antisemitism perceptions reported in Figure 22 reveals several other more or less intimate connections and affinities between topics that usually are discussed separately. One aspect, already noted above, is the domain coherence between features observed both at the cognitive and the experiential level. This is the case with the Internet including social media, perceived as a central transmission channel [11] and as an actual conveyor of antisemitic hatred [1]. Both pertain to the Populist antisemitism domain. In turn, the Media other than the Internet, perceived as a potential [13] and actual [3] vehicle, both fall in the Narrative antisemitism domain. The configuration of all other markers of antisemitism contents and transmission channels within main domains is approximately the same as already seen above in Figure 18 and Figure 20.

It is interesting to assess how and where variables related to feared sanction, discrimination suffered, and social issues appear within this grid of domains. Discrimination suffered on various grounds $[49,50,51,52]$ appears in the Populist domain. Sanction feared against Circumcision [47] appears - quite logically - in the Practical domain, whereas sanction against Animal slaughtering quite appropriately appears in the political domain. With regard to social issues of national concern, Crime level [42] and Unemployment [43] enter into the Practical domain, Immigration [44] into the Narrative domain, Racism [41] into the Political domain, and Government corruption [46] into the Populist domain. The latter domain also hosts Intolerance against Muslims [45].

Perpetrators are now more clearly split between the Populist domain (Christian extremist [33], Right-wing [35], and Colleague [37]), and the Narrative domain (Muslim extremist [32], Left-wing [34], acquaintance [36], customer [38], and teenager [39]).

Summing up, the perceptions of antisemitism contents and transmission channels in this comprehensive analysis confirm the main patterns already seen in greater detail. Classic antisemitic stereotypes touching upon alleged negative characteristics of Jews and Holocaust denial are rooted together with the improvised expressions of the Social media, Graffiti, Public space, and Sports events within the Populist antisemitism domain. Negative and demonizing expressions about Israel are rooted together with the learned and polished tools of the Media, Academia, and Culture within the Narrative antisemitism domain. The dual perception of Muslims is again worth noting: as victims of intolerance associated with perceptions of Right-wing and Christian perpetrators and as perpetrators associated with perceptions of Left-wing peers. 


\section{European Regional Subcultures}

Earlier in this paper (Figures 1, 2, 3, and 4, I presented evidence of some regional clustering of $12 \mathrm{EU}$ countries concerning the frequency of antisemitic prejudice in society, as well as the general and Jewish perceptions about the intensity of that prejudice. In light of the discussion in the previous pages, the question arises whether the detailed typology and configuration of antisemitism perceptions among Jews, too, displays regional variations. This may well be expected due to the significant social, cultural, and political differences that prevail across the continent.

The SSA theoretical and technical procedure mainly followed in this paper allowed us to illustrate structural features regarding each of the topics examined, as generated by variation in the frequencies of the various possible response options to the same questions posed in the different countries. A symmetric approach consists of reversing the observation angle, by representing inter-country structural differences, as generated by variation in the response to questions concerning each separate topic. Keeping in mind a conventional cross-tabulation, such as the one displayed in Table 2 above, we see that the maps displayed thus far configured the variation within each topic (the row categories) as modulated by the countries (the column categories). It is also possible to represent the variation of column categories (the countries) as modulated by the rows (the topic categories). In other words, each of the 17 topical maps displayed in the preceding sections of this paper matches with one equivalent map showing the overall structural configuration of inter-country variation. For the sake of space economy, I shall not review the full array of country configurations, variable-by-variable, but only focus on three principal models that emerged from this study.

Figure 23 exemplifies a circular-radial configuration - the most frequently found in this investigation. The data are the same as those represented in Figure 22, i. e., the most comprehensive simultaneous processing of 52 different categories examined here. Figure 22, it will be recalled, represented the whole combined cognitive and experiential perceptions of contents of antisemitism, transmission channels, national social issues, feared sanction, discrimination suffered, and perpetrators. The whole perceptional space in Figure 23 can be partitioned into four main regional domains: Francophone countries (France and Belgium), Mediterranean countries (Italy and Spain), Northwestern countries (UK, Sweden, Denmark, Netherlands, and Germany), and - stretching geopolitics a little - what I have defined as the Visegrad group of countries named after the castle north of Budapest (Hungary, Poland, and Austria) (Barna and Félix 2017). Austria is not actually part of the Visegrad group, but its government's recent politics were very 


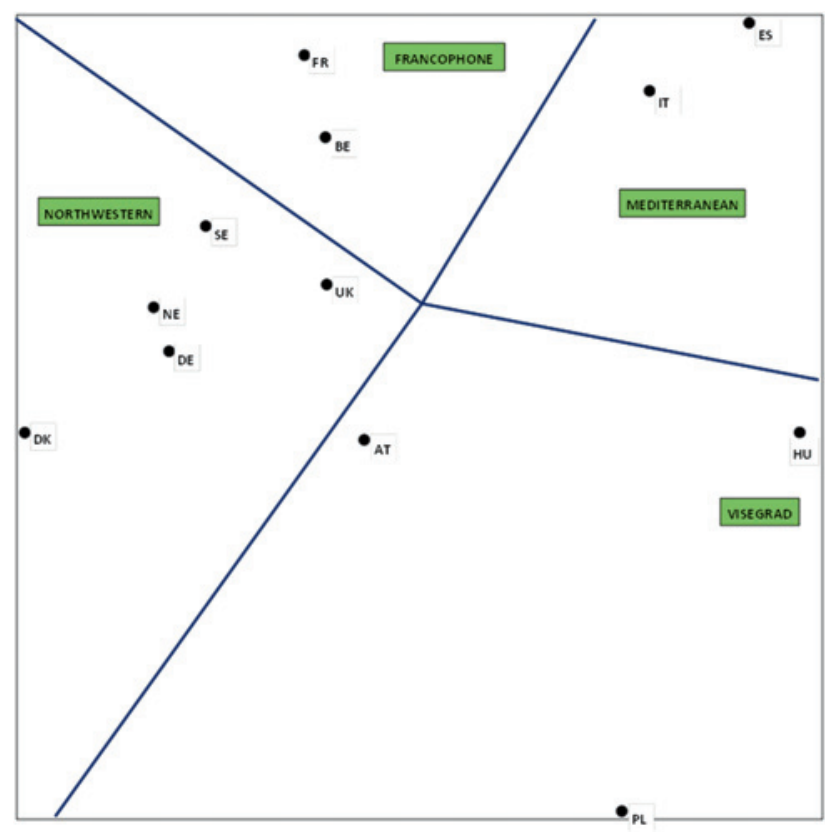

Figure 23: SSA of Country Configuration of Multiple Variable Combined Perceptions of Antisemitism, Modulated by Categories Shown in Figure 22.

Key to Countries: AT: Austria; BE: Belgium; DE: Germany; DK: Denmark; ES: Spain; FR: France; HU: Hungary; IT: Italy; NE: The Netherlands; PL: Poland; SE: Sweden; UK: United Kingdom.

similar to those of the countries adhering to the group. In Figure 23, Austria actually also appears close to the northwestern countries (as already found in Figure 4 above), but the typology chosen here seems better to reflect current European political realities.

Distinctive regional patterns within the entire EU reveal different frequencies of the various aspects of antisemitism covered here, as well as regional differences in multiple reporting to multiple option questions. Very similar circular radial configurations obtain when one processes the data for main social issues of concern and channels of antisemitism transmission separately for the cognitive and for the experiential side, and perpetrators. In some cases, Germany converges with France and Belgium to form a Western domain, versus a Northern domain including the other countries contained in the Northwestern domain in Figure 23. Notably, the Netherlands is very consistently part of the Northern group and diverges from Belgium, which usually strongly correlates with France. France and Belgium possess some of the strongest perceptions of antisemitism, along with higher proportions of Muslims among the total population, either first-generation 
immigrants or second-generation local-born younger adults. Germany, too, hosts a high proportion of Muslim immigrants and children of immigrants. There is a difference, however: in the Francophone countries, most of these immigrants originate from North African former French colonies and protectorates, including many who are multi-generation veterans. In Germany, most Muslims originate from Turkey, and they are apparently better, or at least more quietly, integrated than the North Africans in France. Germany also accepted a large inflow of Syrian refugees following the humanitarian crisis in the wake of the civil war there during the 2010s. Northern or northwestern European countries usually display somewhat lower levels of perceived antisemitism combined with moderate albeit growing shares of recent immigrants. Mediterranean coastal countries in recent years have been exposed to largely visible inflows of refugees sailing from North African coastal locations though originally mostly from African countries south of Sahara. The Visegrad group of countries in recent years featured very explicit nationalistic political discourse and policies and extremely restrictive immigration policies.

One further factor at work in generating country differentiation may have been the policies adopted by national governments regarding the State of Israel. Despite notable contradictions and fluctuations over time in those country policies, and despite a considerably divided domestic opinion, it is plausible that the Jewish public is sensitive to them when integrating the different possible factors within one overall perception of antisemitism. All these reasons may have combined in determining distinct Jewish perceptional patterns in the different regions of Europe.

A second and different model of regional variation in Jewish perceptions of antisemitism is reported in Figure 24, which is based on the same data as in Figure 18 above.

The data reflect the combined perceptions of antisemitism contents and transmission channels based on 31 categories. The configuration appearing here is axial, or characterized by parallel bands, which implies an ordinal logic in the observed regional domains. Such ordering in Figure 24 runs from the Francophone domain through the Northwestern, the Mediterranean, and the Visegrad countries. Here again, it is possible to detect a somewhat higher concern about antisemitism among people living in the two extreme country domains, but a much friendlier declared attitude toward Israel - regardless of actual policies among the Visegrad group of countries. Similar axial configurations obtain for perceived discrimination, antisemitic statements heard, and multiple reporting. One hypothesis to explain the ordinal pattern may be that it conforms with the gradient from higher to lower percentages of Muslims among a given country's total population. 


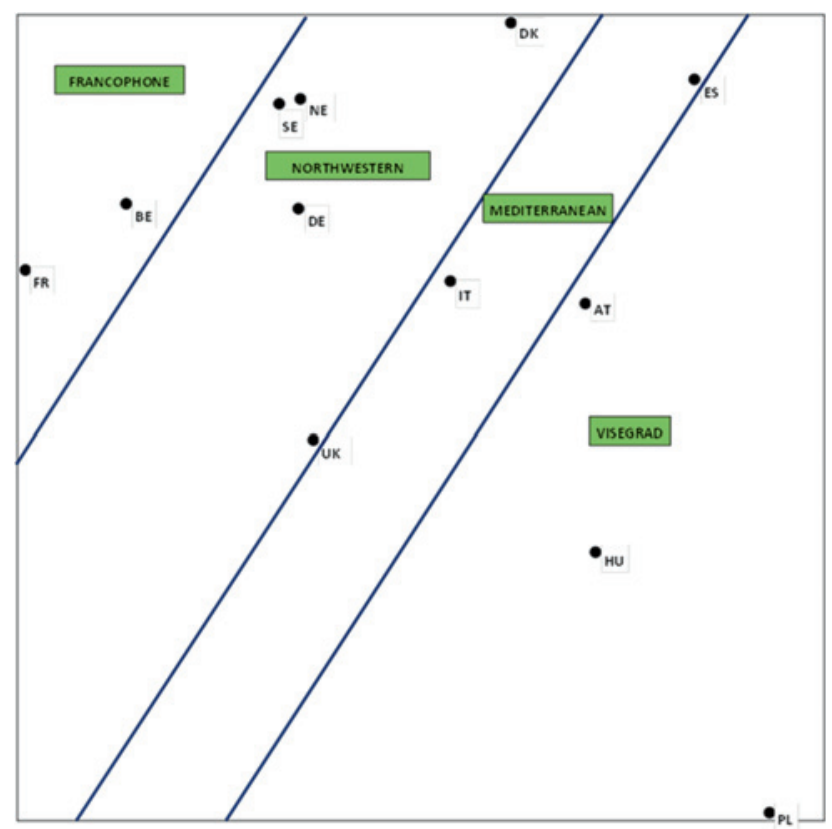

Figure 24: SSA of Country Configuration of Combined Perceptions of Antisemitism Contents and Transmission Channels, Modulated By Categories Shown in Figure 18.

Key to Countries: AT: Austria; BE: Belgium; DE: Germany; DK: Denmark; ES: Spain; FR: France; HU: Hungary; IT: Italy; NE: The Netherlands; PL: Poland; SE: Sweden; UK: United Kingdom.

A third regional model of country variation reported in Figure 25 relates to the perceptions of feared sanction concerning circumcision and animal ritual slaughtering (two categories and their possible overlap). The data are the same as those reported above in Figure 13. The possible interpretation is likely to shed additional light on the preceding configurations as well. Figure 25 suggests a simple bi-partition between countries that are predominantly Catholic and countries that are predominantly Protestant, with the exception of Austria, which here appears to be out of context. In fact, the main opposition to Jewish rituals has been expressed in predominantly Protestant societies, and in some cases, sanction has been effectively implemented.

Summing up, the materials just reviewed suggest caution when addressing antisemitism as a global or continental phenomenology. Regional variation patterns imply the significant involvement of territorially diverse perceptions among resident Jews. Patterns of variation apparently derive from long term religious, cultural, and sociopolitical differences between countries or even cutting across countries - as may be the case in Belgium, Spain, Italy, or the UK. Another 


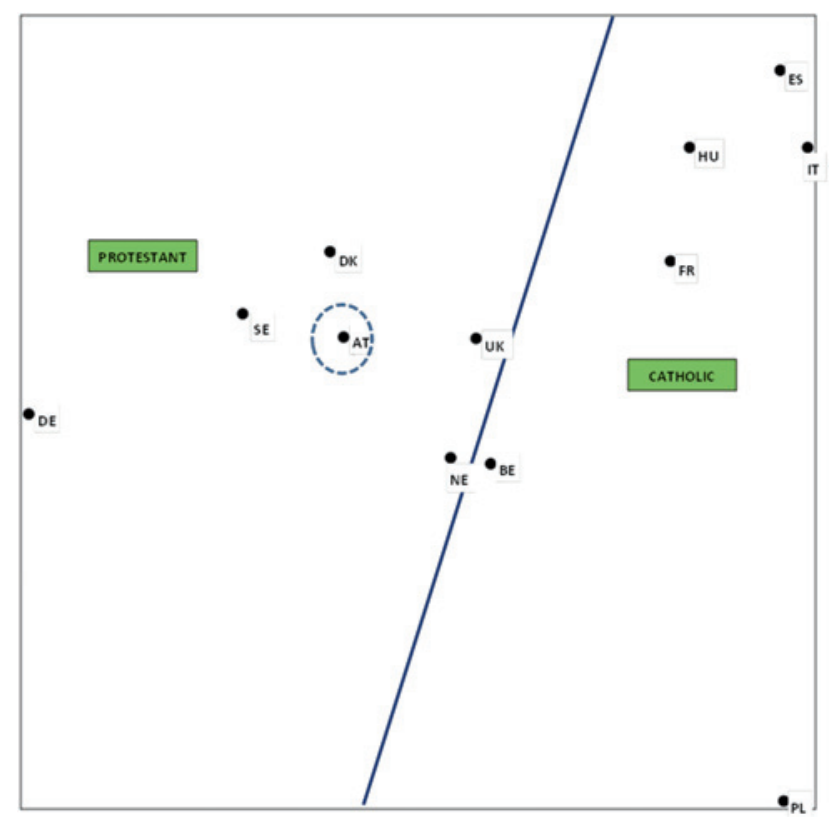

Figure 25: SSA of Country Configuration of Perceptions of Feared Sanction against Jewish Rituals, Modulated by Categories Shown in Figure 13.

Key to Countries: AT: Austria; BE: Belgium; DE: Germany; DK: Denmark; ES: Spain; FR: France; HU: Hungary; IT: Italy; NE: The Netherlands; PL: Poland; SE: Sweden; UK: United Kingdom.

determinant may be more recent events such as the quantity of non-European immigration into Europe and the percentage of foreigners, especially Muslims, among the total population. Finer regional distinctions, country-by country, and by regions within countries, are a matter for further data processing and analysis.

\section{A Note on Antisemitism and Jewish Identity}

Besides its inherent interest as an endemic topic in the long-term history of the Jews, antisemitism requires attention as a component within the broader array of Jewish identificational perceptions and choices. In reference to, among other things, my initial considerations about the early origins of Jewish peoplehood identity, a corporate Jewish identity and awareness seems essential for antisemitism to be effectively perceived among the target group. It can be argued, indeed, that perceived hostility from the non-Jewish environment toward oneself as a Jewish individual or as a member of a Jewish community is an integral or even 
a necessary marker of one's own sense of Jewish identification. Although the study of Jewish identification among Jews in Europe deserves a detailed in-depth study, which is beyond the scope of this paper, here I shall briefly focus on the proximity and distance between different Jewish identification options as they appear from a structural examination of the data collected for the 2018 FRA survey (for a review of the findings of the 2012 FRA study, see Graham 2018).

The FRA 2018 study included a question about the importance of selected modes of expression of Jewish identity: [G08e] How important are the following items to your sense of Jewish identity? The total frequencies of those who answered Very important are reported in Table 3.

At the top of the list stands Remembering the Holocaust, closely followed by Combating antisemitism. The Jewish nation-oriented options (Feeling part of Jewish peoplehood, Support for Israel) appear in the middle of the table. Family oriented reunion on the occasion of the main Jewish festivals ranks about at the same level. Jewish culture, community and faith-oriented options appear at the bottom of the scale. Remarkably, Jews in Israel, in the United States, in Latin America, and in the former Soviet Union presented with these lists of Jewish identity options ranked them very similarly (Bokser Liwerant et al. 2015; DellaPergola, Keysar, and Levy 2019; Russian Jewish Congress - Levada Center 2018a). The significant feature in the context of the present paper is the very high-ranking position of Combating antisemitism along the entire spectrum of Jewish identity. Antisemitism and Holocaust remembrance emerge as the most widely shared and sensitive issues in Jewish personal identification and in Jewish corporate life.

The same data, when transformed into an SSA map that reflects variation across the 12 EU countries investigated, produce the display shown in Figure 26. The display is again circular-radial with a clear central focus. The peripheral domains, represented here each by one proxy question, imply a more comprehensive contents domain. In clockwise direction, based on much previous research (e. $\mathrm{g}$.

Table 3: Frequencies of Jews in 12 EU Countries Reporting Very important about Selected Aspects of Jewish Identity.

\begin{tabular}{lr}
\hline Aspect of Jewish identity & \% Very important \\
\hline Remembering the Holocaust & 79.0 \\
Combating antisemitism & 75.1 \\
Feeling part of the Jewish people & 70.4 \\
Sharing Jewish festivals with my family & 56.4 \\
Supporting Israel & 55.3 \\
Jewish culture, such as Jewish music, literature and art & 44.5 \\
Donating funds to charity & 35.0 \\
Believing in God & 34.4 \\
\hline
\end{tabular}


DellaPergola, Keysar, and Levy 2019), Believing in God can be shown to represent a broader domain of Jewish normative-ritual beliefs and practices. Donating to Jewish charity represents a broader domain of Jewish community affiliation and voluntarism. Holocaust memory and Combating antisemitism are part of a broader domain of historical consciousness and civic ethos. Jewish culture represents a broader involvement with more general and universal cultural interests. Sharing Jewish festivals with the family represents life cycle customs and occasions that naturally lead to closing full circle with Jewish religious tradition.

The configuration of Jewish identification in Europe appears to have a dual central focus: Jewish peoplehood and Support for Israel. In previous research (DellaPergola 2010; DellaPergola, Keysar, and Levy 2019; DellaPergola et al. 2018), we usually found a general sense of belonging to Jewish peoplehood to be the central and more strongly correlated component of Jewish identification in relation to other components of the identificational cluster. This is confirmed here, along with some perceived proximity of Israel with Antisemitism on the map. The additional and even more visible presence of support for Israel at the center of the configuration calls for further comment.

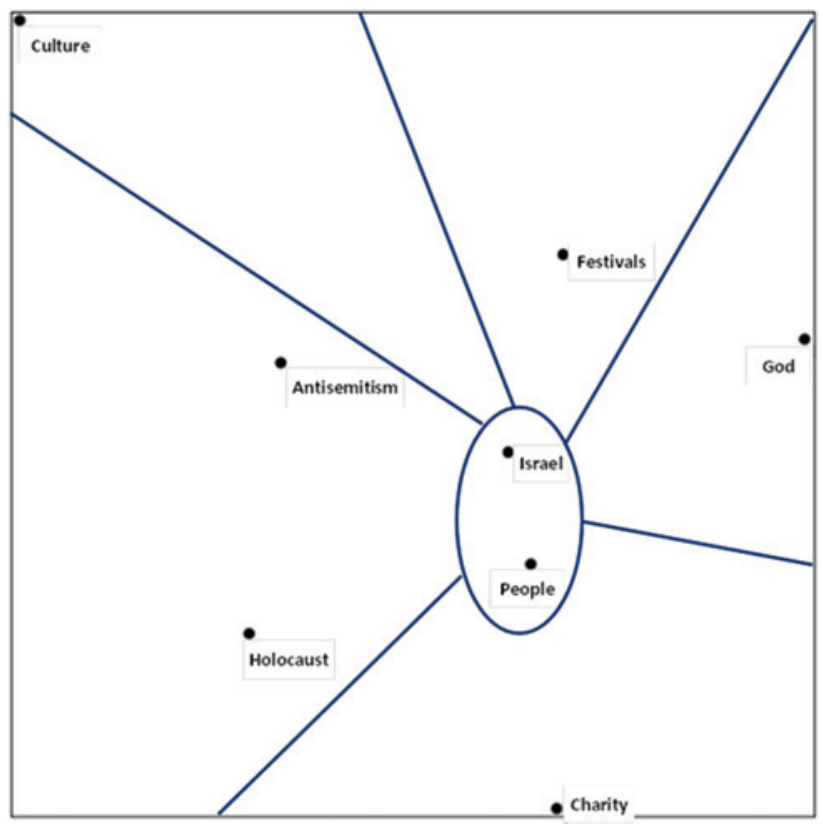

Figure 26: SSA of Selected Indicators Rated as Very Important in Determining the Respondents' Jewish Identity, Modulated by Countries. 
In previous research, the Israeli component of Jewish identification often appeared as one of the peripheral domains on the map. Evidently, as time goes by, the Jewish public has tended to respond - no matter whether rationally or emotionally - to the stimuli it received from the outside environment. The growing perception of negative public opinion and political build-up against Israel may have caused a significant increase in the perceptional salience of Israel. Some rallying behind the Jewish state may have occurred among Jews in different European countries. This is not necessarily going to be translated into a growing tendency to migrate to Israel or even to be active on the Jewish community scene in pro-Israel initiatives. The present findings, however, unequivocally demonstrate that in the latent perception of the European Jewish public, Israel is tending to become a more central identificational locus of attention and concern. Perceptions of critiques and even more so, delegitimization and sometimes demonization versus Israel may have been interpreted by many Jews as attacks against the core of Jewish identification at large. As such, delegitimization has been perceived not only against Israel as a narrow component of the identificational cluster but against the cluster in its totality. Through these declared or undeclared perceptional links and mutations, Jewish perceptions of anti-Israeli moods have become a close match to and an integral component of Jewish perceptions of antisemitism.

\section{Summary and Concluding Remarks}

Among many possible avenues in antisemitism research, this paper focused on perceptions of antisemitic attitudes and experiences among a large representative sample of self-defined Jews in 12 EU countries. The theoretical and technical procedure preferred for data processing and display was the relatively less known and practiced SSA. SSA's holistic approach aims at uncovering the deeper and sometimes latent conceptual structure of an issue beyond its mere descriptive accountancy. As the foregoing presentation may have appeared too formal and technical, I shall summarize here some of the major results and conclusions in nontechnical language.

Earlier in this paper, based on the 2013 ADL and 2018 Eurobarometer studies (ADL 2014, European Commission 2019), I found an inverse correlation between the amount of antisemitism in a country as perceived by its inhabitants and as independently assessed in the same country. The finding that the more antisemitism is diffused in a given society, the less that same society perceives antisemitism as a problem is, perhaps, obvious but not trivial. In an antisemitic environment, the perceived problem is not about antisemitism, it is about the Jews. At the same time, perceptions of antisemitism by Jews are considerably higher than 
perceptions by non-Jews. It may be impossible to adjudicate which of these contrasting perceptions is truer, but from the point of view of research about antisemitism, greater attention should be paid to what the victims, not the potential perpetrators, report. By studying Jewish perceptions of antisemitism, this paper actually dealt with Jewish perceptions of non-Jewish perceptions of Jews.

The essence of antisemitism, and of racism and xenophobia, consists of denying a person's right to belong in the normal mainstream of society and of coercing him/her into a situation of otherness. Paraphrasing Brian Klug (2013), a broad definition of the syndrome may be turning $a$ subject into an other subject. Looking more closely at Jewish perceptions of the contents of antisemitism, antiJewish concepts currently in use sequentially emerged at different stages along history. The empirically verified expressions of contemporary European antisemitic prejudice, indeed, reflect the multiple influences of different doctrines, rhetoric and hatred - whether pagan, Christian, Islamic, nationalist, racist, Nazifascist, Marxist, anarchist, Liberal-humanist, or a synergic combination of these. Each different version of anti-Jewish prejudice emerged in totally different contexts at different junctures of history, was then adopted by contemporaries, and was carried forward unchanged by generations of followers. As all possible antisemitic schools of thought have coexisted at all times until the present, it looks as if history had stopped at each particular point in time when each new type of antisemitism emerged. This is why I defined locked modernizations as the feature of different individuals or entire sectors of society that today cling to a variety of concepts that were developed independently in different historical epochs.

Reviewing the findings in somewhat reverse order, it is important to acknowledge that perceptions of antisemitism constitute a fundamental component of the broader complex of contemporary, and, arguably, earlier Jewish identity. This has been demonstrated not only in the present study of Jews in Europe but also in multiple other cases transnationally (Cohen 2018; DellaPergola 2018). Whether or not antisemitism perceptions are really based on facts or only express excessive sensitivity by the target population does not alter the powerful and influential impact of those perceptions. It is difficult to dispute the validity of Benedict Anderson's portrayal of the construction of imagined communities formed through perceived and sometimes biased ideas about shared collective histories and identities (Anderson 1991). One cannot deny, however, the staying power of those identities and communities, their all-encompassing attraction to people who feel the imagined as real, and sometimes their aggressive role in world affairs cannot be denied either. As far as the Jewish collective is concerned, these perceptions deeply affected Jewish attitudes towards society and civic life at large, stimulated the creation of personal and institutional self-defense mechanisms, and, in some cases, generated pro-active or even militant reactions. 
Two aspects are particularly significant in this respect: one is the very high percentage of Jews who said that the fight against antisemitism is essential in defining their Jewish identity; the other is the perceptional proximity between this measure of Jewish identity and a measure representing concern for the State of Israel. As a result of the strong correlation and implicit affinity that exists between these two different identification perceptions, an attack or offense against one of these often reverberated powerfully on the other. The notable and growing centrality of Israel in Jewish identification perceptions went hand in hand with a diminishing distance between perceptions of legitimate criticism of Israel - let alone defamation or boycott - and perceptions of antisemitism. In turn, this strong connection and the perception of growing antisemitism, clearly documented in the foregoing presentation, probably pushed concern for Israel to a more central and shared position within the whole Jewish identificational space.

The issue of whether it is legitimate to criticize Israel without being accused of antisemitism arose after the June 1967 war and has been reinforced through repeated oscillations that reflect periodical contingencies in the Middle East over the years. The various answers in the FRA study on whether criticizing or boycotting Israel was perceived as antisemitic clearly testifies to the need to apply careful distinctions in this respect. Affirmative answers were given by 38 and $82 \%$, respectively, of the Jewish respondents. The difference is striking and points to the unimpaired ability of the Jewish public at large to render considered judgment when expressing opinions about Israel. Perceptions of policies enacted by Israel's governments in different areas are not the same as perceptions about the legitimacy of Israel's existence. Nonetheless, the two different statements ultimately struck the same perceptional domain (in this case, cognitive) in the broader perceptional space. Large sections of the Jewish public may have lost the subtler distinctions among a general self-perception of antiJewish harassment.

The role of Israel perceptions within the whole antisemitism paradigm calls for further clarification in the light of its increased prominence in Jewish and general perceptions. Nowadays, people and institutions are frequently heard uttering statements such as: "It is not our intention to commit an antisemitic act when we support Israel-oriented BDS. Supporting BDS is not antisemitism.” The question is whether judgment about what constitutes an offense and who is an offender should be left primarily to the potential perpetrators or to the potentially offended. An offense may have been manifest or latent, true or not true, intended or not intended. Nonetheless, if deemed relevant by the offended, it was an offense. Within these limits, the topic of Israel has become unprecedentedly prominent in Jewish perceptions of antisemitic attitudes. How does this relate to other domains of antisemitism perception? 
This study reveals that up to a point, the different contents-wise paradigms were perceived as separate and distinct by Jewish respondents. In the 2012 FRA study, classic antisemitism of the Protocols of the Elders brand (attributing to the Jews distinctive physical markers, foreignness, and a conspiratorial and exploitative nature) occupied a perceptional space distinct from Holocaust denial and from anti-Israel hostility (DellaPergola 2018). In the 2018 FRA study, a definite convergence and fusion appears to have occurred between perceptions of classic antisemitism and Shoah-oriented negationism. Israel-oriented statements to some extent are still understood as a matter separate from classic antisemitism and occupy a distinct perceptional space, but the boundary with the other domains tends to become increasingly blurred and mixed up. I found, for example, that antiIsraeli expressions and the contention of physical recognizability of the Jews - one of the classic items of historical racism - ended up in the same domain on the perceptional map. Such convergence points to the gradual coalescence of antiIsraeli positions and antisemitism into one integrated conceptual complex. Following this logic, Israel's evil is a byproduct of the Jews' evil.

Turning to the perception of who the perpetrators of antisemitism are, this study outlined a wide range of perpetrators and manifestly associated each different perpetrator type to specific expressions of anti-Jewish hatred and discrimination. The European Jewish public perceives an association between the political Left with more sophisticated, educated, and influential cultural circles and individuals, namely the printed and broadcasted media, and academia. Those circles and ideas, in turn, are perceived as associated with a narrative that may range from simple criticism of the State of Israel to actively boycotting it and asserting that the world would be better without Israel's existence. The active role played in promoting such a syndrome by actors in the fields of the media, culture, and academia is a main finding of this study and a cause for serious concern. These people generally perceive themselves among the more knowledgeable and enlightened sectors of society and actually often function themselves as analysts of contemporary antisemitism.

On the opposite side of the political spectrum, the political Right is associated with forms of expression that are more improvised, spontaneous, uneducated, and populist in nature delivered through the social media, graffiti, in social situations, in the public space, at sports events, and so forth. The contents associated with these transmission channels typically refer to classic negative characterizations of Jews as powerful, greedy, selfish, foreign, and hypocritical. Accusations of simulation and exploitation of the Holocaust have become an integral part of this populist/reactionary discourse. Regarding the identification of perceived perpetrators with major religious groups, Christian perpetrators are seen as associated with the Right, Muslim perpetrators with the Left. 
In my analysis of the combined nature of contents and channels of transmission of antisemitism, I detected a four-fold typology articulated in the following domains: Practical, Populist, Narrative, and Political antisemitism. One intriguing finding is the perceived position of the Political antisemitism domain in between the Populist and Practical antisemitism domains. Issues such as perceptions of racism and xenophobia as a societal issue and sanction against ritual animal slaughtering but also occasionally the perception of Jews as not nationals of their countries of residence all pertain to actual recent political discourse in European societies. The perception of Practical antisemitism - the subject matter of much recent documentation and research - appears to bear a non-trivial affinity with general societal issues such as crime levels and unemployment but also feared sanction against circumcision. The perception of Muslims as antisemitic perpetrators is revealingly close to the perceived Practical antisemitism domain although it generally converges with the Narrative antisemitism domain and its left-oriented undertones. Teenager perpetrators are perceived as closely associated with Muslims.

The analysis presented here reveals European Jews' remarkable dual perception of the status of Muslims in Europe: on the one hand, as victims of intolerance mainly from Christian and Right-wing sources, on the other hand, as potentially dangerous perpetrators of antisemitic acts. Significantly, the Muslim issue in Europe is also perceived as distinct from the issue of immigration. Such complex perceptions on the Jewish side, in a highly tense, conflictual, increasingly nationalist and intolerant context ripe with ethnic and racial prejudice, seem to differentiate Jews from the mainstream of emotionally charged political discourse in contemporary European society. This fact may carry ethical advantages but also practical disadvantages.

The foundational breaking point in the perceived anti-Jewish societal challenge is antisemitism cum internet. Unlike preceding major breaking points and conceptual innovations in the antisemitism paradigm, this may appear to be merely a technical incremental step within the available gamut of social, cultural, and political tools and ideas. The consequences, however, are farreaching for society at large and for the relationship between society and the Jewish collective in particular. The peculiarity of this new stage is a more perfect and efficient fusion between all of the conceptual and executive elements listed thus far. In theory, the medium is not supposed to create new contents but only powerfully to enhance the existing ones. In practice, by efficiently helping to blend and circulate those contents, the medium actually generates a product that may appear as objectively new and considerably more harmful. In the era of the digital, the worldwide web, and social media, the transnational character and circulation of the antisemitic ideological package 
is greatly enhanced, thus connecting different actors in proximate and distant alliances. One of the main findings of the present analysis, indeed, is that the contents of antisemitism and its transmission channels tend to coalesce into one indistinguishable complex. At the central focal point of Jewish perceptions, nearly overlapping one with another, we find antisemitism as the societal issue of highest concern and the Internet as the principal conveyor. The contents and the tool have become one.

One explanation may help to bridge the gap lying at the basis of the apparent confusion between perceptions of antisemitic contents and of transmission tools that might logically pertain to separate domains. Antisemitism perceptions reflect, in fact, the multiplier of the number of perpetrators of a given act or expression by the number of people exposed to it. The absolute number or relative percentage of perpetrators within a given population may have actually remained very constant - as several studies, indeed, suggest. As a result of the more effective communication of those involved, however, the public impact of antisemitism actually may have increased. By the same token on the receiving side, in the past, the perceptional impact of antisemitism could derive primarily from items experienced personally, whereas nowadays, it becomes the cumulative impact of experiences shared by all those who are interconnected through the web. Here one probably finds the solution to the noted inconsistency between a relatively static perception of antisemitism as unveiled by repeated surveys of the total population and the pressing perceptions of growing antisemitism as expressed by the overwhelming majority of European Jews in 2012 and confirmed in 2018.

One innovative finding of this study concerns the regional differentials in Jewish perceptions, which seem to follow deeply rooted and well-established cultural and socio-economic divisions within the European continent. The 2018 FRA study allows for distinguishing four major geocultural areas: the European northwestern countries, with mainly Protestant societies and medium levels of perceived antisemitism; the mainly Francophone Western countries with high levels of Muslim immigration, and, recently, the theater of murderous anti-Jewish terrorist acts - characterized by high levels of perceived antisemitism; the Mediterranean coast countries, the target of large scale, though partly transient, refugee, and also predominantly Muslim immigration from the Middle East and North Africa - with intermediate levels of perceived antisemitism; and the CentralEastern European countries of the Visegrad group, characterized by strongly nationalist governments - hence potentially higher perceptions of antisemitism but also relatively low levels of immigration from other countries. The latter countries, at times, had governments among those more friendly toward the State of Israel. 
The basic conceptual elements of antisemitism perceptions are not supposed to differ significantly across cultural areas. However, deeply rooted and different political and social histories in the various countries and regions, along with the different institutional arrangements of Jewish communities that prevail locally, may have determined the observed variation in Jewish sensitivities and emphases. A more in-depth analysis of the structure of antisemitic perceptions within each of the main countries investigated ought to be conducted in the future.

Ultimately, perhaps the most consistent and important finding of this study is the distinction between cognitive and experiential perceptions of antisemitism. In each instance verified in this study, there was a clear separation between the cognitive and experiential perceptional domains. Part of this cleavage reflected the very different frequencies reported for each type of perception - significantly higher for the cognitive than for the experiential. Within each of these two main perceptional modes, however, the typology of contents and transmission channels and of perceived national societal issues and sanction/discrimination was regularly the same. As a perceptional construct, antisemitism appears to be structured into highly coherent, consistent, and stable categories.

Two important implications for future research and policies emerged from this analysis. First, discourse about antisemitism requires clearer articulation that always specifies whether the point of reference is the cognitive or the experiential level. Second, the entire antisemitic syndrome should be treated by acknowledging the distinct domain typologies that I have documented regarding contents, transmission channels, and types of perpetrators, without censorship or mutilations. Partial reading of the whole picture has plagued much of the existing literature about antisemitism.

A third implication for future research emerges from this study. Evidently, any study can report only on the issues it selectively covered. The 2018 FRA survey, but also the previous 2012 survey, and nearly all other recent studies, along with attention to the cognitive and experiential aspects, for the most part, omitted the third main domain of affective perceptions. This omission precludes developing a truly definitive mapping of the latent and explicit connections that are determined in the human mind by the occurrence and/or perception of antisemitic offenses. No plausible and convincing work on antisemitism should ignore the manifold and significant personal emotions that antisemitism arouses in the target individuals and the interrelations of emotional and other perceptional aspects.

The insights provided by the foregoing structural analysis of Jewish perceptions of antisemitism aimed at providing a fresher, more systematic and consistent conceptualization and categorization of the relevant subject matter. In the final analysis, I would suggest a compact reconceptualization of the main gist of 
contemporary antisemitism as three-fold anti-Jewish negationism. Antisemitism denies the entitlement of the Jew:

- as an individual, to enjoy civil, social, cultural, and political rights equal to other individuals in society;

- as a potential victim and a survivor of planned extermination, to preserve and transmit memory of the destruction of his own people - the Shoah;

- as a member of a national collective, to exert corporate national sovereignty through an independent state - Israel.

Several of these conclusions will not surprise many a reader. The contribution of this paper is to introduce a holistic view of a multiple-variable subject matter, whereas much of the existing literature on antisemitism has addressed only one aspect at a time. An effort was deployed to develop a more precise conceptual typology of antisemitic contents and manifestations, to better appreciate the connection between perceptions of antisemitism and Jewish identity, and to evaluate the intra-European regional variation of the perceived antisemitism phenomenology. The vexed question of the pertinence of anti-Zionist and antiIsraeli expressions as an integral component of Jewish perceptions of antisemitism was addressed, and a clearly positive answer was suggested.

Further important insights on perceptions of antisemitism will be gained once separate and more detailed analyses can be conducted comparing across different segments within the total Jewish population, by gender, age groups, socio-economic status, and cultural characteristics including religiosity. Comparisons between anti-Jewish prejudice and similar attitudes against other ethnic, religious, and cultural groups may also provide valuable insights. In spite of its avowed limits, the present study will hopefully mark a step forward on the long and still partially uncharted path of documenting, understanding, and combating antisemitism.

Acknowledgments: Research for this paper was undertaken at the Division of Jewish Demography and Statistics of the Institute of Contemporary Jewry, The Hebrew University of Jerusalem, headed by Prof. Uzi Rebhun. Many persons and institutions contributed to making the present paper possible. The 2018 study of experiences and perceptions of antisemitism in European Union member countries was directed by Ioannis Dimitrakopoulos, head of Equity's and Citizens' Rights Department at FRA - the EU Fundamental Rights Agency. Appreciation is due to Michael O'Flaherty, Director of FRA in Vienna. I benefited from meetings and exchanges with my colleagues in the FRA advisory group to the 2018 survey and the similar 2012 project: Eliezer Ben-Rafael (Tel Aviv University, Israel), Michal Bilewicz (University of Warsaw, Poland), Chantal 
Bordes-Benayoun (National Centre for Scientific Research, France), Jonathan Boyd (Institute for Jewish Policy Research, United Kingdom), Lars Dencik (Roskilde University, Denmark), Olaf Glöckner (Moses Mendelssohn Zentrum, Germany), Erich Griessler (Institute for Advanced Studies, Austria), András Kovács (Central European University, Hungary), Hannah van Solinge (Netherlands Interdisciplinary Demographic Institute), Daniel Staetsky (Institute for Jewish Policy Research, United Kingdom), Mark Tolts (Hebrew University of Jerusalem, Israel) and Martina Weisz (Hebrew University of Jerusalem, Israel). Richard Goldstein at JPR in London coordinated contacts with European Jewish communities aimed at enhancing data collection. The late Prof. Erik Cohen (Bar Ilan University, Israel) contributed to the elaboration of the 2012 FRA Survey. I am indebted to several colleagues who offered valuable suggestions to an early draft, among them Yehuda Bauer, Dan Michman, Judit Bokser Liwerant, Manuela Consonni, Daniel Staetsky, and an anonymous reviewer. Stefani Hoffman ably edited the English text. Responsibility for the contents of this paper is the author's only.

\section{Appendix}

Sample Size in FRA 2012 and 2018 Surveys $^{\mathrm{a}}$.

\begin{tabular}{|c|c|c|c|c|c|}
\hline Country & 2018 & 2012 & $\begin{array}{r}\% \text { Change } \\
2012-2018\end{array}$ & $\begin{array}{r}\text { Core Jewish } \\
\text { population } \\
31 / 12 / 2018\end{array}$ & $\begin{array}{r}2018 \% \text { ratio } \\
\text { respondents/ } \\
\text { population }\end{array}$ \\
\hline Grand total & 16,395 & 5,663 & - & $1,041,200$ & 1.6 \\
\hline Comparable total & 13,083 & 5,663 & 131.0 & 978,800 & 1.3 \\
\hline Austria & 526 & - & - & 10,000 & 5.3 \\
\hline Belgium & 785 & 438 & 79.2 & 29,100 & 2.7 \\
\hline Denmark & 592 & - & - & 6,400 & 9.1 \\
\hline France & 3,869 & 1,162 & 233.0 & 450,000 & 0.9 \\
\hline Germany & 1,233 & 608 & 102.8 & 118,000 & 1.0 \\
\hline Hungary & 590 & 528 & 11.7 & 47,300 & 1.2 \\
\hline Italy & 682 & 649 & 5.1 & 27,400 & 2.5 \\
\hline The Netherlands & 1,202 & - & - & 29,800 & 4.0 \\
\hline Poland & 422 & - & - & 4,500 & 9.4 \\
\hline Spain & 570 & - & - & 11,700 & 4.9 \\
\hline Sweden & 1,193 & 810 & 47.3 & 15,000 & 8.0 \\
\hline United Kingdom & 4,731 & 1,468 & 222.3 & 292,000 & 1.6 \\
\hline
\end{tabular}

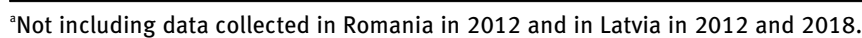

Source: DellaPergola 2019, FRA 2013, FRA 2018a. 


\section{References}

ADL - Anti Defamation League. 2014. ADL Global 100: An Index of Anti-semitism. New York: ADL. ADL - Anti Defamation League. 2015. ADL Global 100: An Index of Anti-semitism. 2015 Update in 19 Countries. New York: ADL.

Adorno, Theodore W., Else Frenkel-Brunswik, Daniel J. Levinson, and Nevitt Sanford. 1950. The Authoritarian Personality. New York: Harper.

Almog, Shmuel, ed. (1988). Antisemitism through the Ages. Oxford-New York-Beijing-FrankfurtSão Paulo-Sydney-Tokyo-Toronto: Pergamon Press.

Amar, Reuven, and Shlomit Levy. 2014. "SSA-Similarity Structure Analysis." In Encyclopedia of Quality of Life and Wellbeing Research, edited by Alex C. Michalos, 6306-6313. Dordrecht: Springer.

Amar, Reuven, and Shlomo Toledano. 2001. Hudap Manual. Jerusalem: The Hebrew University Computing Authority.

Anderson, Benedict. 1991. Imagined Communities. London and New York: Verso.

Arendt, Hannah. 1951. The Origins of Totalitarianism. New York: Schocken.

Arendt, Hannah. 1963. Eichmann in Jerusalem: A Report on the Banality of Evil. New York: Viking Press.

Barna, Ildikó, and Anikó Félix. 2017. Modern Antisemitism in the Visegrád Countries. Budapest: Tom Lantos Institute.

Bauer, Yehuda, ed. (1988). Present-Day Antisemitism. Jerusalem: The Hebrew University, The Vidal Sassoon International Center for the Study of Antisemitism.

Bauer, Yehuda. 2002. Rethinking the Holocaust. New Haven-London: Yale University Press.

Baum, Steven K., Neil J. Kressel, Florette Cohen-Abady, and Steven Leonard Jacobs, eds. (2016). Antisemitism in North America. New World Old Hate. Leiden-Boston: Brill.

Bauman, Zygmunt. 1989. Modernity and the Holocaust. Malden, Massachusetts: Polity Press.

Ben-Itto, Hadassa. 2005. The Lie that Wouldn't Die: The Protocols of The Elders of Zion. London: Vallentine Mitchell.

Ben-Rafael, Eliezer. 2014. Confronting Allosemitism in Europe: The Case of Belgian Jews. LeidenBoston: Brill.

Bokser Liwerant, Judit. 2017. "Expansion and Interconnectedness of Jewish Life in Times (and Spaces) of Transnationalism: New Realities, New Analytical Perspectives." In Jews and Jewish Identities in Latin America: Historical, Cultural, and Literary Perspectives, edited by Margalit Bejarano, Yaron Harel, Marta Francisca Topel, and Margalit Yosifon. New York: Academic Studies Press.

Bokser Liwerant, Judit. 2019. Sinopias and Pentimenti: Conceptual Approaches and Changing Paths of Antisemitism in Latin America. Jerusalem, The Hebrew University, The Vidal Sassoon Center for the Study of Antisemitism, The Third Annual Robert Wistrich Memorial Lecture and Award Ceremony.

Bokser Liwerant, Judit, Sergio DellaPergola, Leo Senkman, and Yosi Goldstein. 2015. El educador judío latinoamericano en un mundo transnacional. Vol. 1, Informe de investigación. Vol. 2, Síntesis, conclusiones y recomendaciones del informe de investigación. Jerusalem: The Hebrew University, Centro Liwerant para el estudio de América Latina, España, Portugal y suyas Comunidades Judías; Mexico: Universidad Hebraica; Buenos Aires: AMIA.

Bokser Liwerant, Judit, and Yael Siman. 2016. "Antisemitism in Mexico and Latin America: Recurrences and Changes." In Antisemitism in North America. New World Old Hate, edited by Steven K. Baum, et al. Leiden-Boston: Brill, 121-189. 
Brown, Michael, ed. (1994). Approaches to Antisemitism: Context and Curriculum. New YorkJerusalem: The American Jewish Committee and the International Center for University Teaching of Jewish Civilization.

Browning, Christopher R. 2004. The Origins of the Final Solution: The Evolution of Nazi Jewish Policy, September 1939 - March 1942 (With contributions by Jürgen Matthäus). Lincoln: University of Nebraska Press.

Brubaker, Rogers. 2005. “The 'Diaspora’ Diaspora.” Ethnic and Racial Studies 28 (1): 1-19, https://doi.org/10.1080/0141987042000289997.

Cattaneo, Carlo. 1837. Interdizioni israelitiche. Torino: Einaudi, new ed., 1962.

Cohen, Erik. 2012. The French Case Study: Towards a multi-dimensional analysis. Perceptions and Experiences of Antisemitism among Jews in selected EU Member States. Ramat Gan: Bar Ilan University (unpublished paper).

Cohen, Erik. 2013. "France." In Staetsky et al., Perceptions and Experiences of Antisemitism among Jews in selected EU Member States. London: JPR Institute for Jewish Policy Research, Ipsos MORI, 91-93.

Cohen, Jeffrey E. 2018. "Generalized Discrimination Perceptions and American Jewish Perceptions of Antisemitism." Contemporary Jewry 38 (3): 404-433.

Cohen, Robin. 1997. Global Diasporas: An Introduction. Seattle: University of Washington Press.

Coleman, James S. 1988. "Social Capital in the Creation of Human Capital." American Journal of Sociology 94, Supplement: Organizations and Institutions: Sociological and Economic Approaches to the Analysis of Social Structure, S95-S120.

Consonni, Manuela. 2015. "Split at the Root: Italian Jewish Identity between Anti-Zionism and Philo-Semitism.” In Research in Jewish Demography and Identity, edited by Eli Lederhendler and Uzi Rebhun, 98-122. Boston: Academic Studies Press.

Cotler, Irving. 2009. Global Antisemitism: Assault on Human Rights. New York: ISGAP, Working paper series. https://isgap.org/wp-content/uploads/2013/08/ISGAP-Working-PapersBooklet-Cotler-09-copy.pdf.

DellaPergola, Sergio. 2010. “Distancing, yet One.” Contemporary Jewry, 30 (2-3): 183-190.

DellaPergola, Sergio. 2015. “Antisemitism in Italy.” International Journal of Global Diaspora Studies 1 (1): 41-61.

DellaPergola, Sergio. 2018. Antisemitism: National or Transnational Constellation? Paper presented at Conference on End to Antisemitism, Vienna, Vienna University, 2018, and at ISA - International Sociological Association, XIX ISA World Congress of Sociology - RC22 Sociology of Religion, Toronto, 2018. Forthcoming in: An End to Antisemitism!, edited by A. Lange, K. Davidowicz, A. Muzicant, D. Porat, and L. Schiffman. Berlin: De Gruyter, 2020.

DellaPergola, Sergio. 2019. “World Jewish Population 2018." In American Jewish Year Book 2018, edited by Arnold Dashefsky and Ira Sheskin. Cham: Springer, 361-449.

DellaPergola, Sergio, Ariela Keysar, and Shlomit Levy. 2019. "Jewish Identification Differentials in Israel and in the United States: Similarity Structure Analysis." Contemporary Jewry 37 (1): 53-90, https://doi.org/10.1007/s12397-019-09283-5.

DellaPergola, Sergio, Shlomit Levy, Uzi Rebhun, and Dalia Sagi. 2018. "The Structure of Jewish Identification in the United States: 2001 Revisited." In Jewish Population and Identity: Concept and Reality, edited by Sergio DellaPergola and Uzi Rebhun, 43-71. Cham: Springer. (Studies of Jews in Society 1).

DellaPergola, Sergio, and L. Daniel Staetsky. 2015. From Old and New Directions: Perceptions and Experiences of Antisemitism among Jews in Italy. London: Jewish Policy Research Institute - JPR. 
De Michelis, Cesare G. 2004. The Non-existent Manuscript: A Study of the Protocols of the Sages of Zion. Lincoln: Univ. of Nebraska Press.

Dencik, Lars, and Karl Marosi. 2017. Different Antisemitisms. Perceptions and Experiences of Antisemitism among Jews in Sweden and across Europe. London: Jewish Policy Research Institute - JPR.

Dencik, Lars, and Karl Marosi. 2018. "On Three Distinct Forms of Antisemitism in Contemporary Europe, with a Special Focus on Sweden." In Anti-Semitism Today and Tomorrow. Global Perspectives on the Many Faces of Contemporary Antisemitism, edited by Mikael Shainkman Brighton, 1-33. Massachusetts: Academic Studies Press.

Eddy, Melissa. 2014. "Anti-Semitism Rises in Europe Amid Israel-Gaza Conflict.” The New York Times, Aug. 1. https://www.nytimes.com/2014/08/02/world/europe/anger-in-europe-overthe-israeli-gaza-conflict-reverberates-as-anti-semitism.html.

Eisenstadt, Shmuel N. 1992. Jewish Civilization: The Jewish Historical Experience. Albany: State of New York University Press.

Engel, David. 2009. "Away from a Definition of Antisemitism: an Essay in the Semantics of Historical Description." In Rethinking European Jewish History, edited by Jeremy Cohen and Moshe Rosman, 30-53. Oxford: Oxford University Press.

Epstein, Simha. 1993. Cyclical Patterns in Antisemitism: The Dynamics of Anti-Jewish Violence in Western Countries since the 1950s. Jerusalem: The Hebrew University, Vidal Sassoon International Center for the Study of Antisemitism, Analysis of Current Trends in Antisemitism/ACTA, no 2.

Ettinger, Shmuel. 1978. Modern Anti-Semitism. Tel Aviv: Moreshet (Hebrew).

EUMC - European Monitoring Centre on Racism and Xenophobia. 2004. Manifestations of Antisemitism in the EU, 2002-2003. Vienna: European Centre on Racism and Xenophobia.

European Commission, Directorate-General for Justice and Consumers. 2019. Perceptions of Antisemitism. Report. Special Eurobarometer, 484. Brussels: Kantar Public.

Feder, Shira. 2019. Where Kosher and Halal Meat Production Are now Forbidden. Forward, January 7. https://forward.com/food/416983/all-the-european-countries-where-kosher-and-halalmeat-production-are-now/.

Feldman, David. 2018. "Toward a History of the Term 'Anti-Semitism'.” The American Historical Review 123 (4): 1139-1150, https://doi.org/10.1093/ahr/rhy029.

Feldman, David, and Ben Gidley. 2018. Antisemitism and Immigration in Western pub Europe Today: Is there a connection? The case of the United Kingdom. Berlin: Foundation 'Remembrance, Responsibility and Future' (EVZ), and London: The Pears Institute for the study of Antisemitism, University of London.

Feldt, Jakob E. 2016. Transnationalism and the Jews. Culture History and Prophecy. London: Rowman and Littlefield.

Finkelstein, Norman. 2005. Beyond Chutzpah: On the Misuse of Anti-Semitism and the Abuse of History. Berkeley: University of California Press.

Finzi, Roberto. 2006. "Tre scritti postbellici sugli ebrei di Benedetto Croce, Cesare Merzagora, Adolfo Omodeo." Studi Storici 47 (1): 81-108, https://doi.org/10.2307/20567338.

FRA - European Union Fundamental Rights Agency. 2013. Discrimination and Hate Crime against Jews in EU Member States: Experiences and Perceptions of Antisemitism. Vienna: European Union Agency for Fundamental Rights.

FRA - European Union Agency for Fundamental Rights. 2018a. Experiences and Perceptions of Antisemitism - Second Survey on Discrimination and Hate Crime against Jews in the EU. Luxembourg: Publications Office of the European Union. 
FRA - European Union Agency for Fundamental Rights. 2018b. Antisemitism: Overview of Data Available in the European Union 2007-2017. Luxembourg: Publications Office of the European Union.

FRA - European Union Agency for Fundamental Rights. 2018c. Experiences and Perceptions of Antisemitism - Second Survey on Discrimination and Hate Crime Against Jews in the EU. Questionnaire. Luxembourg: Publications Office of the European Union.

Gerstenfeld, Manfred. 2005. “The Deep Roots of Anti-Semitism in European Society.” Jewish Political Studies Review 17 (1-2). https://www.jcpa.org/phas/phas-gerstenfeld-s05.htm.

Glock, Charles Y., and Rodney Stark. 1966. Christian Beliefs and Anti-Semitism. New YorkEvanston-London: Harper Torchbooks.

Glöckner, Olaf. 2013. "Germany." In Staetsky et al., Perceptions and Experiences of Antisemitism among Jews in selected EU Member States, 98-100. London: JPR Institute for Jewish Policy Research, Ipsos MORI.

Graham, David. 2018. “European Jewish identity: Mosaic or monolith?” An Empirical Assessment of Eight European Countries. London: Jewish Policy Research Institute JPR.

Greene, Richard A. 2018. CNN Poll Reveals Depth of Anti-Semitism in Europe. https://edition.cnn. com/interactive/2018/11/europe/antisemitism-poll-2018-intl/.

Grégoire, Henri J.B. 1788. Essai sur la régénération physique, morale et politique des Juifs. Paris: Flammarion, new ed., 1988.

Gudkov, Lev, and Alex Levinson. 1992. Attitudes toward Jews in the Soviet Union. Public Opinion in Ten Republics. New York: The American Jewish Committee.

Guetta, Betty. 2013. Immagine degli ebrei - Rapporto indagine qualitative Focus Group. Milano: CDEC - Centro di Documentazione Ebraica Contemporanea.

Guttman, Louis. 1968. "A General Nonmetric Technique for Finding the Smallest Coordinate Space for a Configuration of Points." Psychometrika 33 (4): 469-506.

Helmreich, William B. 1996. Holocaust Survivors and the Successful Lives They Made in America. New Brunswick: Transaction.

Hertz, Joseph H., ed. (1956 [1936]). The Pentateuch and Haftoras, Hebrew Text, English Translations and Commentary. London: Soncino Press.

IHRA - International Holocaust Remembrance Alliance. 2016. Working Definition of Antisemitism. Bucharest: IHRA 2016 Romanian Chairmanship.

ISGAP - Institute for the Study of Antisemitism and Policy. 2018. Measuring Antisemitism - An Expert Research Report in Progress." Jerusalem: ISGAP - Ministry of Diaspora Affairs - JPPI The Jewish People Policy Institute.

Jewish Voice for Peace. 2017. On Antisemitism. Struggle for Justice in the Jewish World, with a preface by Judith Butler. Chicago: Haymarket Books.

Jikeli, Günther. 2015. “A Framework for Assessing Antisemitism. Three Case Studies (Dieudonné, Erdoğan, and Hamas)." In Deciphering the New Antisemitism, edited by Alvin H. Rosenfeld, 43-76. Bloomington: Indiana University Press.

Jickeli, Günther, and Joëlle Allouche-Benayoun. 2013. Perceptions of the Holocaust in Europe and Muslim Communities. Sources, Comparisons and Educational Challenges. Dordrecht: Springer.

Jodice, David A. 1991. United Germany and Jewish Concerns: Attitudes Toward Jews, Israel and the Holocaust. New York: The American Jewish Committee, Working Papers on Contemporary Anti-Semitism.

Judaken, Judah. 2018. "AHR Roundtable Rethinking Anti-Semitism. Introduction.” American Historical Review 123 (4): 1122-38, https://doi.org/10.1093/ahr/rhy024. 
Kantor Center for the Study of Contemporary European Jewry. 2018. Antisemitism Worldwide 2017 - General Analysis. Draft. Tel Aviv: Moshe Kantor Database for the Study of Contemporary Antisemitism and Racism.

Karmasin, Fritz. 1992. Austrian Attitudes toward Jews, Israel and the Holocaust. New York: The American Jewish Committee, Working Papers on Contemporary Anti-Semitism.

Klug, Brian. 2013. “Interrogating ‘New Anti-Semitism.” Ethnic and Racial Studies 36 (3): 468-482, https://doi.org/10.1080/01419870.2013.734385.

Knobel, Marc. 2013. Haine et violence antisémites. Une rétrospective 2000-2013. Paris: Berg International.

Kovács, András. 2013a. "Hungary.” In Staetsky, et al., Perceptions and Experiences of Antisemitism among Jews in selected EU Member States, 97-98. London: JPR Institute for Jewish Policy Research, Ipsos MORI.

Kovács, András. 2013b. "Latvia.” In Staetsky, et al., Perceptions and Experiences of Antisemitism among Jews in selected EU Member States, 105-106. London: JPR Institute for Jewish Policy Research, Ipsos MORI.

Kovács, András. 2014. "Antisemitic Prejudices and Dynamics of Antisemitism in Post-Communist Hungary." Proceedings of the International Conference Antisemitism in Europe Today: the Phenomena, the Conflicts, 8-9 November 2013. Berlin: Jüdisches Museum Berlin, Foundation "Remembrance, Responsibility and Future" and Center for Research on Antisemitism.

Küntzel, Matthias. 2013. "The Roots of Antisemitism in the Middle East. New Debates." In Resurgent Antisemitism. Global Perspectives, edited by Alvin H. Rosenfeld, 382-401. Bloomington: Indiana University Press.

Levi, Primo. 1976. Se questo è un uomo. Appendix. Torino: Einaudi.

Levitt, Peggy, and Mary C. Waters, eds. 2002. The Changing Face of Home: The Transnational Lives of the Second Generation. New York: Russell Sage Foundation.

Lewis, Bernard. 1999. Semites and Anti-Semites. An Enquiry into Conflict and Prejudice. New YorkLondon: Norton.

Lindert, Jutta, and Armen T. Marsoobian, eds. 2018. Multidisciplinary Perspectives on Genocide and Memory. Cham: Springer.

Lipstadt, Deborah. 2019. Antisemitism: Here and Now. New York: Schocken.

Lustick, Ian. 2017. "The Holocaust in Israeli Political Culture: Four Constructions and Their Consequences." Contemporary Jewry 37 (1): 125-170.

Marcus, Kenneth L. 2015. The Definition of Anti-Semitism. New York: Oxford University Press.

Marr, Wilhelm. 1879. Statuten des Vereins “Antisemiten-Liga”. Berlin: Hentze.

Marx, Karl. 1976 [1844]. “Zur Judenfrage, Deutsch-Französische Jahrbücher.” In Karl Marx/ Friedrich Engels - Werke, Vol. 1, 347-377. Berlin: Dietz Verlag.

Meierhenrich, Jens. 2014. Genocide: A Reader. New York: Oxford University Press.

Michman, Dan. 2003. Holocaust Historiography: A Jewish Perspective. Conceptualizations, Terminology, Approaches and Fundamental Issues. London: Vallentine Mitchell.

Michman, Dan. 2014. "The Jewish Dimension of the Holocaust in Dire Straits? Current Challenges of Interpretation and Scope." InJewish Histories of the Holocaust. New Transnational Approaches, edited by Norman Goda, 17-38. New York: Berghahn.

Mignolo, Walter. 2009. "Dispensable and Bare Lives: Coloniality and the Hidden Political/ Economic Agenda of Modernity." Human Architecture: Journal of the Sociology of Selfknowledge 7 (2): 69-87.

Nirenberg, David. 2013. Anti-Judaism: The Western Tradition. New York-London: Norton. 
OSCE - ODIHR. 2016. Hate Crime Reporting. Anti-Semitism 2016. https://hatecrime.osce.org/ what-hate-crime/anti-semitism.

Partington, Alan S. 2012. "The Changing Discourses on Antisemitism in the UK Press from 1993 to 2009." Journal of Language and Politics 11 (1): 51-76, https://doi.org/10.1075/jlp.11.1. 03par.

Paxton, Robert 0. 2004. The Anatomy of Fascism. New York: Alfred A. Knopf.

Petrenko, Victor F., and Olga V. Mitina. 1997. Psikhosemanticheskii analiz dinamiki obshchestvennogo soznaniya. Na materiale politicheskogo mentaliteta. Moscow: Izdatel'stvo Moskovskogo Universiteta.

Pew Research Center. 2015/16. Religious Belief and National Belonging in Eastern Europe. Washington: Pew Research Center, Religion and Public Life Project.

Pew Research Center. 2017. Being Christian in Western Europe. Washington: Pew Research Center, Religion and Public Life Project.

Pinto, Diana. 1996. A New Jewish Identity for Post-1989 Europe. London: Jewish Policy Research Institute JPR, Policy Paper 1.

Poliakov, Leon. 2003. "The History of Anti-Semitism.” Vol. 2, From Mohammed to the Marranos; Vol. 3, From Voltaire to Wagner. Philadelphia: Philadelphia University Press, 4 vols.

Popper, Steven. 2018. Toward a Comprehensive Approach for Assessing Antisemitism: Roadmap for Action. Jerusalem: 6th Global Forum for Combating Antisemitism.

Porat, Dina. 2018. "The Struggle over the International Working Definition of Antisemitism." In Anti-Semitism Today and Tomorrow. Global Perspectives on the Many Faces of Contemporary Antisemitism, edited by Mikael Shainkman, 86-100. Brighton, Massachusetts: Academic Studies Press.

Rebhun, Uzi. 2014. “Correlates of Experiences and Perceptions of Anti-Semitism among Jews in the United States. Social Science Research 47: 44-60.

Rein, Raanan, and Martina Weisz. 2011. "Ghosts of the Past, Challenges of the Present: New and Old 'Others' in Contemporary Spain." In A Road to Nowhere? Jewish Experiences in Unifying Europe, edited by Julius H. Schoeps and Olaf Glöckner, 103-120. Leiden-Boston: Brill.

Romano, Sergio. 1997. Lettera a un amico ebreo. Milano: Longanesi.

Rosenfeld, Alvin. 2019. Anti-Zionism and Antisemitism: The Dynamics of Delegitimization. Bloomington: Indiana University Press.

Rudling, Per A. 2006. "Organized Anti-Semitism in Contemporary Ukraine: Structure, Influence and Ideology." Canadian Slavonic Papers/Revue canadienne des slavistes 48 (1-2): 83-119, https://doi.org/10.1080/00085006.2006.11092403.

Russian Jewish Congress - Levada Center. 2018a. Antisemitism as Perceived by the Jewish Population of Russia. Moscow: Russian Jewish Congress - Levada Center.

Russian Jewish Congress - Levada Center. 2018b. The Issue of Antisemitism as Perceived by the Jews and other Russian Urban Populations. Moscow: Russian Jewish Congress - Levada Center.

Sand, Shlomo. 2009. The Invention of the Jewish People. New York: Verso.

Sartre, Jean Paul. 1946. Réflexions sur la question juive. Paris: Gallimard.

Schiller Glick, Nina, Linda Basch, and Cristina Blanc-Szanton. 1992. "Transnationalism: A New Analytic Framework for Understanding Migration." Annals of the New York Academy of Sciences 645 (1):1-24, https://doi.org/10.1111/j.1749-6632.1992.tb33484.x.

Schwarz-Friesel, Monica, and Jehuda Reinharz. 2017. Inside the Antisemitic Mind: The Language of Jew-Hatred in Contemporary Germany. Boston: University Press of New England. 
Segel, Binjamin W., and Richard S. Levy. 1995. A Lie and a Libel: The History of the Protocols of the Elders of Zion. Lincoln: University of Nebraska Press.

Shainkman, M., ed. 2018. Anti-Semitism Today and Tomorrow. Global Perspectives on the Many Faces of Contemporary Antisemitism. Brighton, Massachusetts: Academic Studies Press.

Snyder, Timothy. 2010. Bloodlands. Europe between Hitler and Stalin. New York: Basic Books.

Staetsky, L. Daniel. 2017. Antisemitism in Contemporary Great Britain. A Study of Attitudes toward Jews and Israel. London: Jewish Policy Research Institute - JPR.

Staetsky, L. Daniel. 2019a. "Can Convenience Samples be Trusted? Lessons from the Survey of Jews in Europe, 2012." Contemporary Jewry 39 (1): 117-153, https://doi.org/10.1007/s12397019-09280-8.

Staetsky, L. Daniel. 2019b. “Global Levels, Trends, and Correlates of Antisemitic Attitudes through the Prism of Modernization Theory: Insights from the Pew Research Center and World Values Surveys." Journal of Contemporary Antisemitism 2 (1): 48-63, https://doi.org/10.26613/jca/ 2.1.22.

Staetsky, L. Daniel, and Jonathan Boyd. 2014. The Exceptional Case? Perceptions and experiences of antisemitism among Jews in the United Kingdom. London: Jewish Policy Research Institute JPR.

Staetsky, L. Daniel, Jonathan Boyd, Eliezer Ben-Rafael, Erik Cohen, Sergio DellaPergola, Lars Dencik, Olaf Glöckner, and Andras Kovács. 2013. Perceptions and Experiences of Antisemitism among Jews in selected EU Member States. London: JPR Institute for Jewish Policy Research, Ipsos MORI.

Stern, Menachem. 1976. Greek and Latin Authors on Jews and Judaism, Vol. 1. Jerusalem: The Israel Academy of Sciences and Humanities.

Stern, Menachem. 1980. Greek and Latin Authors on Jews and Judaism, Vol. 2. Jerusalem: The Israel Academy of Sciences and Humanities.

Szakolczai, Arpad. 2016. "The Distinctiveness of the West: Max Weber from Modernity to Antiquity." Paper Published as: "Il carattere distintivo dell’Occidente: Max Weber dalla modernità all'antichità." Studi di Sociologia 54 (1): 33-48.

The Qur'an. 2004. Translated by M.A.S. Abdel Hadeem. Oxford: Oxford University Press, Oxford World Classics.

Tooby, John, and Leda Cosmides. 1992. "The Psychological Foundations of Culture." In The Adapted Mind: Evolutionary Psychology and the Generation of Culture, edited by Jerome Barkow, Leda Cosmides, and John Tooby, 19-136. New York: Oxford University Press.

Toynbee, Arnold J. 1947. A Study of History. Abridgment of volumes I-VI by D.C. Somerwell. LondonNew York: Oxford University Press, 135-139.

Traverso, Enzo. 2016. La fin de la modernité juive. Histoire d'un tournant conservateur. Paris: Editions La Découverte.

Triadafilopoulos, Triadafilos. 2019. "Religious Groups, Liberal-democratic States and Competitive Boundary Making: The Debate over Ritual Male Circumcision in Germany." Ethnicities 19 (4): 654-673, https://doi.org/10.1177/1468796819843540.

UN Watch. 2018. The United Nations and Antisemitism: 2008-2017 Report Card. New York: UN Watch.

Weber, Max. 1904-5. Die Protestantische Ethik und der Geist des Kapitalismus. Archiv für Sozialwissenschaften und Sozialpolitik, Bd. XX, 1-54, XXI, 1-110. English translation: The Protestant Ethic and the Spirit of Capitalism. London: Allen \& Unwin, 1976.

Weinfeld, Morton, John J. Sigal, and William W. Eaton. 1981. "Long-term Effects of the Holocaust on Selected Social Attitudes and Behaviors of Survivors: A Cautionary Note." Social Forces 60 (1): 1-19, https://doi.org/10.1093/sf/60.1.1. 
Weisz, Martina L. 2018. Jews and Muslims in Contemporary Spain. Redefining National Boundaries. Berlin: De Gruyter, the Vidal Sassoon Studies in Antisemitism, Racism and Prejudice.

Wieviorka, Michael. 2005. L'antisémitisme. Paris: Balland.

Wistrich, Robert. 2010. A Lethal Obsession: Anti-semitism from Antiquity to the Global Jihad. New York: Random House.

Yuval, Israel J. 2006. Two Nations in Your Womb: Perceptions of Jews and Christians in Late Antiquity and the Middle Ages. Berkeley and Los Angeles: University of California Press.

Zick, Andreas, Beate Küpper, and Andreas Hövermann. 2011. Intolerance, Prejudice and Discrimination A European Report. Berlin: Friedrich-Ebert-Stiftung. 